University of Louisville

ThinkIR: The University of Louisville's Institutional Repository

8-2013

\title{
Understanding thought disorder in schizophrenia-spectrum disorders : exploring the relation and implications of affect.
}

Rachel Nicole Waford

University of Louisville

Follow this and additional works at: https://ir.library.louisville.edu/etd

\section{Recommended Citation}

Waford, Rachel Nicole, "Understanding thought disorder in schizophrenia-spectrum disorders : exploring the relation and implications of affect." (2013). Electronic Theses and Dissertations. Paper 1496.

https://doi.org/10.18297/etd/1496

This Doctoral Dissertation is brought to you for free and open access by ThinkIR: The University of Louisville's Institutional Repository. It has been accepted for inclusion in Electronic Theses and Dissertations by an authorized administrator of ThinkIR: The University of Louisville's Institutional Repository. This title appears here courtesy of the author, who has retained all other copyrights. For more information, please contact thinkir@louisville.edu. 
UNDERSTANDING THOUGHT DISORDER IN SCHIZOPHRENIA-SPECTRUM DISORDERS: EXPLORING THE RELATION AND IMPLICATIONS OF AFFECT

By

Rachel Nicole Waford

B.A. Western Kentucky University, 2004

M.A. Western Kentucky University, 2006

\author{
A Dissertation \\ Submitted to the Faculty of the \\ College of Arts and Sciences of the University of Louisville \\ in Partial Fulfillment of the Requirements \\ for the Degree of
}

DOCTOR OF PHILOSOPHY

In

Clinical Psychology

Department of Psychology

University of Louisville

Louisville, Kentucky

August 2013 
Copyright 2013 by Rachel Nicole Waford

All rights reserved. 

UNDERSTANDING THOUGHT DISORDER IN SCHIZOPHRENIA-SPECTRUM DISORDERS: EXPLORING THE RELATION AND IMPLICATIONS OF AFFECT

By

Rachel Nicole Waford

B.A. Western Kentucky University, 2004

M.A. Western Kentucky University, 2006

A Dissertation Approved on

June 6, 2013

by the Following Dissertation Committee

Dissertation Director

Richard Lewine

Suzanne Meeks

Benjamin Mast

Cara Cashon

Osborne Wiggins, Jr. 


\title{
DEDICATION
}

This dissertation is dedicated to my family and friends

who supported me during this journey

and

\author{
Richard R. J. Lewine \\ who provided an environment where curiosity was encouraged and \\ questioning what's trendy was expected.
}




\section{ACKNOWLEDGEMENTS}

I would like to acknowledge the dedication, long hours, and hard work put forth by my lab mates, Cat Robertson and Mara Hart, and the guidance and enthusiasm shown by our mentor, Dr. Rich Lewine. This project was developed and nurtured from our collective passion for understanding the phenomenology of schizophrenia, and focus on recovery and community reintegration. Thank you, thank you, thank you.

I would also like thank Dr. Debbie Levy from McLean Hospital in Boston, MA for her intensive training seminar on the administration, scoring, and interpretation of the Thought Disorder Inventory. In addition, she reviewed a final draft of the dissertation. As an expert in this area she provided a critical eye and helpful feedback.

Finally, I would also like to acknowledge and thank the administrative staff, nurses, physicians, and patients at the University of Louisville Hospital who were an integral part of this project. This dissertation would not have been possible without their participation and support. The staff and clinicians were involved in a variety of ways throughout the 10 months of data collection including disseminating project information, critical feedback, and enthusiasm. The participating inpatients at the University of Louisville Hospital were a curious bunch and were interested in contributing to our understanding of the illness. Their participation demonstrated a powerful drive to interact with others and participate in the world, a notion we do not often associate with psychotic illness. 


\section{ABSTRACT \\ Understanding Thought Disorder in Schizophrenia-Spectrum Disorders: \\ Exploring the Relation and Implications of Affect

\author{
Rachel Nicole Waford
}

June 6, 2013

The significance of affect in schizophrenia-spectrum disorders has received considerable support, including its role in cognitive processing and executive function. Findings examining affect and cognition in schizophrenia appear to parallel findings with healthy controls: positive affect contributes to broad, top-down processing and negative affect leads to narrow, bottom-up processing. This dissertation extends this exploration to the study of affect and its role in thought disorder, a core, and yet enigmatic feature of schizophrenia-spectrum disorders.

This dissertation examines the role of affective intensity and valence in thought disorder severity. Self-reported affective intensity and valence were assessed with the PANAS, and thought disorder severity was evaluated by scoring Rorschach protocols using the Thought Disorder Inventory. The dissertation has two hypotheses: (1) affective intensity is a more significant factor than affective valence in predicting the severity of thought disorder in schizophrenia and schizoaffective disorder, and (2) positive affect is related to categories that reflect broader, more associative processing, while negative affect is related to categories that reflect narrowed processing.

Both hypotheses were supported. Affective intensity significantly predicted thought disorder severity and was a better predictor, overall, then affective valence. 
Furthermore, positive and negative affect were related to indicators of broad versus narrow processing, respectively. Self-reported negative affect emerged as a particularly salient variable in thought disorder severity and presentation. The current findings have implications for our understanding of the mechanisms underlying thought disorder severity in schizophrenia-spectrum disorders, and the significance of affective experience in this spectrum of illness. 
TABLE OF CONTENTS

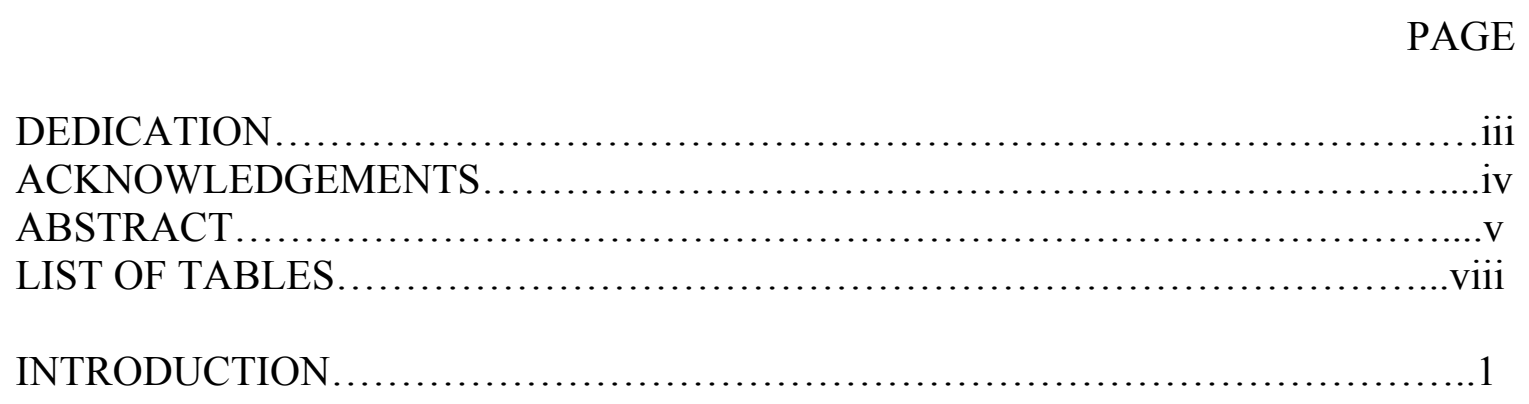

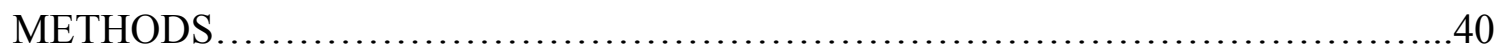

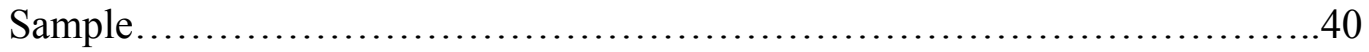

Measures....................................................................... 40

Procedures.............................................................. 46

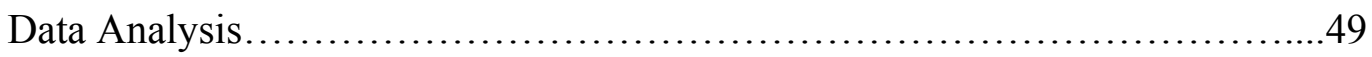

Participant Sample and Statistical Power.....................................51

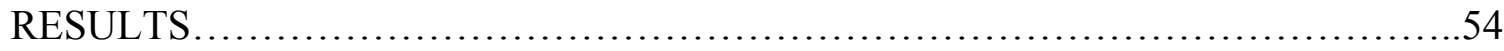

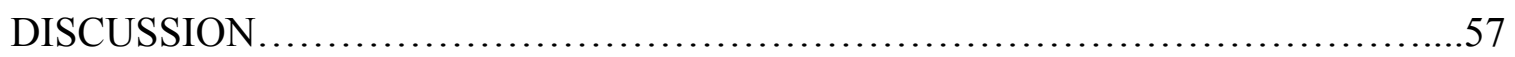

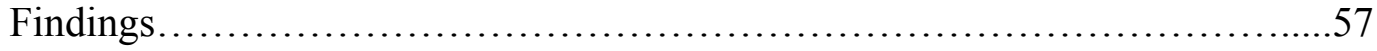

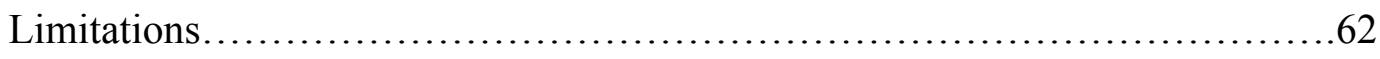

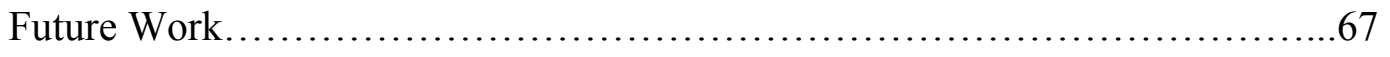

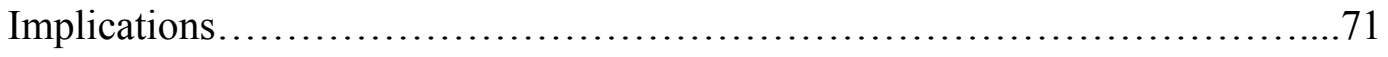

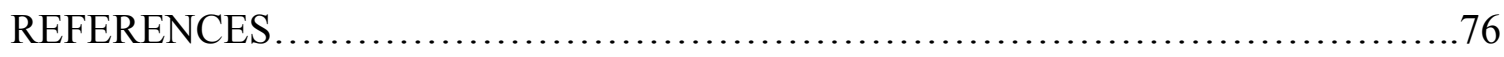

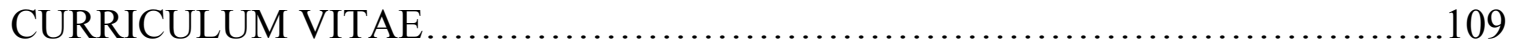




\section{LIST OF TABLES}

TABLE

PAGE

1. Definitions from Thought, Language, and Communication Scale...................90

2. Thought Disorder Scoring Methods........................................... 91

3. Detailed Information for Studies Reviewed..................................94

4. Definitions from the Thought Disorder Index................................... 101

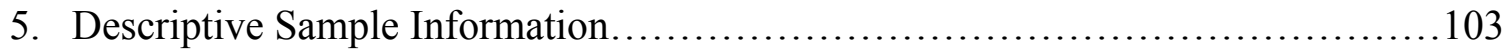

6. Descriptive data for the Thought Disorder Index and Positive

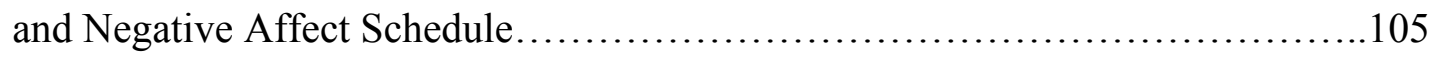

7. Results from Correlation Analyses for the Sociodemographic Data................106

8. Results from Correlation Analyses for the Thought Disorder Index and Positive and Negative Affect Schedule.......................................107

9. Results from Correlation Analyses Examining Positive Affect and Top-Down Processing................................................. 108

10. Results from Correlation Analyses Examining Negative Affect

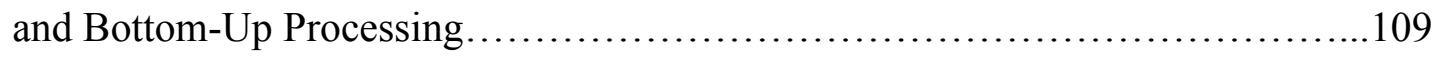

11. Frequency Summary for Each Exemplar......................................110 


\section{INTRODUCTION AND AIMS}

“Naturally, I'm growing my father's hair." Such a remark likely evokes a variety of responses. Some may feel confused but assume they just missed a critical piece of the story. Another may presume that the individual speaking is more intelligent or even poetic and, therefore, may be speaking with more sophisticated language. Finally, one may induce that the person in question is exhibiting disordered thought that is indicative of a minor slip or evidence of a chronic problem. No matter what the response, most would likely conclude that the above statement lacks both clarity and logic, and is somewhat odd. While these descriptions are relevant to the entire range of human thought (McKenna \& Oh, 2005), they are also specific to thought disorder, a significant area of research that has spanned the last century. Historically, thought disorder was a core feature of dementia praecox and later a sine qua non of schizophrenia (Levy et al., 2010). For Paul Meehl, the above utterance was the "diagnostic bell-ringer" for schizophrenia (1977, cited from Levy et al., 2010, p. 177).

In addition to disordered thought, schizophrenia is also characterized by positive symptoms indicative of an excess of what is seen in healthy individuals (e.g., auditory and visual hallucinations, delusional beliefs), negative symptoms indicative of an absence of experience normally seen in healthy individuals (e.g., anhedonia, avolition, flat affect), and notable cognitive decline or dysfunction. Affecting approximately $1 \%$ of individuals in the United States, this chronic disorder has a negative impact on social and 
occupational functioning (American Psychiatric Association, Diagnostic and Statistical Manual of Mental Disorders, $4^{\text {th }}$ ed., text revision [DSM-IV TR], 2000; National Institute of Mental Health [NIMH], 2009). Given the variety of symptoms characteristic of schizophrenia, intragroup heterogeneity is also prevalent, with one individual with schizophrenia potentially symptomatically quite different from another. Thus, consideration of the variability of the clinical presentation of schizophrenia becomes critical. The study of thought disorder, often viewed as a core feature of schizophrenia, is of particular importance as detailed below.

\section{Background and Significance}

Thought disorder (see Table 1 for definition of terms) has been considered a fundamental component of schizophrenia since Emil Kraepelin's description of dementia praecox in the late $19^{\text {th }}$ and early $20^{\text {th }}$ centuries (Andreasen, 1982; Kring, Kerr, Smith, \& Neale, 1993; Levy et al., 2010). Kraepelin defined severe mental illness as disorders of thought and mood, a conceptualization commonly referred to as the Kraepelinian dichotomy (Lake, 2008). He concluded dementia praecox was distinguished by disorders of self-expression, internal speech, and train of thought (Andreasen, 1982). Disordered thought was further characterized by derailments in thinking (Lake, 2008; Levy et al., 2010), specifically loose associations and incoherence (Levy et al., 2010). Eugen Bleuler renamed Kraepelin's dementia praecox as schizophrenia in 1911 to represent what Bleuler conceptualized as a splitting of psychic functions (Andreasen, 1979a). Bleuler paid particular attention to disordered thought, typified by associative loosening that was both fundamental to schizophrenia (Andreasen, 1979a; McKenna \& Oh, 2005) and "always present" (Andreasen, 1979a, p. 1315). While both Kraepelin and Bleuler 
emphasized thought disorder as critical to the understanding of schizophrenia, Kraepelin conceptualized thought disorder as "a train that was derailing" while Bleuler described it as "torn and poorly mended fabric" (Andreasen, 1982, p. 293).

Bleuler's conceptualization of schizophrenia also emphasized affective disturbance as another core feature of the illness, identifying prominent delusions and hallucinations as secondary symptoms (Kring et al., 1993). However, affective symptoms did not gain importance in the understanding of schizophrenia until the introduction of schizoaffective disorder by Jacob Kasanin in 1933 (Lake, 2008). It was during this time that the prominence or absence of affective symptoms differentiated a spectrum of schizophrenic disorders. However, thought disorder maintained its status as a core feature of the illness and efforts continue to "capture the essence" (Levy et al., 2010, p. 177) of schizophrenia.

\section{Current Perspectives}

Despite its lengthy history in the schizophrenia literature, the understanding of and treatment for thought disorder has been far surpassed by research in other areas of schizophrenia as evidenced by extensive reviews and treatment interventions devoted specifically to the more prominent positive and negative symptoms of the illness (see Wykes, Steel, Everitt, \& Tarrier, 2008 and Kingdon \& Turkington, 2008, respectively). Against this backdrop, Levy et al. (2010) recently summarized the field by reporting "general agreement that thought disorder is multidimensional, that it occurs in schizophrenic and nonschizophrenic conditions, and that its manifestations cover a spectrum of severity" (p. 177). Unfortunately, this broad summary appears to highlight

all that is not known by failing to differentiate thought disorder from the multitude of 
other psychiatric symptoms that are subsumed under that description. This recent summary of the field, alone, reflects a need for continued, rigorous study of thought disorder and perhaps speaks to the benefits of getting "back to the basics" of psychopathology to re-examine thought disorder in schizophrenia.

The prevalence of thought disorder in a variety of different psychiatric presentations including but not limited to mania, depression, and healthy individuals, suggests that relevant findings within these groups may reveal something about thought disorder in schizophrenia. The relationship between psychosis and thought disorder has been examined in this regard across individuals with schizophrenia and affective disorders. Specifically, efforts to explore the association between thought disorder and hallucinations and delusions have resulted in inconsistent conclusions, a finding that will be discussed at length. That thought disorder also occurs in disorders primarily characterized by disturbances in affect also suggests that affect may be involved in thought disorder, as it is relevant to a range of psychiatric illness (Cicchetti, Ackerman, \& Izard, 1995; Kring \& Bachorowski, 1999). The aim of the current research is to explore the possible role of affect as a moderator of the severity and presentation of thought disorder in schizophrenia.

\section{Assessments and Models of Thought Disorder}

As the zeitgeist in our formulation of psychopathology has evolved, so has our understanding of thought disorder. The works of Kraepelin and Bleuler emphasized a disordered thought process that while bizarre, vague, and more effortful, was often not flawed (McKenna \& Oh, 2005). These early conceptualizations of thought disorder were global, evaluating the intended thought as a whole. More recently, a debate has surfaced 
over the vague boundaries between disorders of thought, language, and speech, and has led to inconclusive resolutions. Proponents for the use of the term speech disorder rather than thought disorder focus on semantic activation and use of context (Levy et al., 2010), syntax and phonology (Lanin-Kettering \& Harrow, 1985), and referential words or phrases (Docherty \& Hebert, 1997). While there is no disagreement about a link between thought, language, and speech, disagreement has focused on the use of disordered speech as a proxy for disordered thought and the appropriateness of terms such as "communication deviance" or "communication failures" (Levy et al., 2010, p. 179) to describe the complex link between thought, language and speech.

This approach to understanding thought disorder is not novel; Kraepelin and Bleuler also emphasized the importance of disorders of speech and language as vehicles for conveying thought disorder, but identified disordered thought as the primary deficit (Levy et al., 2010). Moreover, Vygotsky addressed this controversy in his classic work on the distinction between thought and language: "Thought is not merely expressed in words; it comes into existence through them. Every thought tends to connect something with something else, to establish a relationship between things" (cited from LaninKettering \& Harrow, 1985). Holzman, Shenton, and Solovay (1986) provided one resolution to this debate by stating that language and speech are "transparent" (p. 361) mediums of thought that can become the focus of evaluation, if one so chooses. The current paper will be operating from the same perspective; the term "thought disorder" will reflect examination of responses as a whole.

\section{Measures of Thought Disorder}


The model of thought disorder to which one subscribes is directly related to the measurement of thought disorder employed for research or clinical purposes. Because the evaluation of thought disorder is subjective, whether one chooses to evaluate within a sentence, from sentence to sentence, or the response in its entirety will directly impact the nature of the measure used as well as any conclusions about the type, rate, and severity of thought disorder (McKenna \& Oh, 2005). Consistent with the perspective discussed earlier, the current review only includes studies that utilized thought disorder measures of full statements and responses. Measures that evaluate thought disorder in this fashion are of two types. For the purpose of the current research these two types of measures will be classified as severity and subtype. Examples of each type, including scoring procedures and psychometric properties, are available in Table 2.

Despite the homogeneity one may expect from a more gestalt view of thought disorder, there remains an underlying inconsistency regarding clear definitions of severity and subtype. Despite Andreasen's early efforts to develop reliable and valid definitions of thought disorder (1979a), the operationalization of thought disorder remains fuzzy and malleable (Andreasen 1979a; 1979b; 1982; Levy et al, 2010). This can be clearly seen in the variability across the five major thought disorder assessments described in Table 2. For example, a response that is extremely brief, concrete, and generally limited would likely be identified as severe poverty of speech using the Scale for the Assessment of Thought, Language and Communication (TLC; Andreasen, 1979a, 1979b), as defined in Tables 1 and 2. However, this same response would receive a score of "0," on the Index of Positive Thought Disorder (IPTD; Marengo, Harrow, Lanin-Kettering, \& Wilson, 1986), indicating the absence of thought disorder as described in Table 2. In addition, 
Nancy Docherty's Communication Disturbance Index (CDI; Docherty, DeRosa, \& Andreasen, 1996) classifies word and phrase use into six categories of communication failure; scores are based on the frequency of each failure and no severity scores, per se, are noted. Rather than reflect theoretical differences, this and other measurement discrepancies emphasize the inconclusive nature of thought disorder research findings, and the need to revisit the study and measurement of this impairment. Inconsistencies such as the one described above and the differences illustrated in Table 2 further suggest a need to examine additional factors that may be related to thought disorder in an effort to better establish a common ground.

\section{Models of Thought Disorder}

Similar to the heterogeneity reflected in the measures of thought disorder shown in Table 2, there is also variability in the general model of thought disorder in schizophrenia as indicated by factor analytic studies. While thought disorder is at times considered a feature of positive symptoms as evidenced by its inclusion in descriptions such as those provided by NIMH (2009) or in measures of positive symptoms such as the Scale for the Assessment of Positive Symptoms (SAPS; Andreasen, 1984), factor analytic studies of schizophrenia have shown factor structures that account for thought disorder as an independent but related factor (Grube, Bilder, \& Goldman, 1998; Kim et al., 2012; Lancon, Auquier, Nayt, \& Reine, 2000; Mojtabai, 1999; Toomey et al., 1997). These findings suggest that thought disorder is an area worthy of individual study, including the factor structure, unique correlates and moderators. However, as discussed below studies specifically examining the factor structure of thought disorder in general and in 
schizophrenia yield inconsistent findings (see Table 3 for sample characteristics and goodness of fit statistics).

In the validation of the TLC, Andreasen (1979b) examined a positive/negative thought disorder dichotomy that was similar to the excess versus absence hypothesis reflected in positive and negative symptoms in schizophrenia, respectively. Negative thought disorder was operationalized as poverty of speech and poverty of content of speech, and positive thought disorder included pressured speech, distractibility, tangentiality, derailment, incoherence, and illogicality. Positive thought disorder was significantly associated with acute schizophrenia and mania, and negative thought disorder was significantly associated with chronic schizophrenia and poorer prognosis.

Harvey et al., (1992) sought to further examine the factor structure of eight TLC elements (poverty of speech, poverty of content of speech, pressured speech, tangentiality, derailment, incoherence, circumstantiality, and loss of goal) using five confirmatory factor analytic models: (1) null model; (2) one-dimensional model of severity; (3) positive/negative thought disorder from Andreasen (1979b) with the inclusion of loss of goal on the positive factor; (4) a two factor model examining verbal productivity (poverty of speech and pressured speech) and disconnection (poverty of content of speech, tangentiality, derailment, incoherence, circumstantiality, and loss of goal); and a (5) three-factor model with poverty of speech, pressured speech, circumstantiality, and loss of goal on factor 1, incoherence and derailment on factor 2 , and poverty of content of speech and tangentiality on factor 3. Goodness-of-fit indices revealed that the two-factor verbal productivity/disconnection model was the best-fitting 
model, followed by the three-factor model. Contrary to Andreasen's earlier findings (1979b), the positive/negative thought disorder model failed to emerge as a solution. Expanding on Harvey et al. (1992), Cuesta and Peralta (1999) examined eight hypothetical models ranging from one to six factors, all of which included all 18 -thought disorder elements from the TLC. Confirmatory factor analyses revealed that the best fitting model was comprised of 6 dimensions: negative (poverty of speech, poverty of content of speech, and perseveration); idiosyncrasies (word approximations and stilted speech); semantics (clanging and neologisms); attention (distractible speech and blocking); reference (echolalia and self-reference); and disorganization (pressured speech, tangentiality, derailment, incoherence, illogicality, circumstantiality, and loss of goal).

While the studies above support the continued interest in examining thought disorder in schizophrenia, they have facilitated little progress toward a deeper understanding of the mechanisms of thought disorder in this population. The speech versus thought disorder controversy is not the only significant discrepancy; the study of thought disorder has been fraught with definitional differences (Andreasen 1979a; 1979b; 1982; Levy et al., 2010) that are echoed in the heterogeneity of measures and models of thought disorders described above. Unfortunately, factor analytic studies of thought disorder have focused solely on the TLC. Moreover, the use of the TLC varied across these three studies; two studies used only a subset of thought disorder elements from the TLC without any explanation for this procedure (Andreasen, 1979b; Harvey et al., 1992). Unfortunately, thought disorder is, at best, vaguely defined. Therefore the current research follows the conceptualization of Holzman et al. (2005), in which thought 
disorder is described as an impairment or deviation of thought measured through speech and characterized, in part, by the following: “... a jarring disconnection between words spoken and their consensual meaning, sudden, unexpected changes in the topic under discussion, a rhythmic repetition of phrases, obscure references to tangential topics, and even neologisms...” (p. 55).

\section{Thought Disorder in Schizophrenia}

As described at length above, the study of thought disorder has a rich history but is burdened by many interpretations about what thought disorder is, and what it isn't. To provide a context to examine affect as a moderator of the severity and presentation of thought disorder in schizophrenia, the next section will review studies relevant to the conceptualization of thought disorder. Refer to Table 3 for sample and study characteristics.

\section{Course and Severity of Thought Disorder: The Chicago Follow-Up Study}

The Chicago Follow-up Study (CFS) is a longitudinal, multidisciplinary study focusing on the course of psychosis and adjustment in adults with schizophrenia (Marengo et al., 1986). Of particular interest in this project are the prevalence, course, severity, and relation to adjustment of thought disorder in schizophrenia and other psychotic and nonpsychotic disorders (Marengo et al., 1986). Psychosis and psychotic disorders were defined by current experiences of delusions and/or hallucinations (Marengo et al., 1986). The CFS utilized the Index of Positive Thought Disorder (IPTD) to assess bizarre-idiosyncratic thinking and separation from reality on a continuum from absent to severe. Participants in this large study were comprised of an inpatient sample diagnosed primarily using Research Diagnostic Criteria (RDC; Spitzer, Endicott, \& 
Robbins, 1978) that specify exclusions for any affective episode. Efforts were made to evaluate patients within the first few weeks of admission to obtain data from an acute, medication-free sample. This subsection will review significant studies from the CFS project related to the goal of the current research.

Harrow, Grossman, Silverstein, and Meltzer (1982) examined acute thought disorder in 35 individuals with schizophrenia at admission and a subsample seven weeks later; twenty-five members of the acute sample were medication-free. Of the sample measured at index, 50\% exhibited severe thought disorder and 29\% exhibited moderate thought disorder, revealing that $79 \%$ of the schizophrenia sample showed definite evidence of thought disorder as defined by the IPTD (Marengo et al., 1986). Thought disorder was examined seven-weeks later in 21 of 35 individuals from the acute phase; $76 \%$ percent of this subsample were receiving antipsychotic medication and fewer than $50 \%$ of this sample were psychotic at follow-up as defined by the CFS project (see above description). Forty-eight percent of individuals continued to exhibit severe thought disorder, followed by $14 \%$ exhibiting moderate thought disorder, suggesting that thought disorder persisted despite antipsychotic medication. Only a trend toward a reduction in thought disorder severity emerged during this phase of treatment.

Similar findings emerged in an examination of thought disorder at admission and one year follow-up (Harrow, Grossman, Silverstein, Meltzer, \& Kettering, 1986a). In a sample of 30 individuals with schizophrenia, $49 \%$ showed severe thought disorder at the acute stage of assessment and $26.5 \%$ exhibited moderate thought disorder, with a total of $75.5 \%$ of the sample exhibiting definite thought disorder. At follow-up, $27 \%$ of individuals displayed severe thought disorder, followed by $26.5 \%$ exhibiting moderate 
thought disorder. While no information was provided about medication status in the acute stage of assessment, $77 \%$ of the sample was taking psychotropic medications at follow-up (91\% on antipsychotic medication), again suggesting that thought disorder persisted at a moderate to severe level despite medication. Furthermore, there were no significant differences in thought disorder severity between unmedicated individuals and individuals taking antipsychotic medication at follow-up.

Harrow, Marengo, and McDonald (1986b) examined the early course of schizophrenia, specifically addressing whether persistent thought disorder occurs as part of an enduring illness or as part of a new episode of illness. Forty-eight individuals with schizophrenia were assessed at hospital admission and one and half years later. Eightythree percent of individuals were on antipsychotic medications at index and 52\% at follow-up. During the acute stage, $56 \%$ of the sample exhibited severe thought disorder, followed by $25 \%$ who displayed moderate thought disorder $(81 \%$ showed definite thought disorder, overall). At follow-up 27\%, of the sample exhibited severe thought disorder, followed by $17 \%$ displaying moderate thought disorder. While there was a significant decrease in thought disorder severity from the acute stage $(M=3.54)$ to follow-up $(M=2.70)$, results revealed that thought disorder (at all levels of severity) most often occurred in the context of a chronic, enduring illness. Moreover, thought disorder did not appear to occur in isolation, but as part of a larger cluster of chronic symptoms or a new acute disturbance. Individuals hospitalized at follow-up showed more severe thought disorder than those not hospitalized, and individuals medicated at follow-up showed more severe thought disorder than unmedicated patients. While all but one of the 
individuals exhibiting severe thought disorder at follow-up exhibited psychosis as defined by the CFS, this relationship was not explicitly examined.

In an effort to further examine the course and persistence of thought disorder, Harrow and Marengo (1986) examined thought disorder in a sample of 44 individuals with schizophrenia at two time points following hospitalization: $1.5-2$ years after discharge (FU1); and two years after follow-up 1 (FU2). The authors specifically examined four trajectories of thought disorder: absent (no thought disorder at FU1 or FU2); acute (thought disorder at FU1 but not FU2); episodic (thought disorder at FU2 but not FU1); and persistent (thought disorder at both). Fifty-three percent of the sample was receiving antipsychotic medication at FU1 and 59\% at FU2. At FU1, 24\% exhibited moderate thought disorder, followed by $21 \%$ exhibiting severe thought disorder. Following the evaluation at FU2 (3.5 - 4 years after discharge), 24\% of the sample showed an absence of thought disorder over time, 13\% exhibited only acute thought disorder, 24\% exhibited an episodic course, and 39\% showed a persistent course of thought disorder over a four-year period.

Building on the early research from the CFS mentioned above, Marengo and Harrow (1997) evaluated the longitudinal course of thought disorder at admission, and again $2,4.5$, and 7.5 years after admission. Of the forty-five individuals with schizophrenia evaluated, $71 \%$ exhibited thought disorder at index. Twenty-four percent of the sample were on no medication at any of the three follow-ups, $31 \%$ were on medication during at least one or two follow-ups, and $45 \%$ were on medication at all follow-ups. The mean severity ratings at 2, 4.5, and 7-year follow-up were 2.8, 3.0, and 3.0, respectively; severity correlated significantly and positively across all time points. 
At the second year follow-up, $51 \%$ of the sample showed no thought disorder, $27 \%$ showed definite signs of abnormal thinking, and 27\% displayed severe thought disorder. At 4.5 years after admission, $42 \%$ exhibited no thought disorder, followed by $20 \%$ showing moderate, and 38\% displaying severe thought disorder. Finally, $36 \%$ showed no thought disorder at 7.5-year follow-up, 22\% displayed moderate thought disorder and $42 \%$ exhibited severe thought disorder. Using the procedure from Harrow and Marengo (1986) to examine trajectories of thought disorder, $18 \%$ showed no thought disorder at any follow-up evaluation, $18 \%$ exhibited an episodic, infrequent course (thought disorder at one follow-up), $40 \%$ displayed an episodic, frequent course (thought disorder at two follow-ups), and $24 \%$ showed a persistent course (thought disorder at all three followups). While thought disorder was associated with psychosis as defined by the CFS at 2year follow-up, further examination of the course of thought disorder in relation to psychosis was nonsignificant, suggesting that thought disorder occurred independent of psychosis.

Marengo and Harrow (1985) directly examined the relationship between psychosis and thought disorder in a sample of eighty-five individuals with schizophrenia. Results showed no difference in thought disorder severity between the $63 \%$ on antipsychotic medication and those unmedicated, and psychosis was shown to be unassociated with thought disorder in this sample.

Overall, results from the CFS consistently reveal a significant and persistent course of thought disorder in hospitalized patients with schizophrenia. Furthermore, thought disorder endured despite antipsychotic medication. However, findings regarding the relationship between psychosis and thought disorder, and differences between 
medicated and unmedicated individuals were mixed. Additional examination of these groups, including remission rates for psychosis are needed to better understand these relationships. While thought disorder persisted despite medication, it must also be noted that more severe individuals were more likely to receive medication, thereby making this cause-effect relationship unclear and in need of more exploration.

\section{Subtypes and Associated Features of Thought Disorder}

While the findings from the CFS highlight the persistence of thought disorder in schizophrenia, methodologies that address subtypes focus on the presentation of thought disorder elements within schizophrenia. Harvey, Earle-Boyer, and Wielgus (1984) sought to examine the consistency of thought disorder in a sample of 20 inpatients with schizophrenia receiving antipsychotic medication. These individuals were diagnosed using the Diagnostic and Statistical Manual of Mental Disorders, $3^{\text {rd }}$ ed., (DSM-III, American Psychiatric Association, 1980). Thought disorder was measured three times over the course of ten days using the TLC. The authors examined two negative signs of thought disorder (poverty of speech and poverty of content of speech) and five positive signs of thought disorder (pressured speech, derailment, tangentiality, illogicality, and incoherence), and found that ratings across these seven elements were significantly related and stable across all three time points. Moreover, the authors examined Andreasen's positive/negative thought disorder dichotomy (1979b) and concluded that schizophrenia was primarily characterized by poverty of speech, and negative thought disorder, overall.

Andreasen and Grove (1986) examined the utility of the TLC for diagnosis and prognosis in a sample of 50 inpatients with RDC -diagnosed (Spitzer et al., 1978) 
schizophrenia. The authors stated that "nearly all were medicated" but all were "severely symptomatic" (Andreasen \& Grove, 1986, p. 350). The participants were assessed on all eighteen elements of the TLC during the first week of their admission, and six months later. Results showed that the sample displayed "empty" and "disorganized" thought disorder at index (Andreasen \& Grove, 1986, p. 351), as defined by a higher frequency of poverty of speech and poverty of content of speech, and derailment, incoherence, and illogicality, respectively. At six-month follow-up, this sample continued to show persistent disorganization with significant improvement only in pressured speech and incoherence.

Harvey, Docherty, Serper, and Rasmussen (1990) examined thought disorder eight months after hospital admission in 22 individuals with DSM-III- (American Psychiatric Association, 1980) diagnosed schizophrenia. Approximately $80 \%$ were receiving antipsychotic medications at follow-up, accompanied by anticholinergic treatments in approximately $70 \%$ of the entire sample. Negative thought disorder, as identified by poverty of speech and poverty of content of speech from the TLC, was shown to be a stable trait in this sample of individuals with schizophrenia. Positive thought disorder, as identified by pressured speech, derailment, tangentiality, incoherence, and illogicality, was also shown to be stable in this sample and related to the presence of psychosis (presence of delusions and/or hallucinations) at 8-month follow-up.

The results from this subset of studies are similar to those of the CFS, suggesting that thought disorder endures despite medication, and a weak relationship exists between psychosis and thought disorder. While the findings suggest heterogeneity of thought disorder, negative thought disorder might be particularly salient in schizophrenia. 


\section{Review of Thought Disorder in Schizophrenia: Problems with Methodology}

Taken together, studies of thought disorder in schizophrenia illustrate that a significant number of hospitalized individuals with schizophrenia exhibit definite abnormalities in thought, with a higher percentage showing moderate and severe thought disorder in the majority of studies. Results further suggest that thought disorder in schizophrenia is often frequent and persists as part of an unremitting illness. Finally, findings suggest that thought disorder in schizophrenia may be primarily characterized by poverty of speech and poverty of content of speech (Andreasen, 1979b; Andreasen \& Grove, 1986; Harvey \& Brault, 1986; Harvey et al., 1984; Taylor et al., 1994). Mixed results for the relationship between psychosis and thought disorder suggest a trend for different symptom courses. However, additional investigation of the remission rates for psychosis compared to thought disorder is needed to further clarify this association. That thought disorder only mildly remits even with antipsychotic medication also supports the need to further explore the relationship with psychotic symptoms, and revisit thought disorder generally in schizophrenia, including reconsidering effective interventions.

However, several methodological problems limit the generalizability of findings and have likely contributed to the narrowed understanding of thought disorder today. First and foremost, the samples used in CFS research were likely overlapping across studies; this procedure limits the strength of the findings. Furthermore, comparisons of medicated versus unmedicated individuals do not clearly reveal whether thought disorder fails to remit despite medication, or whether individuals who are more severely symptomatic are simply receiving more medication and not responding as expected. This 
is an important consideration for later work not only for the proposed relationship of affect and thought disorder, but also the implications for treatment of thought disorder.

The conclusions regarding a positive/negative dichotomy should also be interpreted with caution as a closer look reveals that this conceptualization represents an oversimplification of the prevalence of thought disorder elements in schizophrenia, and the heterogeneity of thought disorder in schizophrenia, more generally. While signs of negative thought disorder were shown to occur at a high frequency in schizophrenia, elements commonly associated with positive thought disorder occurred at an equal (Andreasen \& Grove, 1986) or greater (Andreasen \& Grove, 1986; Harvey et al., 1990; Harvey et al., 1984) frequency in this population. This further supports the need for a better understanding of thought disorder, as it appears that interpretations about the characteristic nature of negative thought disorder in schizophrenia do not fully account for the heterogeneity of this impairment in this population.

The guidance and momentum needed for continued study in this area is also lacking. Speculations about mechanisms of thought disorder have often occurred in a vague manner; very rarely did any of the above studies make explicit inferences about specific mechanisms or moderators, or identify specific areas in need of further research. Some studies implicated an underlying impairment such as frontal lobe pathology (McGrath, 1991), central nervous system dysfunction (Holzman et al., 1986), or speech disorder (Harvey \& Brault, 1986; Harvey et al., 1984), while others have broadly implicated a set of factors, such as " multiple factors, some of which are common to various diagnostic groups, and some of which may be more specific to certain types of thought-disordered patients" (Marengo \& Harrow, 1985, p. 40). Moreover, conclusions 
made vague allusions to "different underlying cognitive processes" (Harvey \& Brault, 1986, p. 171), “different cognitive processes" (Holzman et al., 1986, p. 370), “different mechanisms" (Taylor, Reed, \& Berenbaum, 1994, p. 325), and a need for a continued search of "mechanisms that sustain more persistent forms of thought disorder in schizophrenia...” (Marengo \& Harrow, 1997, p. 282). Psychosis, social inappropriateness, blending of self-referential material during communication, and acute illness have also been implicated as factors related to thought disorder severity, course, and presentation in schizophrenia (Harrow et al., 1982; Harrow et al., 1986b). Finally, affective mechanisms have been identified as possible explanatory factors of thought disorder in schizophrenia, with particular emphasis on the distress, anxiety, emotional intensity, and excessive affect associated with more acute phases of the illness (Andreasen, 1979b; Harrow et al., 1986a; 1986b). These latter speculations represent viable areas of further study.

While the assessment and methodological concerns discussed above are significant, they are likely representative of a more fundamental issue; the conceptualization of thought disorder excludes moderating factors, particularly affect. Returning to the basics of what we know about the continuum from "normal" to pathology, decades of research implicate affect as an integral component of how individuals understand and convey their experience with their environment (Cicchetti et al., 1995; Kring \& Bachorowski, 1999). Therefore, it appears that affect may be a moderator that helps explain the unique severity and presentation of thought disorder in schizophrenia reported in the literature. Specifically, the current research proposes that 
affective intensity and valence moderate the severity and presentation of thought disorder in schizophrenia.

\section{Affect and Thought Disorder in Schizophrenia}

While affect, mood, and emotion are used somewhat interchangeably to describe emotional experience and expression, the literature suggests distinct states. Batson, Shaw, and Oleson (1992), describe affect as the most general and primitive state that informs the individual about preferences or circumstances that are most valued. Mood is further described as a type of affective state that illustrates a tone and level of intensity, and reflects expectations about future events (i.e., positive mood if positive affect and outcomes are expected). Finally, emotion, also a type of affective state and therefore subjected to varying valence and intensity, reflects identification of a specific goal and access to that goal in the present. While examination of emotional states could therefore occur at any one of the above levels, the current review will focus on affect more broadly, with the understanding that mood and emotion are subsumed under affect as these terms are often used synonymously as representative of a general emotional state.

\section{Affect and Cognition}

Research examining the impact of affect on cognitive processes in healthy individuals suggests that positive affect increases activation of associated networks, allowing for increased efficiency and creativity in a variety of different cognitive processes (Ashby, Isen, \& Turken, 1999; Bar, 2009; Clore \& Palmer, 2009; Fredrickson, 2001). A reciprocal relationship is also present, with more broad activation contributing to positive affect (Bar, 2009). 
Conversely, negative affect contributes to narrow, bottom-up processing (Bar, 2009; Clore \& Palmer, 2009) such as the ruminative processes seen in individuals experiencing depression (Bar, 2009). Schizophrenia studies have found a similar impact of negative affect on cognitive processes. In a sample of individuals with schizophrenia, Halari, Mehrotra, Sharma, \& Kumari (2006) found that self-reported feelings of depression and dejection were related to poor performance on measures of attention (adjusted $\left.R^{2}=0.14, p<.05\right)$, executive function ( $\mathrm{B}=-0.50$, adjusted $R^{2}=0.24, p<.05$ ), and verbal memory $\left(\mathrm{B}=-0.47\right.$, adjusted $\left.R^{2}=0.24, p<.05\right)$. Tension and anxiety also predicted poor verbal memory $\left(\mathrm{B}=-0.73\right.$, adjusted $\left.R^{2}=0.24, p<.05\right)$

Nancy Docherty and her colleagues (Docherty, Evans, Sledge, Seibyl, \& Krystal, 1994a; Docherty \& Herbert, 1997; Docherty, Sledge, \& Wexler, 1994b) have consistently shown that discussion of self-reported stressful/unpleasant and pleasant situations elicit negative and positive affect, respectively, in individuals with schizophrenia.

Furthermore, this work has shown that discussion of events that bring about negative affect contribute to increased communication disturbances as measured by deficits in communicating meaning and reference failures from the CDI. Mean differences in reference disturbance were found for pleasant/low stress conditions and unpleasant/high stress conditions $\left(M_{\text {Low }}=1.8\right.$ versus $M_{\text {High }}=3.5, p<.001$, Docherty et al., $1994 \mathrm{a} ; M_{\text {Positive }}$ $=.092$ versus $M_{\text {Negative }}=.098, p<.05$, Docherty, Sledge, $\&$ Wexler, $1994 \mathrm{~b} ; M_{\text {Positive }}=$ 2.45 versus $M_{\text {Negative }}=3.42, p<.01$, Docherty \& Herbert, 1997). Similarly, Burbridge and Barch (2002) found that negative-valenced, open-ended questions elicited more unclear references as measured by the $\operatorname{CDI}\left(M_{\text {Negative }}=3.3\right.$ versus $\left.M_{\text {Neutral }}=1.9\right)$, and correlated with measures of selective attention $(r=.40, p<.05)$. 
Affective intensity has also been shown to moderate the relationship between affect and cognition (Larsen \& Diener, 1987). Low versus high affect intensity differentially affects attention, information processing and encoding strategies during positive and negative mood states (Basso, Schefft, \& Hoffman, 1994; Larsen \& Diener, 1987). For example, a sample of female college students who reported low affective intensity and experienced a positive mood induction performed better on a word recognition task than those in the negative mood induction group. Conversely, participants who reported high affective intensity and experienced neutral or negative mood inductions recognized more words than those in the positive induction condition (Basso et al., 1994). Thus, affective intensity may be a moderator between affective valence and cognition.

Affective intensity also appears to be dispositional and associated with a tendency toward particular cognitive processes or perspectives (Larsen, Diener, \& Cropanzano, 1987; Schimmack \& Diener, 1997) a finding that holds across affective valence (Larsen \& Diener, 1987). It has been found that individuals who report high affective intensity also report using increased personalization, selective abstraction, and overgeneralization processing strategies when viewing positive- and negative-valenced pictures compared to those with low affective intensity who engaged in these operations much less so (Larsen, et al., 1987). Those who reported high affective intensity have also been shown to exhibit a processing style that is more global and elaborative, personalized, and empathic in response to valenced-pictures compared with low-intensity individuals who were less likely respond in that manner (Larsen, et al., 1987). 
While healthy individuals may joke about word-finding difficulties, distractibility, and disorganization during periods of strong negative or positive affect, these anecdotes build on what has been found in the affect and cognition literature: positive affect and increased activation of associated networks may contribute to an abundance of information that may be difficult to filter and lead to disordered thought, and negative affect and narrow processing may lead to limited or perseverative responding. It is expected that this relationship is present in psychiatric populations, albeit at a much greater rate and degree of severity. Given what we know about the relationship between affect and cognition, viewing thought disorder as a cognitive process similar to others suggests that thought disorder may also be moderated by similar factors (e.g., affect) (Goldberg \& Green, 2002).

\section{Affect and Thought Disorder}

Research specifically examining affect and thought disorder is limited both in breadth and depth, with respect to studies outside of affective disorders (i.e. bipolar disorder) and schizoaffective disorder. However, the research that is available is consistent. Individuals experiencing mania and thought disorder showed more mood lability than those with mania and no thought disorder, and individuals with schizophrenia (Jampala, Taylor, \& Abrams, 1989). Bipolar patients exhibiting a normal, non-depressed mood showed a higher proportion of immature responses, more examples of thought disorder, and more severe thought disorder overall than healthy controls as measured by the Rorschach Inkblot Test and Exner scoring system (Osher \& Bersudsky, 2007), and individuals with mania who also exhibited emotional blunting presented significantly more thought disorder elements than both individuals with mania but no 
evidence of emotional blunting and individuals with schizophrenia (Jampala, Abrams, \& Taylor, 1985).

Overall, these findings suggest that dysregulation of affect may be related to increased thought disorder across a variety of groups. However, the following methodological weaknesses limit the generalizability and strength of results: (1) the samples in the above studies were quite variable, and small (see Table 3); (2) both Jampala et al. (1985) and Jampala et al. (1989) utilized a measure of thought disorder that was created by the authors and limited to discussion of the following elements: flight of ideas (Jampala et al., 1989, only); neologisms; driveling; non-sequiters; tangentiality; private use of words; and paraphasias; (3) the measure of mood lability discussed by Jampala et al. (1989) was not explained; and (4) while the results from Jampala et al. (1985) regarding emotional blunting were suggestive, emotional blunting was not measured in the individuals with schizophrenia. Finally, none of these studies acknowledged that mania could include positive mood (euphoria), negative mood (irritability), or both. This is a particularly relevant methodological problem given the robust findings regarding the role of positive and negative affect on cognitive processes, and highlights the importance of examining affect in greater detail, paying specific attention to the range of affective experience.

An indirect measure of affect in thought disorder in schizophrenia was illustrated by examining thought disorder in core schizophrenia (emotional blunting and avolition) and non-core schizophrenia (no loss of expression or history of prominent affective disturbance, avolition possible) (Taylor et al., 1994). Results showed differences in thought disorder between individuals with mania, schizoaffective disorder characterized 
by mania (SADm), and schizophrenia, with significantly more individuals with mania and SADm exhibiting hyperverbal examples of thought disorder (defined by the authors as rapid speech, pressured speech, circumstantiality, distractibility, flight of ideas, clanging, and verbigeration), and significantly more individuals with schizophrenia exhibiting hypoverbal examples of thought disorder (defined by the authors as slow speech and paucity of speech). Within schizophrenia, hypoverbal features primarily characterized individuals with core schizophrenia, while primarily hyperverbal features characterized those with non-core schizophrenia.

This study again implicates the possible role of affect in thought disorder given the differences in thought disorder in manic states and the manifestation of thought disorder related to past and present affective disturbance in schizophrenia. While these findings appear to support the positive/negative thought disorder dichotomy introduced earlier, these findings suggest an alternative perspective: a continuum of affective disturbance that may be related to thought disorder presentation and may impact thought disorder in schizophrenia. While severity of thought disorder was not assessed in this study, the moderating relationship of affect on the severity and presentation of thought disorder proposed in the current research suggests that severity of thought disorder would be moderated by affect in a similar fashion. Despite the significance of these latter findings, the use of only clinician-rated measures of emotional expression and the vague "present" versus "absent" measure of thought disorder pose problems for generalizing these findings.

The studies above suggest promising results for the role of affect in the conceptualization of thought disorder in schizophrenia. Unfortunately, the study by 
Taylor et al. (1994) is the only study found that examined affect and thought disorder in schizophrenia, albeit indirectly. Therefore, we are left to extrapolate from the limited research examining thought disorder and affect. However, that approach is extremely weak given that none of the aforementioned studies measured affect, per se, leaving only inferences about intensity and valence. In addition, only two of the four studies addressed medication usage, quantified by months on antipsychotic medication (Jampala et al., 1985; Jampala et al., 1989). This is a relevant oversight when considering the impact of medication on affective symptoms (positive and negative) and the implications for the proposed relationship in the current research.

\section{Affect in Schizophrenia}

Bleuler described affect as a core feature of schizophrenia with self-reported emotional experiences often incongruent with outward expression. Conversely, Sándor Radó suggested that the limited emotional expression in schizophrenia reflected a lack of emotional experience altogether (cited from Kring et al., 1993). While most would argue against the stringency of the latter point, our understanding of affective experience in schizophrenia remains somewhat limited (Cohen \& Minor, 2010). However, the research that is available highlights the importance of affective experience in schizophrenia and comes from both induction and non-induction paradigms.

\section{Induction studies.}

Emotional experience. It is now well documented that both positive and negative emotions can be induced with affective stimuli in individuals with schizophrenia. These induction paradigms present individuals valenced stimuli (pictures, words, etc.) and then ask for ratings of their level of pleasantness/happiness/arousal, and/or 
unpleasantness/negative affect/aversion following discontinuation of the stimulus.

Studies using these induction paradigms with individuals with schizophrenia demonstrate no differences between medicated versus unmedicated, inpatient versus outpatient, or male versus mixed samples (Cohen \& Minor, 2010). The level and intensity of induction also remains consistent across modalities including gustatory (pleasant and aversive drinks), visual (positive, negative, and neutral pictures), verbal (reading words of differing valence), behavioral (facial gestures and social interactions) (Cohen \& Minor, 2010), and physiological indicators (Kring \& Caponigro, 2010). Individuals with schizophrenia endorse pleasant emotions similar to or greater than that of controls when exposed to these evocative stimuli (Cohen \& Minor, 2010; Kring \& Caponigro, 2010).

While individuals with schizophrenia demonstrate an affective experience that is comparable to controls, some deficits do exist. Individuals with schizophrenia exhibit less prosody during emotional topics when compared to controls (Alpert, Rosenberg, Pouget, \& Shaw, 2000), and have shown less arousal and change in response to emotional topics both physiologically (Park, Gupta, \& Kim, 2011) and neurologically (Ursu, Kring, \& Gard, 2011). Most importantly, individuals with schizophrenia demonstrate difficulty reporting affective experience after a delay (Gold, 2011; Kring \& Caponigro, 2010; Ursu et al., 2011) and at times report affect that is incongruent with the stimulus (Tremeau et al., 2009; Ursu et al., 2011), suggestive of the disconnection between experience of emotion and its verbal expression.

Emotional expression. Emotional expression is often assessed through some observable indicators. For individuals with schizophrenia, a clinician or another collateral reporter often conducts this assessment. The distinction between experience 
and expression is significant because expression is often used as the primary evidence for experience and the limited expression seen in schizophrenia conflates affective and cognitive processes. It is possible that research examining negative symptoms in recent years became the default for affect research in schizophrenia, as some symptoms such as emotional blunting, flat affect, and anhedonia may, on the surface, appear to reflect emotional states. However, robust findings illustrate that individuals with schizophrenia show significant discrepancies between clinician-rated affective expression and selfreported affective experience (Agheveli, Blanchard, \& Horan, 2003; Berenbaum \& Oltmanns, 1992; Healey, Pinkham, Richard, Kohler, 2010; Kring \& Moran, 2008; StHilaire, Cohen, \& Docherty, 2008). Specifically, flat affect has been shown to be unrelated to emotional experience in schizophrenia (Kring \& Moran, 2008) and negative symptoms in schizophrenia are distinct and unrelated to depressive symptoms (Malla, 1995; Ulas, Akdede, Ozbay, Alptekin, 2008). These discrepancies appear to be unrelated to antipsychotic medication treatment (Kring \& Bachorowski, 1999; Kring \& Earnst, 1999).

Non-induction studies. Similar to induction studies, non-induction studies (selfreported affect independent of induction paradigm) demonstrate that individuals with schizophrenia experience significant levels of affect. Studies exploring affective experience across valence show similar levels of positive and negative affect in schizophrenia and healthy controls when asked to rate their current emotional experience (Agheveli et al., 2003), and comparable percentages of positive and negative word use in self-descriptions (St-Hilaire et al., 2008). Other work has emphasized increased baseline levels of negative affect in schizophrenia including depression (Berenbaum \& Oltmanns, 
1992; Halari et al., 2006), social anhedonia (Berenbaum \& Oltmanns, 1992), and other experiences such as anxiety, anger, and fatigue (Halari et al., 2006).

The research available suggests that individuals with schizophrenia can perceive and report on their current emotional experience without stimulus induction, and are reliable and valid reporters of this experience (Kring \& Capongrio, 2010) with their report correlating with clinician-ratings following semi-structured interview (Halari et al., 2006). While it appears that schizophrenia may be characterized by more baseline negative affect (e.g. depression), this conclusion should be interpreted with caution because: (1) this area of research is limited; (2) much of the methodological focus is on negative affect.

In sum, there is strong evidence that the "emotional system" in schizophrenia is intact, although memory of the "in-the-moment" emotions may be inaccurate when reported some time later (Ursu et al., 2011), a phenomenon not restricted to patients with schizophrenia.

\section{Thought Disorder In Affective and Non-Schizophrenic Psychotic Disorders}

While thought disorder is considered a core feature of schizophrenia, it also occurs at a similar rate in individuals with bipolar disorder I (Andreasen, 1979b; Andreasen \& Grove, 1986; Harrow et al., 1982; Harvey et a., 1990; Harvey et al., 1984; Holzman et al., 1986; Levy et al., 2010; Marengo \& Harrow, 1985), and schizoaffective disorder (Andreasen \& Grove, 1986; Holzman et al., 1986), albeit more associated with positive thought disorder in mania (Andreasen \& Grove, 1986; Harvey \& Brault, 1986; Harvey et al., 1990; Harvey et al, 1984; Jampala et al., 1989; Taylor et al., 1994). Furthermore, research suggests that thought disorder in mania is often more severe in 
acute stages (Harrow et al., 1982; Jampala et al., 1989; Marengo \& Harrow, 1985) and interestingly, thought disorder in SADm looks more similar to thought disorder in schizophrenia than to mania in acute stages (Holzman et al., 1986). However, examination of thought disorder longitudinally suggests that thought disorder remits almost completely in mania (Andreasen \& Grove, 1986; Jampala et al., 1989) and somewhat in schizoaffective disorder (Andreasen \& Grove, 1986; Marengo \& Harrow, 1997), including significantly greater reductions overall in mania compared to schizophrenia (Harrow et al., 1982). While evaluated in several studies, findings regarding thought disorder and depression were often only vaguely discussed or neglected altogether.

Similar to thought disorder research in schizophrenia, authors speculate about the potential role of affective processes in the manifestation of thought disorder in mania by implicating excessive affect (Andreasen, 1979b), distress and anxiety (Harrow et al., 1986b) and emotional intensity (Harrow et al., 1986a) in the positive elements of thought disorder often associated with mania. The speculations about schizoaffective disorder are even more ambiguous, with discussion of the heterogeneous and "transitional" nature of the diagnosis (Andreasen \& Grove, 1986, p. 358) and the suggestion that the combination of thought disorder, psychosis, and affective states may implicate a meaningful pattern for schizoaffective disorder, specifically (Marengo \& Harrow, 1997).

One area that is critical when considering the similarities in the acute phase and longitudinal differences in thought disorder between individuals with schizophrenia and those with mania or schizoaffective disorder is pharmacological treatments. However, intergroup medication differences are not statistically explored in any of the 
aforementioned studies; only medicated versus unmedicated intragroup differences were examined. With regard to the current argument for the role of affect in thought disorder, this information is significant when considering that a large majority of those with mania in the aforementioned studies received lithium (a mood stabilizer) or lithium combined with antipsychotic medication at follow-up (see Table 3). One study reported significant remission of thought disorder in mania over seven weeks when compared to individuals with schizophrenia who received antipsychotic medication only (Harrow et al., 1982). However, another study showed no difference in severity at one-year follow-up despite differences in medication (Harrow et al., 1986a). Unfortunately, other studies that exhibited differences in remission rates between those with mania and schizophrenia did not discuss specific differences in pharmacological treatment (Andreasen \& Grove, 1986; Jampala et al., 1989). Additional support for the role of affect in thought disorder in schizophrenia is illustrated by the findings from Marengo \& Harrow (1997) that showed a negative correlation for thought disorder symptoms and anti-depressant medication for the total sample at baseline, and for schizophrenia only at two-year follow-up. However, no specific information was provided about sample characteristics or other pharmacological treatments for those receiving the anti-depressant medication.

Subsamples of studies primarily focused on the role of psychosis in thought disorder have examined thought disorder in schizophrenia, psychotic but nonschizophrenic (PNS), and nonpsychotic groups (NP) (Harrow \& Marengo, 1986; Harrow et al., 1986b; Marengo \& Harrow, 1985; Marengo \& Harrow, 1997) (see Table 3 for the diagnoses included in these categories). While literature discussed earlier illustrated inconsistent results regarding the relationship between psychosis and thought disorder, 
this subsample of research suggested that thought disorder is more severe in schizophrenia than PNS (Marengo \& Harrow, 1985), and both PNS and NP at acute stages (Harrow et al., 1986b) and 1.8 years after discharge (Harrow et al., 1986b). Moreover, thought disorder was more persistent in schizophrenia than in schizoaffective disorder, PNS, and NP groups, and more prevalent than in PNS and NP across 7.5-year follow-up. Thought disorder in schizoaffective disorder was also more prevalent than in NP groups (Marengo \& Harrow, 1997). However, Harrow \& Marengo (1986) found no difference between schizophrenia and PNS at 1.5-2 year follow-up, or 3.5-4 year followup. Both of these groups showed more severe thought disorder than NP at 1.5-2 year follow-up. Not only do these findings echo the inconsistent results discussed previously, the methodologies also fail to consider the impact of affect, as PNS and NP samples were heterogeneous with regard to affective states (see Table 3). PNS groups were primarily comprised of individuals with major depression, mania, and schizoaffective disorder with both depressed and manic subtypes, and NP groups were similarly comprised of individuals with major depression, dysthymia and mania (Harrow \& Marengo, 1986; Harrow et al., 1986b; Marengo \& Harrow, 1997). While the studies did acknowledge the role of pharmacological treatments on psychosis by providing frequencies for antipsychotic medication, these studies provided no discussion of anti-depressants or mood stabilizers, treatments that were likely present given the samples used.

Although the prevalence of thought disorder in affective disorders illustrates that thought disorder is not unique to schizophrenia, findings suggest that the course and prognosis of thought disorder is often different in individuals with affective disorders and schizoaffective disorders than schizophrenia; research further suggests that thought 
disorder is more state-dependent in mania and trait-dependent in schizophrenia (Levy et al., 2010). This may be, in part, due to the differences in interventions implemented for individuals with schizophrenia and those with affective disorders. Antipsychotic medication is the preferred treatment for individuals with schizophrenia (Kuller, Ott, Goisman, Wainwright, \& Rabin, 2010), an intervention that targets the neurological dysfunction associated with hallucinations and delusions. However, while these psychotic symptoms respond well to this particular treatment, research discussed earlier suggests thought disorder remains persistent and chronic. On the other hand, the research discussed above suggests that lithium is the preferred treatment for mania, and individuals in the aforementioned studies experienced remission in thought disorder while receiving this particular treatment. While there is no direct discussion of the impact of mood stabilizers or anti-depressant medication on thought disorder, the breadth of research described above implicates, although indirectly, a relationship between affect and thought disorder that may be extrapolated to schizophrenia. Differences in the course of thought disorder in affective disorders, coupled with consideration of pharmacological and psychotherapeutic interventions that may impact the remission of thought disorder in affective groups suggests that affect may not only be implicated in the severity, presentation, and chronicity of thought disorder in schizophrenia but is also a likely target for treatment. Research further suggests that a history of affective symptoms is a good prognostic indicator in psychiatric illness, generally (Keefe et al., 1987; Marengo \& Harrow, 1997). While this conclusion speaks to the remission of thought disorder in affective disorders, this further suggests that more consideration must be given to affect in schizophrenia to better understand if better prognosis is related to early intervention for 
significant affective symptoms and, if so, what this could mean for symptoms of schizophrenia.

\section{Review of Methodological Critiques}

\section{Course of Literature}

While not explicitly discussed in the review thus far, it appears that, though relevant and significant, much of the seminal research in thought disorder in schizophrenia is over two decades old. This may be due to several factors: (1) more current research uses different terms or conceptualizations of thought disorder (e.g., speech disorder or dysphasia); (2) thought disorder is an indicator of positive symptoms and should therefore respond to interventions in the same fashion; (3) the endophenotypic nature of thought disorder in schizophrenia contributes to less concern about symptom remission and more concern about symptom management; and/or (4) there is an uncertainty of where to go from here given the rich history of thought disorder, and the myriad of formulations and the apparent absence of a consensus view. Furthermore, the tendency to simply infer emotional experience from negative symptoms (i.e., negative emotion or no emotion), an assertion that has been refuted (Kring et al., 1993; Malla, 1995), and the failure to appreciate the differences in experienced versus expressed emotion have likely contributed to the difficulty in pursuing new perspectives such as the one proposed in the current research.

\section{Methodology}

Measurement variability may have also created a challenge to pursuing a better understanding of thought disorder. For example, extensive results from the CFS indicate that limited or no responding suggests absence of thought disorder while the TLC asserts 
that this type of response is indicative of severe poverty of speech. Moreover, different definitions of thought disorder across assessment procedures appear to represent differences in conceptualization with the highest rating on the TLC being representative of frequency and incomprehensibility of speech, compared to the highest rating on the Thought Disorder Index (TDI; Johnston \& Holzman, 1979; Johnston et al., 1986) and the Thought and Language Index (TLI; Liddle et al., 2002) indicating a complete loss of reality. The variability in these three areas has yet to be accounted for by previous literature.

The use of RDC (Spitzer et al., 1978) versus DSM (American Psychiatric Association, 1980; 1994; 2000) diagnostic criteria also presents a methodological problem. As the more stringent of the two, RDC states that a diagnosis of schizophrenia implies no affective disturbance at any time during the illness, with the presence of even a brief episode earning a diagnosis of schizoaffective disorder. This is quite different from DSM-III (American Psychiatric Association, 1980), DSM-IV (American Psychiatric Association, 1994), and DSM-IV-TR (American Psychiatric Association, 2000) criteria that allow for a prominent affective disturbance in schizophrenia as long as it is brief. Differences in the use of diagnostic criteria may result in a comparison of different samples of schizophrenia and schizoaffective disorder, limiting the ability for a consensus view.

Another major criticism of the thought disorder literature, particularly as it relates to the proposed moderating relationship of affect on the severity and presentation of thought disorder in schizophrenia, is the limited acknowledgment and possible effects of medication. Intragroup differences in medicated versus unmedicated states were 
addressed at times, but no differences between classes of medication were examined (i.e., antipsychotic medication versus mood stabilizer). This is particularly important given that different types of medication target different physiological mechanisms, and that failing to acknowledge the different interventions that comparison groups receive not only presents a potential confound but also does not take into account the possible benefits of treatment in one group (affective disorders and schizoaffective disorder) for a shared mechanism that may impact thought processes across groups (i.e., affect).

\section{Research Samples}

The samples utilized in the aforementioned studies are also somewhat problematic. The heterogeneous samples used in many of the CFS studies (i.e. PNS, NP) control for psychosis but do not acknowledge the affective components likely at play given the composition of the samples, particularly with regard to valence and intensity of affect and differences in pharmacological treatments. Moreover, detailed examination of schizoaffective disorder has the potential to be very useful. However, schizoaffective disorder was only examined individually in three of the studies reviewed and in others was included within the PNS grouping in the CFS project (see Table 3), or not discussed. While the exclusion of schizoaffective disorder in these procedures allows for a clean examination of thought disorder in schizophrenia and affective groups, it reflects an implicit disregard for the continuum of affective impairment that links these three diagnostic groups. Finally, the samples described are primarily inpatient samples so they are not representative of the respective diagnoses and limit the generalizability to individuals in other stages of the illness.

\section{Conclusions and Hypotheses}


Affect may contribute to the severity and presentation of acute thought disorder and may be implicated in the persistence of thought disorder in schizophrenia, a conceptualization similarly proposed by Andreasen in her early attempts to quantify thought disorder (1979b). Findings from the affect and cognition literature support a relationship between affective intensity and valence, and manifestation of thought disorder. Following from findings illustrating that positive affect contributes to broad, top-down processing and negative affect leads to narrow, bottom-up processing, it is hypothesized that positive affect will contribute to thought disorder elements indicative of broad, but loose cognitions, and negative affect will contribute to narrow, restricted responding. It can also be hypothesized that affective intensity would impact thought disorder in schizophrenia in a fashion similar to the widespread impact that intense affective experiences have on all individuals from normal to those suffering from severe psychopathology: significant, pervasive disruption and worsening of symptoms in a variety of domains.

\section{Current Hypotheses}

While the study of thought disorder in schizophrenia has seen decades of research, we have only limited knowledge about the factors that contribute to the heterogeneous severity and presentation of this impairment. The earlier review suggests that affect may play a significant role in thought disorder in schizophrenia and schizophrenia-spectrum disorders (e.g. schizoaffective disorder). However, there is limited research in the area of baseline affective experience, and affect and thought disorder, leaving only speculations about this relationship. Therefore, the study of the relationship between thought disorder and affect in schizophrenia requires examination of 
the most basic questions related to affective intensity and valence, and thought disorder severity. While significant questions also remain regarding assessment and understanding of affective experience in schizophrenia, the current research seeks to examine thought disorder and the role that affect may play, and not affective experience per se.

Hypothesis 1. While affect intensity and valence are both thought to contribute to the severity of thought disorder, it is hypothesized that affect intensity is a more significant factor in the severity of thought disorder in schizophrenia and schizoaffective disorder. Affect intensity has shown to be related to impairment in a variety of cognitive processes across individuals and affective valence (Basso, Shefft, \& Hoffmann, 1994; Larsen \& Diener, 1987). Two hypotheses will be tested to address this larger hypothesis.

Hypothesis 1a. Self-reported global affect intensity (positive and negative items combined) as measured by the Positive and Negative Affect Schedule (PANAS, Watson, Clark, \& Tellegen, 1988) will be predictive of thought disorder severity as measured by the TDI total score.

Hypothesis $1 \boldsymbol{b}$. Positive and negative valence components of the PANAS will differentially contribute to thought disorder severity (TDI total score). It is hypothesized that the intensity of positive affect will account for more variance in thought disorder severity than negative affect. This hypothesis follows research that suggests that positive affect, when coupled with high affective intensity, may impair cognitive processes (Basso, Shefft, \& Hoffman, 1994).

Hypothesis 2. Self-reported intensity of positive and negative affect as measured by the PANAS will differentially relate to response categories from the TDI. 
Specifically, positive affect will be related to categories that reflect broader, more associative processing, while negative affect will be related to categories that reflect narrowed processing. See Table 4 for definitions of the response categories for each severity level on the TDI. This hypothesis seeks to explore robust findings from the literature regarding the relationship between positive affect and broad, top-down processing, and negative affect and narrow, bottom-up processing (Bar, 2009; Clore \& Palmer, 2009; Fredrickson, 2001), albeit at the more extreme and impaired end of an implied continuum. Two hypotheses will be tested to address this broader hypothesis.

Hypothesis 2a. Positive and negative affect as measured by the PANAS will be related to exemplars of broad versus narrow processing from the TDI. Sixteen categories were chosen to explore this hypothesis; nine were selected for positive affect and seven for negative affect.

Hypothesis 2b. Using all of the response categories from the TDI, significant factors will be identified using exploratory factor analyses that reflect broad versus narrow processing. These factors will be significantly related to positive and negative affect as measured by the PANAS. 


\section{METHODS}

\section{Sample}

Individuals eligible to participate in the study met the following inclusion criteria: (1) Axis I diagnosis of schizophrenia or schizoaffective disorder as indicated from the patient chart; (2) currently residing in an acute inpatient hospital; (3) native English speaker; and (4) able to provide informed consent. Patients were excluded if they had: (1) an Axis I diagnosis of delirium, or Alzheimer's or Vascular dementia; (2) an Axis II diagnosis of mental retardation; (3) an Axis III diagnosis of traumatic brain injury; (4) other known medical, neurological, or cognitive conditions that are suspected of significantly affecting thinking, behavior, or one's ability to complete study measures; and (5) hearing or visual impairments without corrective treatment. Because this study was formulated as an examination of thought disorder and affect within schizophrenia and schizoaffective disorder and not a study of diagnosis, no control group was used.

\section{Measures}

Individuals who agreed to participate and from whom consent was obtained completed the following self-report measures: sociodemographic form and Positive and Negative Affect Schedule (PANAS). Participants were also administered the Rorschach Inkblot Test and responses to each of the 10 stimulus cards were used to assess thought disorder severity using the TDI. 
Sociodemographic form. The following sociodemographic data was identified through thorough review of the medical chart and confirmed by the patient, with the understanding that information from the medical chart was determined as the most accurate in light of any discrepancies given the extensive medical and psychiatric information obtained by the unit social workers:
1. Age
2. Sex
3. Ethnicity
4. Race
5. Diagnosis
6. Marital Status
7. Educational attainment
8. Employment status
9. Employment history
10. Current living status
11. Current medications
12. Medication adherence
13. Medical history
14. Number of previous hospitalizations
15. Other current treatment
16. Age of first hospitalizations
17. Age of first episode
18. Duration of illness (current age - age at first hospitalization)
19. Family psychiatric history
20. Substance abuse history

Positive and Negative Affect Schedule. The Positive and Negative Affect Schedule (PANAS; Watson, Clark, \& Tellegen, 1988) is 20-item self-report measure of positive affect (PA) and negative affect (NA). Ten exemplars each of positive and negative affect are rated on a 5-point likert scale: 1 (very slightly or not at all) - 5 (very much). Indices of PA include attentive, interested, alert, excited, enthusiastic, inspired, proud, determined, strong, and active. Indices of NA include 2 items across five categories: (a) distress (distressed, upset), (b) angry (hostile, irritable), (c) fearful (scared, afraid), (d) guilty (ashamed, guilty), and (e) jittery (nervous, jittery). Participants are 
asked to rate " to what extent" they have experienced each exemplar for a given span of time determined a priori by the examiner (e.g. "you feel this way right now, at the present moment," "you have felt this way today," "you have felt this way during the past week," "you generally feel this way, that is, how you feel on the average"). The current study asked participants to rate their experience of each of the 20 items "at the present moment." This time instruction was determined most appropriate given research regarding the difficulty of individuals with schizophrenia in identifying emotional states or experiences retrospectively or following even a short delay (Gold, 2011; Ursu et al., 2011). Furthermore, it is expected that affect at the time of thought disorder assessment is the most likely to be related to TDI. A completed PANAS provides a global intensity score determined by the summed ratings across all 20 exemplars (range of 20-100), and an intensity score for PA and NA (range of $10-50$, respectively).

The ten exemplars of positive and negative affect included in this measure were identified through principle components analysis of 60 -items identified by Zevon \& Tellegen (1982). Watson et al. (1988) determined items as exemplars of positive or negative affect with loadings of .40 or higher on the relevant factor and $<0.25$ on the other factor. The PANAS has shown strong reliability in healthy adults with intraclass correlations for PA ranging from $.86-.90$ and $.84-.87$ for NA, and in a psychiatric inpatient sample with correlations of .85 and .91 for PA and NA, respectively (Watson et al., 1988). The correlation across scales is low for both samples with -.12 - -.23 for the healthy sample and -.27 for the psychiatric sample, suggesting independent scales. These reliability estimates have been shown to be unrelated to the time instructions used ("this moment;" "today;" "past few days;" "week;" "past few weeks;" "year;" "general, on 
average"). Test-retest reliability data in healthy individuals shows stability across administrations as well as increased stability over longer time frames (i.e. "today" versus "over the last year") (Watson et al., 1988). Construct validity analyses revealed that PA is negatively correlated across time frames with measures of distress and dysfunction, depression, and responses to stressful and aversive events, with scores ranging from -.19 -.36. Conversely, NA was positively correlated with all of the aforementioned measures with scores ranging from .51 - .74 (Watson et al., 1988).

Thought Disorder Index (TDI). The Thought Disorder Index (TDI, Johnston \& Holzman, 1979; Johnson et al., 1986) is used to identify and rate the severity of thinking disturbances. Using verbatim responses from the Rorschach Inkblot Test (Rorschach, 1942), the TDI assesses thought disorder on a scale of severity from 0.25 (minor idiosyncrasies) -1.0 (complete loss of reality). For use with the TDI, the Rorschach is administered using Rapaport instructions (Rapaport, Gill, \& Schafer, 1968), which allows for inquiry after each card rather than after all ten cards have been shown as is required in other scoring systems (e.g. Exner scoring system, Exner, 1993). While the TDI may be used with any assessment that provides a verbal sample such as the Wechsler Adult Intelligence Scale (WAIS, Wechsler, 2008) or a semi-structured clinical interview, the Rorschach offers many advantages over alternative tests given the novelty of the task and its unstructured format. The design of the Rorschach allows for greater likelihood of thought disorder when compared to other assessments that are comprised of standardized questions that likely result in stereotypic responses (Holzman et al., 2005). Furthermore, research has also shown that the TDI, when used with the Rorschach, is a valid indicator of thought disorder in schizophrenia and shows significant incremental validity in 
predicting future psychotic symptoms when added to a clinical interview (Lilienfeld, Wood, \& Garb, 2000).

A score of 0.25 (minor idiosyncrasies) is given for responses that would be only rarely noticed in normal conversation but would likely become increasingly unclear following an accumulation of such responses. A score of 0.5 (distinct oddness) is given for responses that reflect an idiosyncratic and odd response style, albeit not bizarre. These responses may occur with moderate frequency in normal conversation but would be unlikely to suggest loss of contact with reality. A score of 0.75 is given for responses that clearly illustrate disordered thought. Exemplars of this level reflect instability in thinking and perceiving, and bizarre, absurd responses. At the 1.0 level, responses are significantly disordered and appear to reflect a complete loss of contact with reality. Within each level of severity are categories of characteristic responses that allow for both qualitative and quantitative information. See Table 4 for response categories for each level of severity and definitions of each category. Severity of thought disorder as indicated by total TDI score is calculated using the following equation,

$$
\frac{\Sigma[0.25(A)+0.50(B)+0.75(C)+1.0(D)]}{\text { Total } R} \times 100
$$

where $A$ is the number of responses at the 0.25 level, $B$ is the number of responses at the 0.50 level, $C$ is the number of responses at the 0.75 level, $D$ is the number of responses at the 1.0 level, and $R$ is the total number of Rorschach responses. A total TDI score is derived by the sum of each instance of thought disorder weighted by its severity level and divided by the number of total responses to control for verbal production. This value is then multiplied by 100 and expressed as a percentage of thought disorder severity. 
For each stimulus card from the Rorschach, a score is given for each response where it appears thought disorder is exhibited. In addition, only one score is given per individual response within a stimulus card and the score is chosen based on that which best captures the process that appears evident in the response. A scored protocol provides the frequency of responses for each exemplar, number of responses at each level of severity, the number of responses for each category, and a thought disorder severity total score (Johnston et al., 1986).

Everyone involved in the administration and scoring of the TDI in the current study has completed extensive training followed by regular follow-up meetings to maintain skills. For the current administration, all responses were tape-recorded and then transcribed for scoring purposes. Transcribed responses were retained, de-identified, for later analysis. Each completed protocol was scored by a group of at least three trained researchers.

The use of the Rorschach with the TDI for measuring thought disorder has shown good internal consistency using the Spearman-Brown formula with a value of .78 (Johnston \& Holzman, 1979). In addition, reliability analyses have shown strong interrater reliability for individual and group raters across varying levels of psychopathology. Johnston and Holzman (1979) found strong inter-rater reliability for TDI total score with two independent raters for a sample of individuals with schizophrenia $(r=.90)$, nonpsychotic patients $(r=.93)$ and nonpsychiatric controls $(r=.82)$. Similarly, Solovay, Shenton, and Holzman (1987) examined a sample of individuals with schizophrenia, bipolar disorder and healthy controls, and showed strong inter-rater reliability using the Spearman-Brown formula for two independent raters for TDI total score $(r=.89)$, 
severity level $(r=.79)$, and categories $(r=.81)$. Coleman et al. (1993) used four independent teams of raters to examine thought disorder severity in a sample of individuals with schizophrenia, schizoaffective disorder, or bipolar disorder, as well as first-degree relatives of these patients. Coleman et al. (1993) found strong inter-rater reliability for TDI total scores ranging from $r_{s}=.80$ to .90 . Furthermore, Coleman et al. (1993) showed intraclass correlations of .77, .72, and .77 for levels $0.25,0.5$, and 0.75 , respectively (there were not enough responses at the 1.0 level to calculate reliability), and intraclass correlations of $.58, .76$, and .86 for idiosyncratic verbalizations, combinatory thinking, and irrelevant intrusions, respectively (these were the only categories for which there were enough instances to calculate reliability).

Developers of the TDI determined that a valid measure of thought disorder should distinguish between individuals with schizophrenia, acutely disturbed nonpsychotic individuals, and healthy controls (Johnston \& Holzman, 1979). Research using the TDI with the Rorschach has shown that the TDI can distinguish schizophrenia and bipolar disorder in adolescent and adult samples using principal component factor analytic procedures (Makowski et al., 1997; Solovay et al., 1987), and is an effective tool for identifying other disorders on the schizophrenia spectrum such as schizoaffective disorder and schizotypy (Coleman, Levy, Lenzenweger, \& Holzman, 1996; Holzman et al., 1995).

\section{Procedures}

Recruitment. The current project was approved by the director of nursing on the inpatient unit at the University of Louisville Hospital, as well as the University of Louisville and the University of Louisville Hospital Institutional Review Board. 
Information was provided to all staff on the inpatient unit to describe the purpose and procedures of the study, as well as any assistance from the staff that might have been necessary. All recruitment took place on the unit. Participants were first identified for eligibility by reviewing diagnoses relevant to the inclusion and exclusion criteria, and confirming their ability to participate with the unit nurse; permission for this information was obtained through a partial waiver approved by the University of Louisville Hospital Institutional Review Board. Potential participants were approached to inquire about their interest in participating in the current study.

Individuals identified as being eligible for the study were given pertinent study information, including why the study was being conducted, and risks, benefits, confidentiality, and payment. Following that, individuals were told the following: "If you choose to participate in this study I will be asking you to answer some questions about yourself and how you are currently feeling. I will also ask you to answer questions about a set of pictures." Individuals were informed that their verbal responses would be tape-recorded for transcription and that responses would be retained, de-identified, for later analyses. Finally, individuals were told that all data would be coded with a participant identification number that will be secured separately with each participant's identifying information (i.e. name, age, race, and date of birth). Participants had the opportunity to ask any additional questions and were given the option to proceed through the informed consent process, consider participating with the option to proceed with informed consent and participation at a later time, or decline participation altogether. Because the average length of stay on this particular unit is six days, all attempts were made to conduct testing on the day interested patients provided consent to do so. For 
participants who requested a break or who were interrupted by a unit activity, testing was completed within 24 hours of the stopping point.

Informed consent. Individuals who expressed interest in study participation were introduced to the informed consent process. Each individual who provided consent was assessed for understanding of the consenting process and the requirements of participation. The following questions were required to be answered such that an adequate level of understanding was observed: (a) "What are you being asked to do as a participant in this project;" (b) "Who should you ask if you have questions about any part of the project;" (c) "What would you do if you were experiencing distress or discomfort during the study;" and (d) "Do you have to participate?"

After consent was obtained, each participant was briefed about the hospital HIPAA policy and asked to sign a form indicating their understanding of the policy and how their protected health information may be used. Following signing the HIPAA form, the participant's medical chart was reviewed to further determine eligibility.

Completion of measures. Administration of screening and assessment instruments is standard procedure on most inpatient psychiatric units, including University of Louisville Hospital. Therefore, it was not expected that completion of the measures for the current study would cause significant disruption for patients or staff, or the daily routine of the milieu. Moreover, screening and assessment done currently on this unit is usually not considered invasive or above minimal risk by patients or staff.

A majority of the socio-demographic information was obtained from the patient. Additional information was obtained and/or corroborated from the patient's chart, as needed. Following consent for participation and completing the socio-demographic 
questionnaire, each participant was administered the Rorschach and asked to fill out the PANAS. Patients with reading difficulties had the PANAS read to them. The order of administration of these assessments was counterbalanced across participants to control for any order effects. Following the administration of all measures, participants were engaged in a short, neutral conversation to provide a distraction from any distress that may have been caused by the study items. The average length of time for completion was approximately 1.5 hours.

\section{Data Analyses}

Descriptive analyses. Descriptive analyses were completed for all variables using IBM SPSS Statistics 20. Correlation analyses were conducted for the following socio-demographic variables, and PANAS scores and the TDI total score to explore statistically significant relationships: age, days in the hospital, years of education, age at first psychiatric episode, age at first hospitalization, number of hospitalizations, and duration of illness. Other socio-demographic variables were not analyzed due to large sample size discrepancies across variable categories.

\section{Hypothesis 1a.}

Simple regression analysis. Simple regression analysis was used to examine the relation between affect intensity from the PANAS and total thought disorder score from the TDI. Global intensity level was summed across all 20 PA and NA exemplars from the PANAS, yielding a range of 20-100. Significant findings were determined using $\alpha=$ .05 .

\section{Hypothesis $1 \mathrm{~b}$.}


Multiple regression analysis. Multiple regression analysis was conducted to examine the variance in TDI total scores explained by intensity of positive and negative affect from the PANAS. PA and NA were determined by summing the intensity ratings for the 10 exemplars for PA and NA, respectively. To make the component ranges comparable to the global intensity range, each summed component score was multiplied by two, yielding a possible range of scores from 20-100. Pearson's correlation analysis was used to check for multicollinearity. A correlation of $r<.80$ was used as the cut-off for determining the appropriateness of using a pair of variables as independent predictors in the multiple regression analysis in accordance with recommendations by Field (2009) as well a collinearity diagnostics from the regression analyses. The total TDI score was the criterion variable. Both the overall model and the fit of each predictor were explored. The forced-entry method was used to evaluate the relative significance of intensity of positive affect and intensity of negative affect. This method was chosen over other methods, as it is most appropriate for theory testing and less influenced by random variation that could impact the replicability of findings (Field, 2009).

\section{Hypothesis 2a.}

Correlation analysis. Pearson's correlation analysis was used to examine the relation of indices of PA and NA from the PANAS with instances of broad versus narrow cognitive processing from the TDI to further explore the association between affect and cognitive processing hypothesized in the literature (Bar, 2009; Clore \& Palmer, 2009; Fredrickson, 2001). The PA and NA variables were determined by the sum of the ratings across each of the 10 exemplars, respectively. Cognitive processing was examined with response categories from the TDI that are characteristic of broad versus narrow 
processing. Exemplars from the $0.25,0.50$, and 0.75 severity levels that demonstrate broad and narrow processing were chosen a priori based on extensive descriptions from Johnston and Holzman (1979) and Holzman et al. (2005). The response categories for broad processing included clang, relationship verbalization, idiosyncratic symbolism, looseness, fabulized combinations, playful confabulations, fluidity, confabulations, and flippancy. Narrow processing was explored using inappropriate distance, vagueness, word-finding difficulties, perseveration, incongruous combinations, fragmentation, and autistic logic. Categories not used in this analysis are thought to show greater variability in processing and could theoretically reflect broad or narrow processing depending on the response. No categories were chosen from the 1.0 level due to the infrequency of response types at that level. The TDI scores for each exemplar used in the correlation analysis reflect a proportion, determined by the frequency of the exemplar divided by the total number of responses $(R)$ for each individual. Significant relationships were determined using $\alpha=.05$.

\section{Hypothesis 2b.}

Exploratory factor analysis. In addition to examining the relation between affect and cognitive processing using a set of exemplars determined a priori, an exploratory factor analysis (EFA) was hypothesized to quantitatively determine if response categories from the TDI load on a set of factors that reflect broad versus narrow cognitive processing that may, in turn, be related to PA and NA. However, the data collected did not allow this analysis to be conducted. See Results section for continued explanation.

\section{Participant Sample and Statistical Power}


G*Power 3.1 (Erdfelder, Faul, Lang, \& Buchner, 2007) was used to calculate the sample size necessary to conduct the proposed analyses. Standard Cohen's $d$ effect sizes were used to calculate power analyses given the wide range of effect sizes seen in the literature (i.e. Cohen \& Minor, 2010). Given an alpha level $=.05$, estimated power $=.80$, two predictors, and a standard medium effect size of $\mathrm{f}^{2}=.15$, the estimated sample size necessary for multiple regression analysis is 68 participants. This estimation is more stringent than the rule of thumb described by Field (2009) that suggests 10-15 cases for each predictor, which in this case would recommend 20-30 participants. To examine correlation analyses, $\mathrm{G}^{*}$ Power suggests a sample of 84 participants when using an alpha level $=.05$, estimated power $=.80$, and a medium effect size of $r=.30$.

While Field (2009) describes rules of thumb for estimating sample size when using EFA such as 10-15 participants per variable, or 5-10 participants per variable up to a total of 300 , research has shown it is ultimately the factor loadings that are of the utmost importance when establishing the fit of a particular model (Field, 2009; Winter, Dodou, \& Wieringa, 2009). Winter et al. (2009) reported that lower sample sizes are satisfactory when factor loadings and the number of variables are high, and when the number of factors is small. For example, a model specifying factor loadings of .4, two factors, and 24 variables estimated a sample size of 134, compared to a model specifying factor loadings of .6, two factors, and 24 variables that estimated a sample size of 34 . Given the difficulty recruiting clinical samples and the variability in the patient sample on the inpatient unit at any given time (potentially limiting recruitment of individual with schizophrenia and schizoaffective disorder), more stringent guidelines will be used for factor loadings, allowing for a smaller sample. 
Taken together, a sample range of 20-84 participants was deemed acceptable to address the aforementioned hypotheses and associated analyses. The elimination of the EFA from the current study did not change the estimated sample size needed. This range represents the floor and ceiling of the sample size estimation, with anything lower than 20 yielding questionable power and anything above 84 unlikely to add additional power. 


\section{RESULTS}

\section{Descriptive Analyses}

The current sample is comprised of twenty-four inpatients with a diagnosis of schizophrenia or schizoaffective disorder. See Table 5 for descriptive sample information. Table 6 includes the mean, standard deviation, and range information for the criterion and predictor variables: PANAS total score, PANAS NA, PANAS, PA, and total TDI score. The mean total TDI score for the current sample was comparable to other studies reviewed, albeit somewhat higher $(M=40.62, S D=35.85)$. In a sample of inpatients and outpatients with functional psychosis, bipolar disorder, personality disorder, and first-degree relatives with psychosis, mean TDI total scores were 24.05 (SD $=28.74)$ for one sample and $22.56(S D=27.38)$ for another (Carpenter et al., 1993).

Coleman et al. (1993) examined twenty protocols from a sample of inpatients with schizophrenia, schizoaffective disorder, and bipolar disorder. Four separate rating teams found mean TDI total scores of $35.25(S D=50.20), 22.78(S D=30.06), 37.92(S D=$ 47.29), and $18.79(S D=29.15)$, respectively. Holzman et al. (1986) found a mean TDI score of $34.60(S D=38.80)$ for a sample of inpatients with schizophrenia and $22.80(S D$ $=21.40$ ) for schizoaffective disorder. The range presented in Table 6 is also comparable to and falls within the ranges found by four different scoring groups in Coleman et al. (1993). 
The following variables from the socio-demographic form were analyzed for their relations with the predictor and criterion variables: age, days in the hospital, years of education, age at first psychiatric episode, age at first hospitalization, number of hospitalizations, and duration of illness. Other socio-demographic variables were not analyzed due to large sample size discrepancies across variable categories. Spearman's correlations were used for this analysis due to non-normal distributions of all the aforementioned socio-demographic variables. See Table 7 for the correlation coefficients for the PANAS and TDI variables, and each of the socio-demographic variables, as well correlation coefficients across the socio-demographic variables. There were no significant correlations between any of the socio-demographic variables and PANAS and TDI scores. Age at the time of testing was positively correlated with age at first psychotic episode, age at first hospitalization, and duration of illness. Age at first psychiatric episode was positively related to age at first hospitalization.

\section{Hypothesis 1}

Hypothesis 1a. Pearson correlation analyses were conducted for the PANAS total score and the total TDI score; affective intensity as measured by the PANAS total score was positively correlated with thought disorder severity as measured by the total TDI score (see Table 8). Simple regression analysis was conducted to examine the hypothesis that affective intensity predicts thought disorder severity. PANAS total score was a significant predictor of TDI total score and accounted for $40 \%$ of the variance in thought disorder severity, $R=.408, F(1,23)=4.39, p<.05$.

Hypothesis 1b. Pearson correlation analyses were conducted for the PANAS PA and PANAS NA scores and the total TDI score to examine the differential contribution of 
positive and negative affect in thought disorder severity. No multicollinearity was demonstrated between PA and NA, $r=-.074$. Neither positive nor negative affect was significantly associated with thought disorder severity (see Table 8). While a conventional significance level was approached, multiple regression analysis examining positive and negative affect as predictors of thought disorder severity was not significant, $R=.412, F(1,23)=2.14, p=.142$.

\section{Hypothesis 2}

Hypothesis 2a. Pearson correlation analysis was conducted for PANAS PA and PANAS NA, and exemplars of broad, associative processing and narrow processing, respectively. The following exemplars were chosen a priori as indicators of broad, associative processing: clang, relationship verbalization, idiosyncratic symbolism, looseness, fabulized combinations, playful confabulations, fluidity, confabulations, and flippancy. There was a significant negative correlation for positive affect and fabulized combinations (see Table 9). The following exemplars were chosen a priori as indicators of narrow processing: inappropriate distance, vagueness, word-finding difficulties, perseveration, incongruous combinations, fragmentation, and autistic logic. There was a significant positive correlation for negative affect and autistic logic (see Table 10).

Pearson correlations were also examined for PANAS NA and fabulized combinations, and PANAS PA and autistic logic to explore discriminant validity. The correlation coefficients were non-significant.

Hypothesis 2b. EFA was not conducted due to low frequencies across the majority of TDI factors. An EFA analysis would have been driven by the item frequencies and not by theory and the hypothesized relationships. 


\section{DISCUSSION}

\section{Findings}

Hypothesis 1. Affective intensity was a better predictor of thought disorder severity and a more salient predictor of the severity of thought disorder than affective valence. This offers some support to work examining the impact of affective intensity, across valence, on a variety of cognitive processes. As reported earlier, Basso et al. (1994) showed that affective intensity moderates the relationship between affective valence and cognition, specifically word recognition. It was found that low self-reported affective intensity coupled with positive mood was related to better word recognition in a sample of college women, and high self-reported intensity coupled with negative mood was related to better word recognition in the same sample. Unlike Basso et al. (1993), the current results did not explore nor demonstrate an intensity by valence interaction for a measure of cognitive dysfunction, but instead hypothesized the significance of affective intensity over and above valence. However, taken together with the earlier literature, it is posited that affective intensity may contribute to a more disorganized thought process by disrupting one's ability to recruit associated networks and filter out unnecessary data. In turn, this impacts the use of effective processing strategies and integration associated information in a way that allows for coherent expression.

Hypothesis $1 \mathrm{~b}$ was not supported; positive affect did not account for more variance in thought disorder severity than negative affect. Conversely, negative affect 
demonstrated a trend toward significance, $t(22)=1.77, p=.092$. This suggests that selfreported NA may be more salient to thought disorder severity in this population than PA. It is unclear why NA emerged as a more relevant factor. Ratings of NA intensity were lower $(M=38.50)$ than those of PA intensity $(M=67.83)$, which suggests that the current sample was experiencing more PA than NA, overall. However, the current findings support earlier work in this area that has shown a relationship between NA and measures of neuropsychological dysfunction (Halari et al., 2006), and communication disturbance from the CDI (Burbridge \& Barch, 2002; Docherty et al., 1994a; Docherty et al., 1997; Docherty et al., 1994b). Taken together, this may reflect that the narrow, bottom-up processing associated with NA is more disruptive, because it impairs the ability to develop an organized expression of thought. Impairment in the development of a coherent idea may be more detrimental than the inability to filter our expansive and overly inclusive information that was hypothesized.

Hypothesis 2. Results from the current study are also consistent with the relation between affective valence and cognitive processing reported in the literature. The significant relationship between NA and autistic logic supports the association between negative affect and bottom-up, narrow processing seen in the literature. Holzman et al. (2005) define autistic logic as "the respondent justifies a statement by rationalizing it with a 'because' statement that is illogical or based on private autistic reasoning processes rather than conventional, logical reasoning," p. 70. This definition describes an extremely narrow processing style that not only ignores or inhibits use of associated networks, but also fails to filter out irrelevant information. This reflects a pathological "bottom-up" processing strategy in that the initial response details used to develop a 
representation are illogically related. While one might question whether the "private autistic reasoning" mentioned above includes attempts at recruitment of associated networks, albeit even loosely or tangentially, the inherent nature of autistic logic is a response style in which two parts (the statement and its rationalization) are not related by any logical or relational thread. Overall, autistic logic appears to be very similar to the narrow processing strategy posited to stem from NA that is discussed in the affect and cognition literature.

While the relationship between NA and autistic logic occurred in the expected direction, the significant correlation for PA and fabulized combinations did not. Examination of PA and exemplars of broad, associative processing demonstrated a significant, negative association for PA and fabulized combinations. While PA is often associated with more effective use of associated networks (Ashby, Isen, \& Turken, 1999; Bar, 2009; Clore \& Palmer, 2009; Fredrickson, 2001) and therefore more effective cognitive processing, it was hypothesized that PA would be related to an associative process that was over-inclusive and too broad in schizophrenia and schizoaffective disorder, and related to disordered thought. However, the current findings suggest that PA is associated with decreased frequency of fabulized combinations in this sample. While this was the only significant relationship, this suggests that despite psychopathology, the positive influence of PA stands and may be protective in some way. Although it is not debated that cognitive decline is a prevalent feature of schizophrenia and schizoaffective disorder, the presence of PA may have facilitated the patients' use of some preserved premorbid cognitive networks. Fabulized combinations are characterized by forcing two contiguous percepts into a relationship that violates reality. In the current 
sample, this dysfunctional process may have been disrupted through an ability to access some more reality-based networks. However, review of the direction of the other correlation coefficients does not fully support this pattern and further study is necessary to fully explore this relationship.

Post hoc analyses were conducted to further understand the relationship between affective valence and thought disorder. Mean PA and NA group differences were explored for the presence versus absence of each exemplar. Of the 24 exemplars, independent samples $t$-tests could only be conducted on nine of the exemplars due to very low or zero frequencies (see Table 11). A significant mean group difference was found for level of PA and presence of vagueness; individuals who exhibited vagueness demonstrated higher self-reported PA $(M=78.57, \mathrm{n}=7)$ than those who did not exhibit vagueness $(M=68.41, \mathrm{n}=17)$. Significant mean group differences were found for selfreported NA and confabulations, incoherence, and absurd responses. Those who demonstrated confabulations reported higher levels of NA $(M=45.73, \mathrm{n}=15)$ than those without any confabulated responses $(M=26.44, \mathrm{n}=9)$. Individuals who exhibited incoherent responses reported higher NA $(M=52.00, \mathrm{n}=6)$ than those who $\operatorname{did} \operatorname{not}(M=$ $34.00, \mathrm{n}=18$ ), and individuals who did not exhibit any absurd responses on the Rorschach exhibited higher self-reported NA $(M=39.91, \mathrm{n}=22)$ than those who demonstrated absurd thinking $(M=23.00, \mathrm{n}=2)$.

While the a priori and post hoc analyses described above support a relationship between affective valence and cognitive processing, the nature of the association is unclear from the current data and needs further study. PA appeared to demonstrate some protective features in a priori analyses, but was later associated with the presence of 
vague responding in post hoc analyses. Moreover, vagueness was initially hypothesized to represent a narrow, bottom-up processing due to the use of very limited information and details used to create a response. The relationship between PA and the presence of vagueness may represent the protective nature of PA described earlier; access to preserved premorbid reality based cognitive networks may have prevented more severe and unrealistic responses, but did not facilitate the development of a more detailed response. Similarly, confabulated responses were hypothesized to be related to PA, however post hoc analyses demonstrated a relationship with NA. In hindsight, the confabulatory process may reflect a bottom-up process. A confabulated response is characterized by extreme elaboration of a percept that extends past the bounds of reality. Therefore, one focuses on details that later develop into an elaborate, unrealistic representation. Interestingly, the correlation between NA and confabulations demonstrated a trend toward significance, $r=.369, p=.076$.

Neither incoherence nor absurd responses were included in the a priori analyses for hypothesis $2 \mathrm{a}$ due to their level of disorganization and the difficulty understanding any form or source of the response by the examiner. While, it is unclear, why NA was related to the presence or absence of such a disorganized response style, perhaps both NA, and incoherence and absurd responses reflect severity of schizophrenia accounted for by some other process(es) not examined in the dissertation.

The exploratory factor analysis (EFA) that was initially suggested was unable to be conducted due to low frequency of many of the exemplars. Because all exemplars from the TDI were to be used in the EFA, those with a frequency of zero would introduce a confound in the analysis. The analysis itself would no longer be theory-driven, but 
instead driven by the presence of the exemplars that demonstrated a frequency greater than zero in this sample. Therefore, the EFA was not conducted but should be reconsidered with a larger sample to explore the relationship between PA and NA and indicators of broad, top-down processing versus narrow, bottom-up processing, respectively, obtained in this sample. While there are different rules of thumb for identifying a sufficient sample size for EFA (Field, 2009; Winter et al., 2009) it is difficult to project a necessary sample size to conduct the hypothesized EFA for the current study. A large sample size will not necessarily increase the frequency of all exemplars and might elicit a set of exemplars that are most popular. It could make sense to conduct an EFA based on the most popular exemplars, per previous studies. However, of the most rare exemplars identified by D. L. Levy (personal communication, January 19, 2013) (flippancy, vague, word-finding difficulty, relationship verbalization, fragmentation, neologisms), only relationship verbalization and neologisms were not in the present sample, suggesting that the frequency of some exemplars may be based on the composition of a particular sample or biases of a particular research group. While the TDI is an empirically supported assessment of thought disorder in schizophrenia, the process itself is somewhat subjective, and scores are based on discussion and consensus of a scoring group, as was done in the current study.

\section{Limitations}

Sample. The current study has some limitations that impact the generalizability of the findings. First, the sample size was somewhat small. For example, significant results from two of the a priori and post hoc analyses using exemplars from the TDI included only $\mathrm{n}=1$ (hypothesis $2 \mathrm{a}=$ autistic logic) or $\mathrm{n}=2$ (post hoc analysis $=$ presence of absurd 
responses). Although the sample size exceeded the lower end of the sample necessary for the proposed analyses, a larger sample is necessary to broaden the frequency and type of thought disorder exemplars, replicate findings in this sample and increase the power of the analyses.

Second, the current sample was an inpatient sample from an acute psychiatric unit that primarily serves an indigent population. The sample likely differs in a number of ways from other inpatient and outpatient samples. Individuals in the current sample are more likely to come from a more disadvantaged background than individuals who may be inpatients at other hospitals in the area. Moreover, one might assert that individuals in the current sample may have had access to fewer resources throughout the course of their illness than individuals who are inpatients in other psychiatric settings within the study area, which may impact the severity of their current symptoms and overall deterioration. Paradoxically, some authors have found that higher social class is related to increased thought disorder severity using the TDI (Arboleda \& Holzman, 1985; Haimo \& Holzman, 1979). While level of education was the only measure of SES or social class included in the current study, there were no significant relationships between education level and TDI scores. The level of education in the current sample $(M=12.13)$ is comparable to education levels reported in other studies using the TDI $\left(M_{\text {schizophrenia }}=12.70\right.$, $M_{\text {schizoaffective }}=13.70$, Holzman et al., $1986 ; M_{\text {sample } 1}=13.80, M_{\text {sample }} 2=13.61 ;$ Carpenter et al., 1993).

The point was argued earlier in this dissertation about the relevance of medication for understanding previous work examining the relationship between affect and thought disorder and differences between schizophrenia and affective groups. For the current 
study, all individuals were on at least one antipsychotic medication. Nine individuals were on antipsychotics alone, and fifteen individuals were on antipsychotics plus some medication for affective disturbance. Of the latter group of individuals, eight were on an antipsychotic plus a mood stabilizer, four were on an antipsychotic plus an antidepressant, and three individuals were on all three medication types. There were no significant mean differences in thought disorder severity between those who were on antipsychotics only $(M=55.30)$ and those on antipsychotics plus an antidepressant ( $M=$ 20.86), antipsychotics plus a mood stabilizer $(M=41.31)$, or those taking antipsychotics, an antidepressant, and a mood stabilizer $(M=21.14), F(3,20)=1.24, p=.321$. When the sample was dichotomized into those receiving only antipsychotics $(M=55.30)$ and those receiving some combination of antipsychotics and medication for mood $(M=31.82)$, the results remained nonsignificant, $F(1,22)=2.58, p=.123$. Lack of significant differences may be due to combination of small sample and large variance.

A similar comparison was done for medication and PANAS scores. There were no significant mean differences for the four medication groups and PANAS total score, $F(3,20)=1.23, p=.325$, NA, $F(3,20)=1.07, p=.386$, or PA, $F(3,20)=2.12, p=.129$. The dichotomized medication groups also did not yield significant mean differences for PANAS total score, $F(1,22)=.116, p=.736$, NA, $F(1,22)=.955, p=.339$, or PA, $F(1,22)=2.77, p=.110$.

Given the acuity of symptoms and the circumstances of an inpatient admission, this sample is also likely to be quite different from an outpatient sample of individuals with schizophrenia on concurrent measures of thought disorder and affective intensity and valence. It is expected that the current sample exhibited more severe symptoms than 
would be seen in an outpatient sample, therefore the current findings should not be generalized to an outpatient population. While the persistence of thought disorder symptoms despite antipsychotic medication has been described here, it is likely that the current inpatient sample was more symptomatic across all features of the illness, introducing a more severe and complex presentation overall. Finally, because of the short length of stay ( six days) and the average length of time between hospital admission and testing, the current sample may have been experiencing increased stress and anxiety following the recent inpatient admission. This distress could result in an overall increase in negative affect, and may be a contributing factor in the significance of negative affect in thought disorder severity. While the PANAS asks for an "in the moment" rating of affective experience, adjustment to an inpatient unit likely has some residual effects that may contribute to one's affective state for several days.

Setting. The testing setting also introduced a number of factors that limit the generalizability of the current results. First, there was no designated testing location; individuals were tested in a group room that at times was frequented by other patients. While intrusions were discouraged as much as possible, the testing location was part of the larger unit milieu and therefore needed to remain open and available to other patients. Therefore, interruptions did occur and may have contributed to distraction during the testing. Distraction could have disrupted the cognitive process such that (a) participants may have exhibited increased difficulty with organization due to disruption of the task and focus, (b) participants may have benefited from the distraction after being awarded an opportunity to redirect their attention, and/or (c) participants may have felt less comfortable sharing their thoughts with others coming in and out of the room. A handful 
of participants were irritated with others coming in and out of the room, and some even became angry and yelled at the other patients entering the room. Depending on the progression of the testing battery when this occurred, one might expect that disruptions for these particular individuals could contribute to increased negative affect, which in turn may have impacted performance on the Rorschach and TDI scores. While qualitative notes were kept about these types of occurrences, these were not specifically captured or assessed in any measure or analyses.

Participants were also not able to be uniformly tested at the same time each day because of the inpatient group schedule and the availability of appropriate testing space (the group room was the primary testing location), and the availability of the research group. Therefore, some participants were tested in the evening on a weekday, while others were tested at a variety of different times on weekends. This is significant given that the weekday schedule includes several therapist-led groups during the day and the weekend has none. While no behavioral differences were observed, this could contribute to differences in performance, as one testing environment may have been more taxing than the other. Physical and cognitive fatigue can contribute to disorganization of thought and variations in affect. Therefore, a more taxing day on the unit may impact one's ability to engage in the task, and may result in performance that looks more or less disorganized depending on the demands of the day.

Administration. All members of the research team participated in an intensive, three-day training on Rorschach administration and TDI scoring, as well as regular practice sessions prior to testing. However, the current sample represents the first group 
of individuals formally assessed by this research group and may be less uniform across testers than later samples evaluated by this group.

\section{Future Work}

Efforts to examine the proposed relationship between affect and thought disorder in schizophrenia involve several areas of study, all of which are reviewed in some detail in the current research.

Procedure. The current work should be expanded to include mood induction procedures to explore the impact of induced positive and negative affective states and thought disorder severity. Broadening the current paradigm would allow for comparison of trait (as explored in the current research) versus state (via mood-induction paradigms) affect, and exploration of the robustness of the relationship between affect and thought disorder in schizophrenia. A variety of mood-induction paradigms have been developed; a recent meta-analysis provides a comprehensive list of procedures used with this population (Cohen \& Minor, 2010).

Sample. The current sample should be increased and replicated within other inpatient samples to examine stability of the current findings. As stated earlier, the current inpatient sample is characteristically indigent and is therefore not representative of other patients who are psychiatric inpatients. Moreover, this particular inpatient unit has an average length of stay of six days; the patients' symptom characteristics likely differ from inpatient units with a more chronic sample and longer length of treatment.

The relationship between affect and thought disorder in schizophrenia and schizoaffective disorder should also be conducted with outpatient samples to examine the similarities and areas of heterogeneity across these samples. The current project has 
recently been expanded to include a sample of individuals at a local outpatient care unit that specializes in low income, chronically ill adults with severe psychiatric illness. The addition of this sample will likely highlight other physical and psychiatric factors, and socioeconomic stressors that may exacerbate disordered thought in schizophrenia and schizoaffective disorder including homelessness, access to resources, substance use, and medication status (use, compliance, etc.).

There are other factors that may moderate the relationship between affect and thought disorder severity and are worthy of examination. An expanded version of the current study includes the Wechsler Test of Adult Reading (WTAR; Wechsler, 2001) to explore the role of premorbid IQ in thought disorder severity. Measures of reading level are utilized frequently to assess level of intelligence prior to illness onset, and the subsequent cognitive decline that often follows. Exploration of affect should also be expanded to include measures of specific affective experiences such as the Beck Depression Inventory (BDI; Beck, Steer, \& Brown, 1996), Beck Anxiety Inventory (BAI; Beck \& Steer, 1990), and the Profile of Mood States (POMS; Lorr \& McNair, 1988) which explores the following scales: tension-anxiety; anger-hostility; fatigue-inertia; depression-dejection; vigor-activity; and confusion-bewilderment. Moderation analyses, similar to the work conducted by Basso et al., 1994, should be explored to examine affective intensity as a moderator of affect valence and thought disorder severity. Finally, given the support for the role of disposition posited in the literature examining affective intensity and cognitive functioning (Larsen et al., 1987; Schimmack \& Diener, 1997), personality factors should be explored as a moderator of the relationship between 
affective intensity and valence, and thought disorder severity in schizophrenia and schizoaffective disorder.

Broaden current analyses. The current work examines fundamental questions related to the relationship between affect and thought disorder in schizophrenia and schizoaffective disorder. Results from the present study can be expanded in a variety of ways to more fully explore thought disorder in schizophrenia and schizoaffective. The TDI allows for detailed exploration of thought disorder at the exemplar level, as was explored in a limited manner here, as well as the category and severity levels.

Hypotheses $2 \mathrm{a}$ and $2 \mathrm{~b}$ should be expanded to include exemplars from the 1.0 severity level. While it was initially thought that exemplars at the 1.0 level were rare, the current sample demonstrated twenty-two instances of incoherent responses and one instance of contamination. Therefore, future analyses with a larger sample could likely include exemplars at the 1.0 level. Future analyses will pursue the EFA proposed in the current research when the sample and frequency of noted exemplars increase. In addition, there are four categories to examine: deviant verbalizations, associative, combinatory, and disorganized. These categories should each be explored, including their relationship with PANAS total score and NA and PA scores. Analyses should also be conducted at each severity level $(0.25,0.50,0.75$, and 1.0$)$. The frequency of responses at each severity level can be calculated and compared to PANAS total scores, and NA and PA scores. These severity levels can be further dichotomized into minor but odd responses $(0.25+0.50)$ and distinct presence of thought disorder $(0.75+1.0)$. This represents yet another perspective from which to explore the impact of affective intensity 
and valence on not only thought disorder severity, but also the clear presence versus absence of thought disorder as well.

In addition to the category and severity levels present in the TDI, the total number of responses and measures of verbosity/poverty of speech may be useful with regard to the their respective relationships with affective intensity and valence.

Finally, total TDI scores can be categorized into clinically significant severity groups: $>=12$ is clinically significant; $12-15$ is mild elevation; $16-19$ is moderate elevation, and $>=20$ is severe elevation. These categories can be used to further examine the relationship between thought disorder severity and affect intensity and valence. The current sample includes 18 individuals that fall in the severe category, three in the moderate category, and three below clinical significance.

Expand the exploration of affect. The study of affect in schizophrenia is of the utmost importance, given the somewhat limited but significant literature that is available. Routine assessment of affect including self-report of current emotional experience and changes in affect should be conducted to (1) improve understanding of the affective experience, (2) ensure the differentiation of negative affect and negative symptoms (Malla, 1995), and (3) monitor affect in relation to other core features of schizophrenia including, but not limited to thought disorder. Furthermore, assessment should include indices of valence and intensity for a detailed explication of how thought disorder in schizophrenia may be differentially affected by positive versus negative affective states and on a continuum of intensity. It is unclear if experiences such as irritability, depression, and euphoria in schizophrenia are differentially exacerbated by increasing intensity levels, and whether these changes contribute to different manifestations of 
thought disorder; exploration of this idea will clarify the role of affect in thought disorder in schizophrenia and extrapolate to different affective states significant to mania (i.e., euphoria versus irritability).

To develop a comprehensive picture of the moderating effects of affect on thought disorder in schizophrenia, it is also important to explore this relationship in more detail in schizoaffective disorder. Differing from schizophrenia by the presence of a significant affective episode, schizoaffective disorder provides a unique sample with which to explore the proposed conceptualization of thought disorder and affect in schizophrenia. While the diagnosis of schizoaffective disorder implies clinically significant emotional dysregulation, it is unclear to what extent these individuals exhibit the same difficulties in emotional expression and weak emotion-cognition associations described in schizophrenia. Therefore, the assessment procedures described above should be implemented in this population as well to establish a comprehensive picture of affective experience in the schizophrenia spectrum. Other testable hypotheses include differences in thought disorder in schizophrenia and schizoaffective disorder when controlling for affect, differences in affect intensity between individuals with schizoaffective disorder characterized by depression compared to those characterized by mania, and each of these subgroups compared with individuals with a primary diagnosis of depression and mania, respectively.

\section{Implications}

The current study has significant implications for understanding the role of affect in thought disorder in schizophrenia and schizoaffective disorder. This study appears to be the first to directly examine the relationship between thought disorder and affect 
intensity and valence in schizophrenia and schizophrenia-spectrum disorders, and represents the initial steps in what is hoped to be a new area of study. The current research is not novel in the constructs that it examines, but in the manner in which it does so. While both thought disorder and affect have been studied in schizophrenia, recent research suggests that there is still much to be learned about thought disorder in schizophrenia and schizophrenia-spectrum disorders, and affect may be a significant contributing factor in the presentation and severity of this impairment. The current study represents the first steps by examining fundamental questions regarding the relationship between thought disorder and affect. Overall, thought disorder needs to be systematically evaluated with the appropriate measures and throughout stages of treatment and recovery to better understand the features that are related to the remission of symptoms. The current study hypothesizes that targeting affective disturbance will provide more immediate effects on thought disorder severity and reduce the likelihood of a more persistent and unremitting course.

Studies of thought disorder in affective disorders and schizoaffective disorder suggest that those who receive treatment targeting mood lability or other affective symptoms also see a decrease in thought disorder symptoms. While there is no direct evidence of these affective symptoms also remitting in the same fashion, it can be postulated that if affect is not a targeted area of intervention, as can be the case in schizophrenia, thought disorder is likely to endure in a chronic fashion. This may be due to a similar imbalance in regulatory systems implicated in thought disorder in mania (Lake, 2008) that likely persists in schizophrenia in the absence of intervention. This conceptualization further suggests that if affect is addressed and treated early in 
schizophrenia then thought disorder might be less likely to persist in the enduring, severe manner for which it is well known.

In addition to the novel exploration of the relationship between thought disorder and affect in schizophrenia-spectrum disorders, the current study also supports work that formulates thought disorder as a form of cognitive dysfunction; significant relationships have been shown for measures of working memory (Docherty, 2005; Docherty, Hall, \& Gordinier, \& Cutting, 2000; Docherty et al., 1996b; Docherty, Strauss, Dinzeo, \& StHilaire, 2006; Kearns, 2007; Stirling, Hellewell, Blakey, Deakin, 2006); attention (Docherty, 2005; Docherty et al., 2000; Docherty et al., 1996b; Docherty et al., 2006; Subotnik et al., 2006); fluency (Docherty et al., 1996b; Stirling et al., 2006), memory (Docherty et al., 2000; Subotnik et al., 2006), and nonverbal sorting ability (Harrow et al., 2003). Moreover, both cognitive dysfunction and thought disorder are both early symptoms of the illness that often remain stable and intractable despite antipsychotic medication (Goldberg \& Green, 1995). Therefore, it may be that in addition to treatments for affective dysregulation that may decrease the severity of thought disorder symptoms presently, treatments for cognitive dysfunction such as Cognitive Enhancement Therapy (Hogarty \& Greenwald, 2006) or Cognitive Remediation Therapy (Wykes et al., 2007) when used in conjunction with treatment for affective disturbance may contribute to an amelioration of symptoms over time as brain function improves. This latter point needs further exploration as thought disorder is not evaluated separately from other features of cognitive dysfunction in treatment studies, and cannot be measured with typical neuropsychological batteries alone. 
The findings from this study have significant implications for treatment of thought disorder in schizophrenia. The current review clearly illustrates the limited impact of antipsychotic medication for thought disorder. Extrapolation from studies of thought disorder in individuals with schizoaffective disorder suggests that treatment for affective disturbance may be beneficial (Andreasen \& Grove, 1986; Harrow et al., 1986b; Holzman et al., 1986; Marengo \& Harrow, 1997). Furthermore, Cognitive Behavior Therapy (CBT), the second most preferred treatment for schizophrenia by clinicians has proven to be an efficacious and effective treatment for many symptoms of the illness (Wykes et al., 2008). However, this intervention has limited support for thought disorder with no studies in a recent meta-analysis examining the use of CBT for thought disorder, specifically Wykes et al. (2008), and only brief acknowledgment in a manual for CBT of schizophrenia (Kingdon \& Turkington, 2008). While Kingdon and Turkington (2008) discuss that "emotional disturbance may be a significant feature of thought disorder" (Kingdon \& Turkington, 2008, p. 134) and that, if recognized, "a different approach route may be needed" (Kingdon \& Turkington, 2008, p. 134), they make no recommendations for how to do so. Findings from the current study will likely provide additional support for the role of affect in thought disorder that, according to Kingdon and Turkington (2008) would constitute a modified treatment strategy than what is currently employed. One example may be the adjunctive use of a cognitive remediation program.

As the current research trend in schizophrenia continues on the path of genetic mapping and functional MRI topographies, the need for exploration of endophenotypic features and treatments that are directly applicable to symptoms and the phenomenology of the illness is argued here. The possibility of finding the etiology or cause of 
schizophrenia is incredibly attractive, but sole reliance on that work often detracts us from focusing on remission of symptoms, reintegration into the community, and improved quality of life for people suffering with schizophrenia. Several recent papers (Andreasen, 2007, Parnas, 2011; Strauss, 2011) have alluded to this conundrum and suggest that a return to the phenomenology of core schizophrenia symptoms such as thought disorder, affective experience, and the "whatness" of the illness (Parnas, 2011) will lead to the greatest pay-off for individuals living with this illness. 


\section{REFERENCES}

Agheveli, M. A., Blanchard, J. J., \& Horan, W. P. (2003). The expression and experience of emotion in schizophrenia: A study of social interactions. Psychiatry Research, 119, 261-270.

Alpert, M., Rosenberg, S. D., Pouget, E. R., \& Shaw, R. J. (2000). Prosody and lexical accuracy in flat affect in schizophrenia. Psychiatry Research, 97, 107-118.

American Psychiatric Association. (1980). Diagnostic and Statistical Manual of Mental Disorders (3rd ed.). Washington, DC: American Psychiatric Association.

American Psychiatric Association. (1994). Diagnostic and Statistical Manual of Mental Disorders (4th ed.). Washington, DC: American Psychiatric Association.

American Psychiatric Association. (2000). Diagnostic and Statistical Manual of Mental

Disorders (4th ed., text rev.). Washington, DC: American Psychiatric Association.

Andreasen, N. C. (1979a). Thought, language, and communication disorders. I. Clinical assessment, definition of terms, and evaluation of their reliability. Archives of General Psychiatry, 36(12), 1315-1321.

Andreasen, N. C. (1979b). Thought, language, and communication disorders. II. Diagnostic significance. Archives of General Psychiatry, 36(12), 1325-1330.

Andreasen, N. C. (1982). Should the term "thought disorder" be revised? Comprehensive Psychiatry, 23(4), 291-299.

Andreasen, N. C. (1984). The Scale for the Assessment of Positive Symptoms (SAPS). 
Iowa City, IA: The University of Iowa.

Andreasen, N.C. (2007). DSM and the death of phenomenology in America: An example of unintended consequences. Schizophrenia Bulletin, 33(1), 108-112.

Andreasen, N. C., \& Grove, W. M. (1986). Thought, language, and communication in schizophrenia: diagnosis and prognosis. Schizophrenia Bulletin, 12(3), 348-359.

Arboleda, C. \& Holzam, P. S. (1985). Thought disorder in children at risk for psychosis. Archives of General Psychiatry, 42, 1004-1013.

Ashby, F. G., Isen, A. M., \& Turken, A. U. (1999). A neuropsychological theory of positive affect and its influence on cognition. Psychological Review, 106(3), 529550.

Bar, M. (2009). A cognitive neuroscience hypothesis of mood and depression. Trends in Cognitive Sciences, 13(11), 456-463.

Basso, M., Shefft, B., \& Hoffmann, R. (1994). Mood-moderating effects of affect intensity on cognition: Sometimes euphoria is not beneficial and dysphoria is not detrimental. Journal of Personality and Social Psychology, 66(2), 363-368.

Batson, C., Shaw, L., \& Oleson, K. (1992). Differentiating affect, mood, and emotion. Toward functionally based conceptual distinctions. In M.S. Clark (Ed.), Emotion (pp. 294-326). Newbury Park, CA: Sage.

Beck, A.T., \& Steer, R. A. (1990). Manual for the Beck Anxiety Inventory. San Antonio, TX: Psychological Corporation.

Beck, A.; Steer, R. \& Brown, G. (1996). Beck Depression Inventory-II Manual. The Psychological Corporation: San Antonio. 
Berenbaum, H. \& Oltmanns, T. F. (1992). Emotional experience and expression in schizophrenia and depression. Journal of Abnormal Psychology, 101, 37-44.

Burbridge, J.A., \& Barch, D. M. (2002). Emotional valence and reference disturbance in schizophrenia. Journal of Abnormal Psychology, 111, 186-191.

Carpenter, J. T., Coleman, M. J., Waternaux, C. M., Perry, J., Wong, H., O’Brien, C., \& Holzman, P. S. (1993). The Thought Disorder Index: Short-Form Assessments. Psychological Assessment, 5(1), 75-80.

Cicchetti, D., Ackerman, B. P., \& Izard, C. E. (1995). Emotions and emotion regulation in developmental psychopathology. Development and Psychopathology, 7, 1-10.

Clore, G. L., \& Palmer, J. E. (2009). Affective guidance of intelligent agents: How Emotion Controls Cognition. Cognitive Systems Research, 10(1), 21-30.

Cohen, A. S., \& Minor, K. S. (2010). Emotional experience in patients with schizophrenia revisited: Meta-analysis of laboratory studies. Schizophrenia Bulletin, 36(1), 143-150.

Coleman, M., Carpenter, J., Waternaux, C., Levy, D., Shenton, M., Perry, J., Medoff, D., Wong, H., Monoach, D., Meyer, P., O’Brian, C., Valentino, C., Robinson, D., Smith, M., Makowski, D., \& Holzman, P. (1993). The Thought Disorder Index: A reliability study. Psychological Assessment, 5(3), 336-342.

Coleman, M., Levy, D., Lenzenweger, M., \& Holzman, P. (1996). Thought disorder, perceptual aberration, and schizotypy. Journal of Abnormal Psychology, 105, $469-473$. 
Cuesta, M. J., \& Peralta, V. (1999). Thought disorder in schizophrenia. Testing models through confirmatory factor analysis. European Archives of Psychiatry and Clinical Neuroscience, 249(2), 55-61.

Docherty, N. M. (2005). Cognitive impairments and disordered speech in schizophrenia: Thought disorder, disorganization, and communication failure perspectives. Journal Of Abnormal Psychology, 114(2), 269-278.

Docherty, N. M., DeRosa, M., \& Andreasen, N. C. (1996a). Communication disturbances in schizophrenia and mania. Archives of General Psychiatry, 53, 358-364.

Docherty, N. M., Evans, I. M., \& Sledge, W. H., et al. (1994a). Affective reactivity of language in schizophrenia. The Journal of Nervous and Mental Disease, 182, 98102.

Docherty, N. M., Hall, M. J., Gordinier, S. W., \& Cutting, L. P. (2000). Conceptual sequencing and disordered speech in schizophrenia. Schizophrenia Bulletin, 26(3), 723-735.

Docherty, N. M., Hawkins, K. A., \& Hoffman, R.E., Quinlin, D. M., Rakfeldt, J., \& Sledge, W. H. (1996b). Working memory, attention, and communication disturbances in schizophrenia. Journal of Abnormal Psychology, 105, 212-219.

Docherty, N. M., \& Hebert, A.S. (1997). Comparative affective reactivity of different types of communication disturbances in schizophrenia. Journal of Abnormal Psychology, 106, 325-330.

Docherty, N. M., Sledge, W. H., \& Wexler, B. E. (1994b). Affective reactivity of language in stable schizophrenic outpatients and their parents. The Journal of Nervous and Mental Disease, 182, 313-318. 
Docherty, N. M., Strauss, M. E., Dinzeo, T. J., \& St-Hilaire, A. (2006). The cognitive origins of specific types of schizophrenia speech disturbances. American Journal of Psychiatry, 163, 2111-2118.

Erdfelder, E., Faul, F., \& Buchner, A. (1996). GPOWER: A general power analysis program. Behavior Research Methods, Instruments, \& Computers, 28, 1-11.

Exner, J.E., Jr. (1974). The Rorschach: A Comprehensive System. New York: Wiley.

Field, A. (2009). Discovering Statistics Using SPSS ( $3^{\text {rd }}$ ed.). Thousand Oaks, CA: Sage.

Fredrickson, B. L. (2001). The role of positive emotions in positive psychology. The broaden-and-build theory of positive emotions. American Psychologist, 56(3), 218-226.

Gold, J. (2011). Imaging emotion in schizophrenia: Not finding feelings in all the right places. American Journal of Psychiatry, 168(3), 237-239

Goldberg, T., \& Green, M. (2002). Neurocognitive functioning in patients with schizophrenia: An overview. In K. L. Davis, D. Charney, J. T. Coyle, \& C. Nemeroff (Eds.), Neuropsychopharmacology: The Fifth Generation of Progress (pp. 657-669). Philadelphia, PA: Lippincott, Williams, \& Wilkins.

Grube, B., Bilder, R., \& Goldman, R. (1998). Meta-analysis of symptom factors in schizophrenia. Schizophrenia Research, 31, 113-120.

Haimo, S. F., \& Holzman, P. S. (1979). Thought disorder in schizophrenics and normal controls: Social class and race differences. Journal of Consulting and Clinical Psychology, 47(5), 963-967. 
Halari, R., Mehrotra, R., Sharma, T., \& Kumari, V. (2006). Does self-perceived mood predict more variance in cognitive performance than clinician-rated symptoms in schizophrenia? Schizophrenia Bulletin, 32(4), 751-757.

Harrow, M., Grossman, L. S., Silverstein, M. L., \& Meltzer, H. Y. (1982). Thought pathology in manic and schizophrenic patients. Its occurrence at hospital admission and seven weeks later. Archives of General Psychiatry, 39(6), 665-671.

Harrow, M., Grossman, L. S., Silverstein, M. L., Meltzer, H. Y., \& Kettering, R. L. (1986a). A longitudinal study of thought disorder in manic patients. Archives of General Psychiatry, 43(8), 781-785.

Harrow, M., Marengo, J. T., \& McDonald, C. (1986b). The early course of schizophrenic thought disorder. Schizophrenia Bulletin, 12(2), 208-224.

Harrow, M., \& Marengo, J. T. (1986). Schizophrenic thought disorder at follow-up: Its persistence and prognostic significance. Schizophrenia Bulletin, 12(3), 373-393.

Harrow, M., O’Connell, E. M., Herbener, E. S., Altman, A. M., Kaplan, K. J., \& Jobe, T. H. (2003). Disordered verbalization in schizophrenia: A speech disorder or thought disorder? Comprehensive Psychiatry, 44(5), 353-359.

Harvey, P. D., \& Brault, J. (1986). Speech performance in mania and schizophrenia: The association of positive and negative thought disorders and reference failures. Journal of Communication Disorders, 19, 161-173.

Harvey, P. D., Docherty, N. M., Serper, M. R., \& Rasmussen, M. (1990). Cognitive deficits and thought disorder: II. An 8-month follow-up study. Schizophrenia Bulletin, 16(1), 147-156. 
Harvey, P. D., Earle-Boyer, E. A., \& Wielgus, M. S. (1984). The consistency of thought disorder in mania and schizophrenia. An assessment of acute psychotics. Journal of Nervous and Mental Disease, 172(8), 458-463.

Harvey, P. D., Lenzenweger, M. F., Keefe, R. S., Pogge, D. L., Serper, M. R., \& Mohs, R. C. (1992). Empirical assessment of the factorial structure of clinical symptoms in schizophrenic patients: Formal thought disorder. Psychiatry Research, 44(2), $141-151$.

Healey, K. M., Pinkham, A. E., Richard, J. A., \& Kohler, C. G. (2010). Do we recognize facial expressions of emotions from persons with schizophrenia? Schizophrenia Research, 122, 144-150.

Hogarty, G. E. \& Greenwald, D.P. (2006). Cognitive enhancement therapy (http://www.cognitiveenhancementtherapy. com). Accessed December 19, 2012.

Holzman, P. S., Coleman, M., Lenzenweger, M., Levy, D. L., Matthysse, S., O’Driscoll, G., \& Park, S. (1995). Working memory deficits, antisaccades, and thought disorder in relation to perceptual aberration. In A. Raine, T. Lencz, \& S. Mednick (Eds.), Schizotypal Personality (pp. 353-381). Cambridge, England: Cambridge University Press.

Holzman, P. S., Levy, D. L., \& Johnston, M. H. (2005). The use of the Rorschach technique for assessing formal thought disorder. In R. Bornstein \& J. Masling (Eds.), Scoring the Rorschach: Seven Validated Systems (55-95). Mahwah, New Jersey: Lawrence Erlbaum Associates.

Holzman, P. S., Shenton, M. E., \& Solovay, M. R. (1986). Quality of thought disorder in differential diagnosis. Schizophrenia Bulletin, 12(3), 360-371. 
Jampala, V. C., Abrams, R., \& Taylor, M. A. (1985). Mania with emotional blunting: affective disorder or schizophrenia? American Journal of Psychiatry, 142(5), 608612.

Jampala, V. C., Taylor, M. A., \& Abrams, R. (1989). The diagnostic implications of formal thought disorder in mania and schizophrenia: A reassessment. American Journal of Psychiatry, 146(4), 459-463.

Johnston, M.H. \& Holzman, P. S. (1979). Assessing schizophrenic thinking. San Francisco, CA: Jossey-Bass.

Johnston, M.H., Holzman, P.S., Solovay, M.R. Shenton, M.E., Gasperetti, C., Coleman, M., Kestnbaum, E., and Carpenter, J.T. (1986). Scoring manual for the Thought Disorder Index. Schizophrenia Bulletin, 12(3), 483-496.

Kearns, J. G. (2007). Verbal communication impairments and cognitive control components in people with schizophrenia. Journal of Abnormal Psychology, $116(2), 279-289$.

Keefe, R. S., Mohs, R. C., Losonczy, M. F., Davidson, M., Silverman, J. M., Kendler, K. S., Horvath, T. B., Nora, R., \& Davis, K. L. (1987). Characteristics of very poor outcome in schizophrenia. American Journal of Psychiatry, 144(7), 889-895.

Kim, J-H. Kim, S-Y., Lee, J., Oh, K-J., Kim, Y-B., \& Cho, Z-H. (2012). Evaluation of the factor structure of symptoms in-patient with schizophrenia. Psychiatry Research, 197, 285-289.

Kingdon, D., \& Turkington, D. (2008). Cognitive therapy of schizophrenia (Guides to individualized evidenced-based treatment). New York: Guilford Press. 
Kring, A. M., \& Bachorowski, J. (1999). Emotion and psychopathology. Cognition and Emotion, 13(5), 575-599.

Kring, A. M., \& Caponigro, J. M. (2010). Emotion in schizophrenia: Where feeling meets thinking. Current Directions in Psychological Science, 19, 255-259.

Kring, A. M., \& Earnst, K. S. (1999). Stability of emotional responding in schizophrenia. Behavior Therapy, 30, 373-388.

Kring, A. M., Kerr, S. L., Smith, D. A., \& Neale, J. M. (1993). Flat affect in schizophrenia does not reflect diminished subjective experience of emotion. Journal of Abnormal Psychology, 102(4), 507-517.

Kring, A. M., \& Moran, E. K. (2008). Emotional response deficits in schizophrenia: insights from affective science. Schizophrenia Bulletin, 34(5), 819-834.

Kuller, A. M., Ott, B. D., Goisman, R. M., Wainwright, L. D., \& Rabin, R. J. (2010). Cognitive behavioral therapy and schizophrenia: a survey of clinical practices and views on efficacy in the United States and United Kingdom. Community Mental Health Journal, 46(1), 2-9.

Lake, C. R. (2008). Disorders of thought are severe mood disorders: The selective attention deficit in mania challenges the Kraepelinian dichotomy - a review. Schizophrenia Bulletin, 34(1), 109-117.

Lancon, C., Auquier, P., Nayt, G., \& Reine, G. (2000). Stability of the five-factor structure of the Positive and Negative Syndrome Scale. Schizophrenia Research, $42,231-239$.

Lanin-Kettering, I., \& Harrow, M. (1985). The thought behind the words: a view of schizophrenic speech and thinking disorders. Schizophrenia Bulletin, 11(1), 1-15. 
Larsen, R. J. \& Diener, E. (1987). Affective intensity as an individual difference characteristic: A review. Journal of Research in Personality, 21, 1-39.

Larsen, R. J., Diener, E., \& Cropanzano, R. S. (1987). Cognitive operations associated with individual differences in affect intensity. Journal of Personality and Social Psychology, 53(4), 767-774.

Levy, D. L., Coleman, M. J., Sung, H., Ji, F., Matthysse, S., Mendell, N. R., \& Titone, D. (2010). The genetic basis of thought disorder and language and communication disturbances in schizophrenia. Journal of Neurolinguistics, 23(3), 176.

Liddle, P. F., Ngan, E. T., Caissie, S. L., Anderson, C. M., Bates, A. T., Quested, D. J., White, R., \& Web, R. (2002). Thought and Language Index: an instrument for assessing thought and language in schizophrenia. British Journal of Psychiatry, 181, 326-330.

Lilienfeld, S., Wood, J., \& Garb, H. (2000). The scientific status of projective techniques. Psychological Science in the Public Interest, 1(2), 27-66.

Lorr, M., \& McNair, D. M. (1988). Manual of Profile of Mood States, Bipolar Form. San Diego: Educational and Industrial Testing Service.

Makowski, D., Waternaux, C., Lajonchere, C., Dicker, R., Smoke, N., Koplewicz, H., Min, D., Mendell, N., \& Levy, D. (1997). Thought disorder in early adolescent onset schizophrenia. Schizophrenia Research, 23, 147-165.

Malla, A. K. (1995). Negative symptoms and affective disturbance in schizophrenia and related disorders. Canadian Journal of Psychiatry, 40 (7 Supplement 2), S55-z59.

Marengo, J. T., \& Harrow, M. (1985). Thought disorder. A function of schizophrenia, mania, or psychosis? Journal of Nervous and Mental Disease, 173(1), 35-41. 
Marengo, J. T., \& Harrow, M. (1997). Longitudinal courses of thought disorder in schizophrenia and schizoaffective disorder. Schizophrenia Bulletin, 23(2), 273285.

Marengo, J. T., Harrow, M., Lanin-Kettering, I., \& Wilson, A. (1986). Evaluating bizarre-idiosyncratic thinking: A comprehensive index of positive thought disorder. Schizophrenia Bulletin, 12(3), 497-511.

McGrath, J. (1991). Ordering thoughts on thought disorder. British Journal of Psychiatry, $158,307-316$.

McKenna, P. \& Oh, T. (2005). Schizophrenic speech. Making sense of bathroots and ponds that fall in doorways. New York, NY: Cambridge University Press.

Mojtabai, R. (1999). Duration of illness and structure of symptoms in schizophrenia. Psychological Medicine, 29, 915-924.

National Institute of Mental Health. (2009). Schizophrenia. Retrieved March 2011, from http://www.nimh.nih.gov/health/publications/schizophrenia/completeindex.shtml.

Osher, Y., \& Bersudsky, Y. (2007). Thought disorder in euthymic bipolar patients: a possible endophenotype of bipolar affective disorder? Journal of Nervous and Mental Disease, 195(10), 857-860.

Park, S., Gupta, M., \& Kim, K. (2011). Physiological reactivity and facial expression to emotion-inducing films in patients with schizophrenia. Archives of Psychiatric Nursing, 25, e37-e47.

Parnas J. (2011). A disappearing heritage: The clinical core of schizophrenia. Schizophrenia Bulletin 37, 1121-1130. 
Rapaport, D., Gill, M., \& Schafer, R. (1968). In R. Holt (Ed.). Diagnostic Psychological Testing. New York: International Universities Press.

Rorschach, H. (1942). Psychodiagnostics: A diagnostic test based on perception. Bern, Switzerland: Hans Huber. (Original work published 1921).

Schimmack, U. \& Diener, E. (1997). Affect intensity: Separating intensity and frequency in repeatedly measured affect. Journal of Personality and Social Psychology, 73(6), 1313-1329.

Solovay, M., Shenton, M., \& Holzman, P. S. (1987). Comparative studies of thought disorders. Archives of General Psychiatry, 44, 13-20.

Spitzer, R. L., Endicott, J., \& Robins, E. (1978). Research diagnostic criteria: rationale and reliability. Archives of general psychiatry, 35(6), 773-782.

St-Hilaire, A., Cohen, A. S., \& Docherty, N. M. (2008). Emotion word use in the conversational speech of schizophrenia patients. Cognitive Neuropsychiatry, $13,343-356$.

Stirling, J., Hellewell, J., Blakey, A., \& Deakin, W. (2006). Thought disorder in schizophrenia is associated with both executive dysfunction and circumscribed impairments in semantic function. Psychological Medicine, 36(4), 475-484.

Strauss J. (2011). Subjectivity and severe psychotic disorders. Schizophrenia Bulletin, 37 , 8-13.

Subotnik, K. L., Nuechterlein, K. H., Green, M. F., Horan, W. P., Nienow, T. M., Ventura, J., \& Nguyen, A. T. (2006). Neurocognitive and social cognitive correlates of formal thought disorder in schizophrenia patients. Schizophrenia Research, 85, 84-95. 
Taylor, M. A., Reed, R., \& Berenbaum, S. (1994). Patterns of speech disorders in schizophrenia and mania. Journal of Nervous and Mental Disease, 182(6), 319326.

Toomey, R., Kremen, W. S., Simposon, J. C., Samson, J. A., Seidman, L. J., Lyons, M. J., Faraone, S. V., \& Tsuang, M. T. (1997). Revisiting the factor structure for positive and negative symptoms: Evidence from a large heterogeneous group of psychiatric patients. The American Journal of Psychiatry, 154(3), 371-377.

Ulas, H., Akdede, B. B., Ozbay, D., \& Alptekin, K. (2008). Effect of thought disorders on quality of life in patients with schizophrenia. Progress in Neuropsychopharmacology and Biological Psychiatry, 32(2), 332-335.

Ursu, S., Kring, A. M., Gard, M. G., Minzenberg, M. J., Yoon, J. H., Ragland, J. D., Soloman, M., \& Carter, C. S. (2011). Prefrontal cortical deficits and impaired cognition-emotion interactions in schizophrenia. American Journal of Psychiatry, $168(3), 276-285$.

Watson, D., Clark, L., \& Tellegen, A. (1988). Development and validation of brief measures of positive and negative affect: The PANAS scales. Journal of Personality and Social Psychology, 54(6), 1063-1070.

Wechsler, D. (2008). Wechsler Adult Intelligence Scale $-4^{\text {th }}$ Edition (WAIS-IV). San Antonio, TX: Pearson.

Wechsler, D. (2001). Wechsler Test of Adult Reading: WTAR. San Antonio, TX: Pearson. Winter, J., Dodou, D., \& Wieringa, P. (2009). Exploratory factor analyses with small sample sizes. Multivariate Behavioral Research, 44, 147-181.

Wykes, T., Reeder, C., Landau, S., Everitt, B., Knapp, M., Patel, A., \& Romeo, R. 
(2007). Cognitive remediation therapy in schizophrenia. The British Journal of Psychiatry, 190, 421-427.

Wykes, T., Steel, C., Everitt, B., \& Tarrier, N. (2008). Cognitive behavior therapy for schizophrenia: effect sizes, clinical models, and methodological rigor. Schizophrenia Bulletin, 34(3), 523-537.

Zevon, M. \& Tellegen, A. (1982). The structure of mood change: An idiographic/nomothetic analysis. Journal of Personality and Social Psychology, $43,111-122$. 


\section{Table 1}

Thought Disorder Definitions (Andreasen, 1979a)

\begin{tabular}{|c|c|}
\hline $\begin{array}{l}\text { Poverty of } \\
\text { speech }\end{array}$ & Restriction in the amount of spontaneous speech \\
\hline $\begin{array}{l}\text { Poverty of } \\
\text { content } \\
\text { of speech }\end{array}$ & $\begin{array}{l}\text { Amount of speech is adequate, but language is vague, concrete, and } \\
\text { repetitive }\end{array}$ \\
\hline $\begin{array}{l}\text { Pressure of } \\
\text { speech }\end{array}$ & An increase in the amount of spontaneous speech \\
\hline $\begin{array}{l}\text { Distractible } \\
\text { speech }\end{array}$ & $\begin{array}{l}\text { Disruption in the course of speech as evidenced by stopping in the } \\
\text { middle of a sentence and changing the subject in response to a nearby } \\
\text { stimulus }\end{array}$ \\
\hline Tangentiality & Replying to a question in an oblique, tangential, or irrelevant manner \\
\hline $\begin{array}{l}\text { Derailment } \\
\text { (loose } \\
\text { associations, } \\
\text { flight of ideas) }\end{array}$ & $\begin{array}{l}\text { A pattern of spontaneous speech in which the ideas slip off the track } \\
\text { onto another one that is clearly but obliquely related, or completely } \\
\text { unrelated }\end{array}$ \\
\hline $\begin{array}{l}\text { Incoherence } \\
\text { (word salad) }\end{array}$ & A pattern of speech that is essentially incomprehensible at times \\
\hline Illogicality & $\begin{array}{l}\text { A pattern of speech in which conclusions are reached that do not } \\
\text { follow logically }\end{array}$ \\
\hline Clanging & $\begin{array}{l}\text { A pattern of speech in which sounds rather than meaningful } \\
\text { relationships appear to govern word choice }\end{array}$ \\
\hline Neologisms & $\begin{array}{l}\text { A completely new word or phrase whose derivation cannot be } \\
\text { understood }\end{array}$ \\
\hline $\begin{array}{l}\text { Word } \\
\text { Approximations }\end{array}$ & $\begin{array}{l}\text { Old words that are used in a new or unconventional way, or new } \\
\text { words that are developed by conventional rules of word formation }\end{array}$ \\
\hline Circumstantiality & $\begin{array}{l}\text { A pattern of speech that is very indirect and delayed in reaching its } \\
\text { goal idea }\end{array}$ \\
\hline Loss of goal & Failure to follow a chain of thought through to its natural conclusion \\
\hline Perseveration & Persistent repetition of words, ideas, or subjects \\
\hline Echolalia & A pattern of speech in which words or phrases of others are echoed \\
\hline Blocking & $\begin{array}{l}\text { Interruption of a train of speech before a thought or idea has been } \\
\text { completed }\end{array}$ \\
\hline Stilted Speech & Speech that has an excessively stilted or formal quality \\
\hline Self-reference & $\begin{array}{l}\text { A pattern of speech in which the subject under discussion is referred } \\
\text { back to oneself when either the person in question or another is } \\
\text { speaking }\end{array}$ \\
\hline
\end{tabular}


Table 2

\section{Measures of Thought Disorder}

\begin{tabular}{|c|c|c|c|c|c|c|}
\hline $\begin{array}{l}\text { Name of } \\
\text { Scoring sustem }\end{array}$ & Authors & $\begin{array}{l}\text { Level of } \\
\text { measurement }\end{array}$ & $\begin{array}{l}\text { Measure of } \\
\text { Thought Disorder }\end{array}$ & Scoring system & Subtypes & Psychometrics \\
\hline $\begin{array}{l}\text { Communication } \\
\text { Disturbances } \\
\text { Index (CDI) }\end{array}$ & $\begin{array}{l}\text { Docherty, } \\
\text { DeRosa, \& } \\
\text { Andreasen, } \\
1996)\end{array}$ & Subtype & $\begin{array}{l}\text { Semi-structured } \\
\text { interview }\end{array}$ & $\begin{array}{l}\text { Responses are scored } \\
\text { for the frequency of } \\
\text { each of six types of } \\
\text { communication failure: }\end{array}$ & $\begin{array}{l}\text { 1. Vague references } \\
\text { 2. Confused } \\
\text { references } \\
\text { 3. Missing } \\
\text { information } \\
\text { references } \\
\text { 4. Ambiguous word } \\
\text { meanings } \\
\text { 5. Wrong word } \\
\text { references } \\
\text { 6. Structural } \\
\text { unclarities }\end{array}$ & $\begin{array}{l}\text { IRR: } \\
\text { Vague: } \\
r=.73 \\
\text { Confused: } \\
r=.88 \\
\text { Missing: } \\
r=.89 \\
\text { Ambiguous: } \\
r=.88 \\
\text { Wrong word: } \\
r=.80 \\
\text { Structural: } \\
r=.93 \\
\text { Total CDI: } \\
r=.94\end{array}$ \\
\hline $\begin{array}{l}\text { Index of } \\
\text { Positive } \\
\text { Thought } \\
\text { Disorder } \\
\text { (IPTD) }\end{array}$ & $\begin{array}{l}\text { (Marengo et } \\
\text { al., 1986) }\end{array}$ & $\begin{array}{l}\text { Global, } \\
\text { severity }\end{array}$ & $\begin{array}{l}\text { Gorham Proverbs Test } \\
\text { WAIS Comprehension } \\
\text { subtest } \\
\text { Goldstein-Scheerer } \\
\text { Object Sorting Test }\end{array}$ & $\begin{array}{l}\text { 1. Overall score from } \\
\text { each response ranging } \\
\text { from absent to severe: } \\
\text { 0: Idiosyncratic } \\
\text { verbalizations are } \\
\text { absent } \\
\text { 0.5: Mild cognitive } \\
\text { slips } \\
\text { 1: A definite } \\
\text { characteristic or } \\
\text { bizarre response } \\
\text { 3: A very severe } \\
\text { bizarre response } \\
\text { 2. Continuum score } \\
\text { based on total summed } \\
\text { scores from measures: } \\
\text { 1: Absent } \\
\text { 2: Mild } \\
\text { 3: Definite } \\
\text { 4: Severe } \\
\text { 5: Very severe } \\
\text { 3. Composite index } \\
\text { score used to assign } \\
\text { individual to the } \\
\text { highest/most severe } \\
\text { level from the IPTD } \\
\text { tests (continuum } \\
\text { ratings } 1-5 \text { ) }\end{array}$ & $\mathrm{N} / \mathrm{A}$ & $\begin{array}{l}\text { IRR: } r=.85 \\
\text { Comprehension } \\
\text { and Proverbs: } \\
r=.64 \\
\text { Comprehension } \\
\text { and Object: } \\
r=.50 \\
\text { Proverbs and } \\
\text { Object: } \\
r=.60\end{array}$ \\
\hline
\end{tabular}




\begin{tabular}{|c|c|c|c|c|c|c|}
\hline $\begin{array}{l}\text { Name of } \\
\text { Scoring system }\end{array}$ & Authors & $\begin{array}{l}\text { Level of } \\
\text { measurement }\end{array}$ & $\begin{array}{l}\text { Measure of } \\
\text { Thought Disorder }\end{array}$ & Scoring system & Subtypes & Psychometrics \\
\hline $\begin{array}{l}\text { Scale for the } \\
\text { Assessment of } \\
\text { Thought, } \\
\text { Language, and } \\
\text { Communication } \\
\text { (TLC) }\end{array}$ & $\begin{array}{l}\text { (Andreasen, } \\
1979 \mathrm{a} ; \\
1979 \mathrm{~b})\end{array}$ & $\begin{array}{l}\text { Subtypes, } \\
\text { severity }\end{array}$ & $\begin{array}{l}\text { Scores based on a } 45 \\
\text { minute open-ended } \\
\text { interview; psychiatric } \\
\text { symptomatology is } \\
\text { not discussed }\end{array}$ & $\begin{array}{l}\text { Ratings of each of the } \\
18 \text { subtypes of thought } \\
\text { disorder based on a } 0-4 \\
\text { (1-9) or } 0-3 \text { (10-18) } \\
\text { scale: } \\
\text { 0: Absent } \\
\text { 1: Mild (occurs once) } \\
\text { 2. Moderate (occurs } \\
\text { 2 to } 4 \text { times) } \\
\text { 3. Severe (occurs five } \\
\text { or more times) } \\
\text { OR } \\
\text { 0. None } \\
\text { 1. Mild (occurs once) } \\
\text { 2. Moderate (occurs } \\
\text { 2 to } 4 \text { times) } \\
\text { 3. Severe (occurs } 5 \text { to } \\
\text { 10 times) } \\
\text { 4. Extreme (occurs } \\
\text { more than } 10 \text { times, or } \\
\text { so frequently that the } \\
\text { interview is } \\
\text { incomprehensible) }\end{array}$ & $\begin{array}{l}\text { 1. Poverty of speech } \\
\text { 2. Poverty of } \\
\text { content of speech } \\
\text { 3. Pressure of } \\
\text { speech } \\
\text { 4. Distractible } \\
\text { speech } \\
\text { 5. Tangentiality } \\
\text { 6. Derailment } \\
\text { 7. Incoherence } \\
\text { 8. Illogicality } \\
\text { 9. Clanging } \\
\text { 10. Neologisms } \\
\text { 11. Word } \\
\text { approximations } \\
\text { 12. } \quad \text { Circumst } \\
\quad \text { antiality } \\
\text { 13. Loss of goal } \\
\text { 14. Perseveration } \\
\text { 15. Echolalia } \\
\text { 16. Blocking } \\
\text { 17. Stilted speech } \\
\text { 18. Self-reference }\end{array}$ & $\begin{array}{l}\text { See Andreasen } \\
(1979 \text { a) for } \\
\text { weighted } k \text { for } \\
\text { all definitions. } \\
\text { Weighted } k \text { for } \\
\text { global score: } \\
\quad k=.89\end{array}$ \\
\hline $\begin{array}{l}\text { Thought and } \\
\text { Language } \\
\text { Index (TLI) }\end{array}$ & $\begin{array}{l}\text { (Liddle et } \\
\text { al., 2002) }\end{array}$ & $\begin{array}{l}\text { Subtypes, } \\
\text { severity }\end{array}$ & $\begin{array}{l}\text { 1-minute responses to } \\
\text { eight Rorschach or } \\
\text { Thematic } \\
\text { Apperception Test } \\
\text { items }\end{array}$ & $\begin{array}{l}\text { Responses are scored } \\
\text { for the presence and } \\
\text { severity of } 8 \text { subtypes } \\
\text { of thought disorder: } \\
\text { 0.25: Minor } \\
\text { idiosyncrasies } \\
\text { 0.50: Distinct oddness } \\
\text { 0.75: Instability of } \\
\text { thinking and } \\
\text { perception, absurdity } \\
\text { 1.0: Complete loss of } \\
\text { reality }\end{array}$ & $\begin{array}{l}\text { Impoverishment } \\
\text { Poverty of Speech } \\
\text { Weakening of Goal } \\
\text { Disorganization } \\
\text { Looseness } \\
\text { Peculiar Word Use } \\
\text { Peculiar sentence } \\
\text { construction } \\
\text { Peculiar Logic } \\
\text { Non-specific } \\
\text { dysregulation } \\
\text { Perseveration } \\
\text { Distractibility }\end{array}$ & $\begin{array}{l}\text { IRR (range): } \\
\quad r=.60 \\
\text { (peculiar word } \\
\text { use) - } \\
r=.93 \\
\text { (poverty of } \\
\text { speech) } \\
\text { Impoverishment } \\
\text { IRR: } \\
\quad r=.88 \\
\text { Disorganization } \\
\text { IRR: } \\
r=.82\end{array}$ \\
\hline
\end{tabular}




\begin{tabular}{|c|c|c|c|c|c|c|}
\hline $\begin{array}{l}\text { Name of } \\
\text { Scoring system }\end{array}$ & Authors & $\begin{array}{l}\text { Level of } \\
\text { measurement }\end{array}$ & $\begin{array}{l}\text { Measure of } \\
\text { Thought Disorder }\end{array}$ & Scoring system & Subtypes & Psychometrics \\
\hline $\begin{array}{l}\text { Thought } \\
\text { Disorder Index } \\
\text { (TDI) }\end{array}$ & $\begin{array}{l}\text { (Johnston \& } \\
\text { Holzman, } \\
1979 ; \\
\text { Johnston et } \\
\text { al.,1986) }\end{array}$ & $\begin{array}{l}\text { Subtypes, } \\
\text { severity }\end{array}$ & $\begin{array}{l}\text { Scores based on } \\
\text { responses from the } \\
\text { Rorschach or } \\
\text { Wechsler Adult } \\
\text { Intelligence Scale }\end{array}$ & $\begin{array}{l}\text { Responses are scored } \\
\text { based on presence of } \\
\text { subtypes that represent } \\
\text { a continuum of } \\
\text { severity: } \\
\text { 0.25: Minor } \\
\text { idiosyncrasies } \\
\text { 0.50: Distinct } \\
\text { oddness } \\
\text { 0.75: Instability of } \\
\text { thinking and } \\
\text { perception, absurdity } \\
\text { 1.0: Complete loss of } \\
\text { reality }\end{array}$ & $\begin{array}{l}0.25 \\
\text { Inappropriate } \\
\text { distance } \\
\text { Vagueness } \\
\text { Peculiar } \\
\quad \text { verbalization } \\
\text { Word-finding } \\
\quad \text { difficulty } \\
\text { Clang } \\
\text { Perseveration } \\
\text { Relationship } \\
\text { verbalization } \\
\text { Incongruous } \\
\text { combination } \\
\\
\text { Intermediate } 0.25 \text {, } \\
0.50 \\
\text { Idiosyncratic } \\
\text { symbolism } \\
\text { 0.50 } \\
\text { Queer response } \\
\text { Confusion } \\
\text { Looseness } \\
\text { Fabulized } \\
\text { combination } \\
\text { 0.75 } \\
\text { Fluidity } \\
\text { Absurd response } \\
\text { Confabulation } \\
\text { Autistic Logic } \\
\text { 1.0 } \\
\text { Contamination } \\
\text { Incoherence } \\
\text { Neologism }\end{array}$ & IRR: $r=.90$ \\
\hline
\end{tabular}

Note. IRR $=$ Interrater reliability. 
Table 3

Thought Disorder Literature Reviewed

\begin{tabular}{|c|c|c|c|c|c|c|c|c|}
\hline \multirow[t]{2}{*}{ Study } & \multicolumn{5}{|c|}{ Sample characteristics } & \multirow{2}{*}{$\begin{array}{l}\text { Thought } \\
\text { Disorder } \\
\text { Measure }\end{array}$} & \multirow[t]{2}{*}{ Follow-up } & \multirow{2}{*}{$\begin{array}{l}\text { Outcomes for } \\
\text { Thought Disorder }\end{array}$} \\
\hline & Sample & $\begin{array}{l}\text { Sample } \\
\text { Composition }\end{array}$ & \begin{tabular}{|l|} 
Diagnostic \\
Procedure \\
\end{tabular} & $\begin{array}{l}\text { Gender } \\
\text { (\% Male) }\end{array}$ & Medication (\%) & & & \\
\hline (Andreasen, 1979b) & $\begin{array}{l}\mathrm{N}=113 \\
\text { Inpatient at } \\
\text { index }\end{array}$ & $\begin{array}{l}\mathrm{Sz}=45 \\
\text { Mania }=32 \\
\text { Depression }=36\end{array}$ & RDC & $\begin{array}{l}\mathrm{Sz}=60 \% \\
\text { Mania }=44 \% \\
\text { Depression }= \\
39 \%\end{array}$ & $\begin{array}{l}\text { "Nearly all } \\
\text { receiving } \\
\text { medication" (p. } \\
\text { 1326) }\end{array}$ & TLC & None & $\begin{array}{l}\text { PFTD/NFTD model significantly } \\
\text { discriminated Sz and mania, and } \\
\text { within Sz: } \\
\text { PFTD - Acute Sz and mania } \\
\text { NFTD - Chronic Sz }\end{array}$ \\
\hline $\begin{array}{l}\text { (Andreasen } \\
\& \text { Grove, 1986) }\end{array}$ & $\begin{array}{l}\mathrm{N}=194 \\
\text { Inpatient at } \\
\text { index }\end{array}$ & $\begin{array}{l}\mathrm{Sz}=50 \\
\mathrm{SAD}=25 \\
\text { Mania }=25 \\
\text { Control }=94\end{array}$ & RDC & $\begin{array}{l}\mathrm{Sz}=20 \% \\
\mathrm{SAD}=44 \% \\
\text { Mania }=48 \% \\
\text { Control }=41 \%\end{array}$ & $\begin{array}{l}\text { "Nearly all } \\
\text { receiving } \\
\text { medication" (p. } \\
350)\end{array}$ & TLC & $\begin{array}{l}\text { FU1: } 6 \\
\text { months } \\
\text { after index }\end{array}$ & $\begin{array}{l}\text { Acute: } \\
\text { Sig. distributions for most TLC } \\
\text { elements } \\
\text { Sz and SAD distributions similar } \\
\text { Mania }>\text { all, SAD, Sz (PFTD } \\
\text { versus NFTD) } \\
\text { FU1: } \\
\text { Mania, SAD }>\text { Sz } \\
\text { (Remittance, n.s.) } \\
\text { Sz }>\text { Mania, SAD (persistent } \\
\text { disorganization) }\end{array}$ \\
\hline
\end{tabular}




\begin{tabular}{|c|c|c|c|c|c|c|c|c|}
\hline \multirow[t]{2}{*}{ Study } & \multicolumn{5}{|c|}{ Sample characteristics } & \multirow{2}{*}{$\begin{array}{l}\text { Thought } \\
\text { Disorder } \\
\text { Measure }\end{array}$} & \multirow[t]{2}{*}{ Follow-up } & \multirow{2}{*}{$\begin{array}{l}\text { Outcomes for } \\
\text { Thought Disorder }\end{array}$} \\
\hline & Sample & $\begin{array}{l}\text { Sample } \\
\text { Composition }\end{array}$ & $\begin{array}{l}\text { Diagnostic } \\
\text { Procedure }\end{array}$ & $\begin{array}{l}\text { Gender } \\
(\% \text { Male })\end{array}$ & Medication (\%) & & & \\
\hline (Harrow et al., 1982) & $\begin{array}{l}\mathrm{N}=113 \\
\text { Inpatient at } \\
\text { index }\end{array}$ & $\begin{array}{l}\mathrm{Sz}=48 \\
\mathrm{Mania}=34 \\
\mathrm{NP}=31 \\
\mathrm{MDD} \text { and } \\
\mathrm{mDD}\end{array}$ & RDC & Total $=60 \%$ & $\begin{array}{l}\text { Medication at Index } \\
\text { (no med details): } \\
\mathrm{Sz}=29 \% \\
\mathrm{Mania}=37.5 \% \\
\mathrm{NP}=21 \% \\
\mathrm{FU} 1 \\
\mathrm{Sz}=76 \% \\
\mathrm{AP} \text { only }=100 \% \\
\text { Mania }=83 \% \\
\text { Lith only }=58.3 \% \\
\text { Lith }+\mathrm{AP}=25 \% \\
\text { None }=16.7 \%\end{array}$ & IPTD & $\begin{array}{l}\text { FU1: } 7 \\
\text { weeks after } \\
\text { index }\end{array}$ & $\begin{array}{l}\text { Acute: } \\
\text { Mania }>\text { Sz } \\
\text { Mania, Sz }>\text { NP } \\
\text { FU1: } \\
\text { No difference in severity } \\
\text { Mania }>\text { Sz (greater reduction) }\end{array}$ \\
\hline (Harrow et al., 1986a) & $\begin{array}{l}\mathrm{N}=94 \\
\text { Inpatient at } \\
\text { index }\end{array}$ & $\begin{array}{l}\mathrm{Sz}=30 \\
\mathrm{Mania}=34 \\
\mathrm{NP}=30 \\
\mathrm{MDD}=21 \\
\mathrm{mDD}=4 \\
\text { Other }=5 \\
\text { Control }=34\end{array}$ & RDC & $\begin{array}{l}\text { Total }=61 \% \\
\text { Mania }=55 \% \\
\text { Control }=53 \%\end{array}$ & $\begin{array}{l}\text { Medication at FU1: } \\
\text { Sz }=77 \% \\
\text { AP only }=91 \% \\
\text { Mania }=62 \% \\
\text { Lith }=26 \% \\
\text { Lith }+\mathrm{AP}=15 \% \\
\text { AP only }=21 \% \\
\text { None }=38 \%\end{array}$ & IPTD & $\begin{array}{l}\text { FU1: } 1 \text { year } \\
\text { after index }\end{array}$ & $\begin{array}{l}\text { FU1: } \\
\text { Sz }>\text { NP } \\
\text { Sz }=\text { Mania } \\
\text { Mania = NP }\end{array}$ \\
\hline $\begin{array}{l}\text { (Harrow } \\
\text { \& Marengo, 1986) }\end{array}$ & $\begin{array}{l}\mathrm{N}=191 \\
\text { Inpatient at } \\
\text { index }\end{array}$ & $\begin{array}{l}\mathrm{Sz}=44 \\
\mathrm{PNS}=67 \\
\mathrm{MDD}=13 \\
\mathrm{Mania}=16 \\
\mathrm{SADd}=21 \\
\mathrm{SADm}=5 \\
\text { Unspecified }=12 \\
\mathrm{NP}=80 \\
\mathrm{MDD}=49 \\
\mathrm{mDD}=5 \\
\text { Mania }=4 \\
\text { Other }=22\end{array}$ & $\begin{array}{l}\text { RDC (primary) } \\
\text { \& DSM-III }\end{array}$ & $\begin{array}{l}\mathrm{Sz}=61 \% \\
\mathrm{PNS}=52 \% \\
\mathrm{NP}=39 \%\end{array}$ & $\begin{array}{l}\text { Antipsychotics at } \\
\text { FU1: } \\
\text { Sz }=53 \% \\
\text { PNS }=33 \% \\
\text { NP }=13 \% \\
\text { Antipsychotics at } \\
\text { FU2: } \\
\text { Sz }=59 \% \\
\text { PNS }=36 \% \\
\text { NP }=8 \%\end{array}$ & IPTD & $\begin{array}{l}\text { FU1: } 1.5-2 \\
\text { yrs after } \\
\text { DC } \\
\text { FU2: } 3.5-4 \\
\text { yrs after } \\
\text { DC }\end{array}$ & $\begin{array}{l}\text { FU1: } \\
\text { Sz, PNS > NP } \\
\text { FU2: } \\
\text { No difference }\end{array}$ \\
\hline
\end{tabular}




\begin{tabular}{|c|c|c|c|c|c|c|c|c|}
\hline \multirow[t]{2}{*}{ Study } & \multicolumn{5}{|c|}{ Sample characteristics } & \multirow{2}{*}{$\begin{array}{l}\text { Thought } \\
\text { Disorder } \\
\text { Measure }\end{array}$} & \multirow[t]{2}{*}{ Follow-up } & \multirow{2}{*}{$\begin{array}{l}\text { Outcomes for } \\
\text { Thought Disorder }\end{array}$} \\
\hline & Sample & $\begin{array}{l}\text { Sample } \\
\text { Composition }\end{array}$ & $\begin{array}{l}\text { Diagnostic } \\
\text { Procedure } \\
\end{array}$ & $\begin{array}{l}\begin{array}{l}\text { Gender } \\
(\% \text { Male })\end{array} \\
\end{array}$ & Medication (\%) & & & \\
\hline $\begin{array}{l}\text { (Harrow et al., } \\
\text { 1986b) }\end{array}$ & $\begin{array}{l}\mathrm{N}=166 \\
\text { Inpatient at } \\
\text { index }\end{array}$ & $\begin{array}{l}\mathrm{Sz}=48 \\
\mathrm{PNS}=51 \\
\mathrm{MDD}=13 \\
\text { Mania }=9 \\
\mathrm{SADd}=14 \\
\mathrm{SADm}=5 \\
\text { Substance }=3 \\
\text { Unspecified }=7 \\
\mathrm{NP}=67 \\
\mathrm{MDD}=38 \\
\mathrm{mDD}=9 \\
\text { Mania }=1 \\
\text { Hypoman }=2 \\
\text { Other }=17\end{array}$ & $\begin{array}{l}\text { RDC } \\
\& \text { DSM-III }\end{array}$ & Total $=46 \%$ & $\begin{array}{l}\text { Antipsychotics at } \\
\text { Index: } \\
\text { Sz }=83 \% \\
\text { PNS }=67 \% \\
\text { NP }=23 \% \\
\text { Antipsychotics at } \\
\text { FU1: } \\
\text { Sz }=52 \% \\
\text { PNS }=36 \% \\
\text { NP }=13 \%\end{array}$ & IPTD & $\begin{array}{l}\text { FU1: } 1.8 \\
\text { yrs after } \\
\text { index }\end{array}$ & $\begin{array}{l}\text { Acute: } \\
\text { Sz > PNS, NP (RDC, DSM-III) } \\
\text { PNS > NP (DSM-III) } \\
\text { FU1: } \\
\text { Sz > PNS, NP (RDC, DSM-III) }\end{array}$ \\
\hline $\begin{array}{l}\text { (Harvey } \\
\& \text { Brault, 1986) }\end{array}$ & $\begin{array}{l}\mathrm{N}=43 \\
\text { Inpatient at } \\
\text { index }\end{array}$ & $\begin{array}{l}\mathrm{Sz}=22 \\
\text { Mania }=21\end{array}$ & DSM-III & $\begin{array}{l}\mathrm{Sz}=82 \% \\
\text { Mania }=81 \%\end{array}$ & $\begin{array}{l}\text { Antipsychotics at } \\
\text { Index: } \\
\text { Sz }=100 \% \\
\text { Mania }=100 \% \\
\text { AP only }=52 \% \\
\text { Lith }=48 \%\end{array}$ & TLC & None & $\begin{array}{l}\text { Acute: } \\
\text { Sz > Mania (POS, POC) } \\
\text { Mania > Sz (pressured) }\end{array}$ \\
\hline
\end{tabular}




\begin{tabular}{|c|c|c|c|c|c|c|c|c|}
\hline \multirow[t]{2}{*}{ Study } & \multicolumn{5}{|c|}{ Sample characteristics } & \multirow{2}{*}{$\begin{array}{l}\text { Thought } \\
\text { Disorder } \\
\text { Measure }\end{array}$} & \multirow[t]{2}{*}{ Follow-up } & \multirow{2}{*}{$\begin{array}{l}\text { Outcomes for } \\
\text { Thought Disorder }\end{array}$} \\
\hline & Sample & $\begin{array}{l}\text { Sample } \\
\text { Composition }\end{array}$ & $\begin{array}{l}\text { Diagnostic } \\
\text { Procedure }\end{array}$ & $\begin{array}{l}\text { Gender } \\
(\% \text { Male })\end{array}$ & Medication (\%) & & & \\
\hline (Harvey et al., 1984) & $\begin{array}{l}\mathrm{N}=40 \\
\text { Inpatient at } \\
\text { index }\end{array}$ & $\begin{array}{l}\mathrm{Sz}=20 \\
\text { Mania }=20\end{array}$ & DSM-III & $\begin{array}{l}\mathrm{Sz}=75 \% \\
\text { Mania }=70 \%\end{array}$ & $\begin{array}{l}\text { Medication at } \\
\text { Index: } \\
\text { Sz }=100 \% \\
\text { AP only }=100 \% \\
\text { Mania }=100 \% \\
\text { AP only, Lith, or } \\
\text { Lith + AP }\end{array}$ & TLC & None & $\begin{array}{l}\text { Acute: } \\
\text { Sz > Mania (POC, NFTD) } \\
\text { Mania > Sz (pressured, PFTD) }\end{array}$ \\
\hline
\end{tabular}




\begin{tabular}{|c|c|c|c|c|c|c|c|c|}
\hline \multirow[t]{2}{*}{ Study } & \multicolumn{5}{|c|}{ Sample characteristics } & \multirow{2}{*}{$\begin{array}{l}\text { Thought } \\
\text { Disorder } \\
\text { Measure }\end{array}$} & \multirow[t]{2}{*}{ Follow-up } & \multirow{2}{*}{$\begin{array}{l}\text { Outcomes for } \\
\text { Thought Disorder }\end{array}$} \\
\hline & Sample & $\begin{array}{l}\text { Sample } \\
\text { Composition }\end{array}$ & $\begin{array}{l}\text { Diagnostic } \\
\text { Procedure }\end{array}$ & $\begin{array}{l}\text { Gender } \\
(\% \text { Male })\end{array}$ & Medication (\%) & & & \\
\hline $\begin{array}{l}\text { (Jampala et al., } \\
\text { 1985) }\end{array}$ & $\begin{array}{l}\mathrm{N}=165 \\
\text { Inpatient at } \\
\text { index }\end{array}$ & $\begin{array}{l}\mathrm{Sz}=31 \\
\mathrm{Mania}=134 \\
\text { Blunt }=14 \\
\text { Non-blunt }=120\end{array}$ & $\begin{array}{l}\text { (See Taylor \& } \\
\text { Abrams 1978) }\end{array}$ & $\begin{array}{l}\text { Sz }=58 \% \\
\text { Blunt }=43 \% \\
\text { Non-blunt }=30 \%\end{array}$ & $\begin{array}{l}\text { No discussion of } \\
\text { specific medications } \\
\\
\text { Lifetime exposure } \\
\text { to antipsychotics } \\
\text { (months): } \\
\mathrm{Sz}=33.8 \\
\text { Mania/Blunt }=36 \\
\text { Mania/Non-blunt }= \\
\text { 13.91 }\end{array}$ & Unspecified & None & $\begin{array}{l}\text { Acute: } \\
\text { Blunt }>\text { Sz } \\
\text { Blunt }>\text { Non-blunt }\end{array}$ \\
\hline (Jampala et al., 1989) & $\begin{array}{l}\mathrm{N}=142 \\
\text { Inpatient at } \\
\text { index }\end{array}$ & $\begin{array}{l}\mathrm{Sz}=31 \\
\text { Mania }-111 \\
\mathrm{TD}=9 \\
\text { No } \mathrm{TD}=102\end{array}$ & $\begin{array}{l}\text { Washington } \\
\text { University } \\
\text { criteria (Mania) } \\
\text { Taylor-Abrams } \\
\text { criteria (Sz) }\end{array}$ & Unspecified & $\begin{array}{l}\text { No discussion of } \\
\text { specific medications } \\
\text { Lifetime exposure } \\
\text { to antipsychotics } \\
\text { (months): } \\
\text { Sz }=33.9 \\
\text { Mania } / \mathrm{TD}=25.4 \\
\text { Mania } / \mathrm{o} \mathrm{TD}= \\
13.3\end{array}$ & Unspecified & $\begin{array}{l}\text { FU1: } \\
\text { discharge } \\
\text { from } \\
\text { hospital }\end{array}$ & $\begin{array}{l}\text { Acute: } \\
\text { Mania }>\text { Sz (severity) } \\
\text { Mania }>\text { Sz (nonseq, FOI) } \\
\text { Sz }>\text { Mania (bizarre) } \\
\text { Mania w/ TD }>\text { Mania w/o TD } \\
\text { (mood lability) } \\
\text { FU1: } \\
\text { Sz }>\text { mania (severity) }\end{array}$ \\
\hline
\end{tabular}




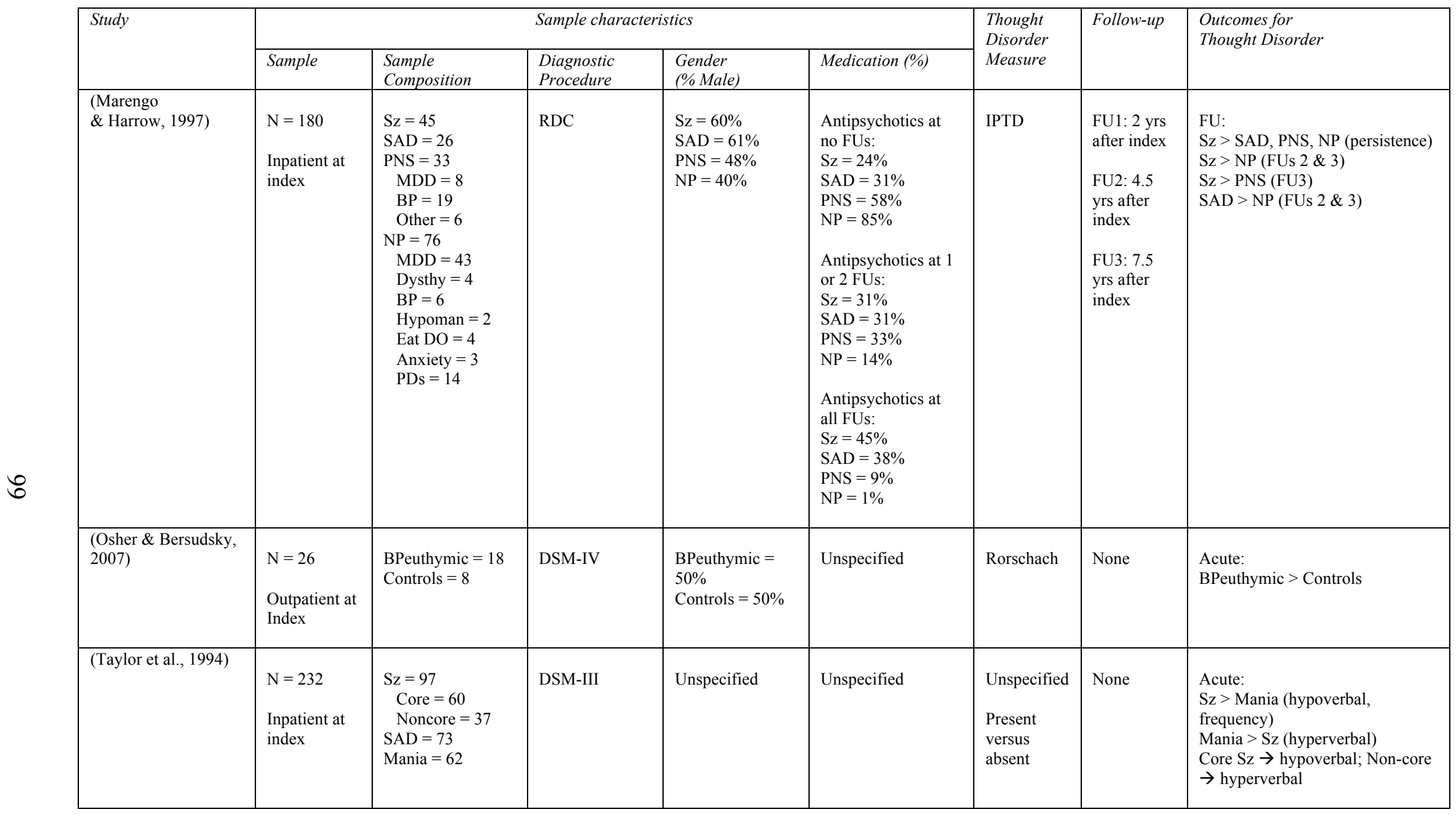




\begin{tabular}{|c|c|c|c|c|c|c|c|c|}
\hline \multirow[t]{2}{*}{ Study } & \multicolumn{5}{|c|}{ Sample characteristics } & \multirow{2}{*}{$\begin{array}{l}\text { Thought } \\
\text { Disorder } \\
\text { Measure }\end{array}$} & \multirow[t]{2}{*}{ Follow-up } & \multirow{2}{*}{$\begin{array}{l}\text { Outcomes for } \\
\text { Thought Disorder }\end{array}$} \\
\hline & Sample & $\begin{array}{l}\text { Sample } \\
\text { Composition }\end{array}$ & $\begin{array}{l}\text { Diagnostic } \\
\text { Procedure }\end{array}$ & $\begin{array}{l}\text { Gender } \\
(\% \text { Male })\end{array}$ & Medication (\%) & & & \\
\hline (Ulas et al., 2008) & $\begin{array}{l}\mathrm{N}=118 \\
16 \% \\
\text { inpatient at } \\
\text { index }\end{array}$ & $\begin{array}{l}\mathrm{Sz}=72 \\
\text { Control }=46\end{array}$ & DSM-IV & $\begin{array}{l}\mathrm{Sz}=61 \% \\
\text { Control }=56.5 \%\end{array}$ & $\begin{array}{l}\text { Antipsychotic } \\
\text { medication: } \\
\text { Sz }=97 \%\end{array}$ & TLI & None & $\begin{array}{l}\mathrm{Sz}<\text { Control (QoL) } \\
\mathrm{TLI} \text { unrelated to QoL or } \\
\text { depression }\end{array}$ \\
\hline
\end{tabular}

Note. Antichol= anticholinergic medication; $\mathrm{AP}=$ antipsychotic medication; $\mathrm{BP}=$ bipolar disorder; $\mathrm{DSM}=$ Diagnostic and Statistical Manual of Mental Disorders; DC = discharge; Dysthy = dysthymia FOI = flight of ideas; FU = follow-up; Hypoman = hypomania; IPTD = Index of Positive Thought Disorder; Lith = lithium; MDD = major depressive disorder; mDD = minor depressive disorder; NFTD $=$ Negative formal thought disorder; Nonseq = nonsequiters; $\mathrm{NP}=$ nonpsychotic; $\mathrm{PD}=$ personality disorder; $\mathrm{PFTD}=$ Positive formal thought disorder; $\mathrm{PNS}=$ psychotic/not schizophrenic; $\mathrm{POC}=$ poverty of content of speech; $\mathrm{POS}=$ poverty of speech, $\mathrm{QoL}=$ Quality of life; $\mathrm{RDC}=$ research diagnostic criteria; $\mathrm{Sz}=$ schizophrenia; $\mathrm{SAD}=\mathrm{schizoaffective}$ disorder; $\mathrm{TD}=$ thought disorder; $\mathrm{TLC}=$ Thought and Language Index; TLI = Thought and Language Index. 


\section{Table 4}

Thought Disorder Inventory Response Categories Using the Rorschach Inkblot Test (Holzman, Levy, \& Johnston, 2005; D. L. Levy, personal communication, July 21, 2011)

\begin{tabular}{|c|c|}
\hline \multicolumn{2}{|l|}{0.25 Level } \\
\hline Inappropriate distance & $\begin{array}{l}\text { Increase of distance: failing to recognize that the inkblot is merely a stimulus for a response and unable to consider what it } \\
\text { "looks like" rather than what "it is" } \\
\text { Loss of distance: becoming personally involved with the inkblot, including aversive verbal reactions or behaviors } \\
\text { Concreteness: awarding underserved reality to incidental aspects of the blot } \\
\text { Overspecificity: responses involving an effort at excessive and unwarranted precision }\end{array}$ \\
\hline Flippancy & Flippant remarks, gratuitous joke telling, or wise cracks that depart from the usual social constraints of a testing situation \\
\hline Vagueness & $\begin{array}{l}\text { A response that contains too little information to score as a Rorschach response and may be a short cryptic phrase or a long, } \\
\text { meandering, circumstantial paragraph }\end{array}$ \\
\hline Peculiar verbalization & Odd words or phrases that may have a recognizable meaning but do not fit the context in which they are used \\
\hline Word-finding difficulty & Simple absence of knowledge about what word to use \\
\hline Clang & Rhyming or alliterative phrases \\
\hline Perseveration & A response that has poor form with regard to the inkblot is repeated at least three times \\
\hline Incongruous combinations & Single details of a blot that are contiguous with each other are merged into a single response \\
\hline \multicolumn{2}{|l|}{0.5 Level } \\
\hline Relationship verbalization & Linking the current response to a prior one on a previous card and relating the two separate percepts \\
\hline Idiosyncratic symbolism & $\begin{array}{l}\text { Color symbolism: relationship between color and form are idiosyncratic } \\
\text { Image symbolism: using concrete images to represent abstract ideas in an idiosyncratic way and with an air of reality rather } \\
\text { than playfulness }\end{array}$ \\
\hline Queer verbalizations & $\begin{array}{l}\text { On a continuum with peculiar verbalizations with the exception that the examiner is generally uncertain about what is meant } \\
\text { by the word or phrase used }\end{array}$ \\
\hline Confusion & $\begin{array}{l}\text { Responses reflecting a loss of train of thought, and respondents are unsure what they are seeing or saying, indicating some } \\
\text { disorientation }\end{array}$ \\
\hline Looseness & Losing focus of the communication; taking off into an unrelated, tangential or arbitrary area \\
\hline Fabulized combinations & $\begin{array}{l}\text { On a continuum with incongruous combinations; percept and ideas are condensed into conclusions that violate reality } \\
\text { considerations about relationships between images, blot qualities, and objects }\end{array}$ \\
\hline Playful confabulations & Fabulized combinations that are fancifully overelaborated and typically involve humorous and playful images \\
\hline
\end{tabular}




\begin{tabular}{|c|l|}
\hline Fragmentation & Clear inability to integrate separate elements into a whole percept \\
\hline 0.75 Level & \\
\hline Fluidity & Something seen as one thing at one instance will be seen as a different object at the next instant \\
\hline Absurd verbalizations & Responses that are totally arbitrary, and bear little if any resemblance to objective reality \\
\hline Confabulations & $\begin{array}{l}\text { Extreme elaboration: carrying to an extreme an elaborative ideational tendency that extends the percept beyond the bounds of } \\
\text { reality constraints } \\
\text { Details in one area generalized to a larger area: single small detail is clearly perceived, but is then used to interpret the entire } \\
\text { inkblot in a way that violates the shape of the larger area }\end{array}$ \\
\hline Autistic logic & $\begin{array}{l}\text { Justifying a response by rationalizing it with a "because" state that is illogical or based on private autistic reasoning processes } \\
\text { rather than conventional, logical reasoning }\end{array}$ \\
\hline 1.0 Level & \\
\hline Contamination & Two separate and unrelated percepts are merged into one \\
\hline Incoherence & Responses that are unrelated to the task and are not possible for the examiner or scorer to understand in any context \\
\hline Neologisms & New, invented words that do not violate English morphology or phonotactics, yet are not real words \\
\hline
\end{tabular}




\section{Table 5}

Sociodemographic Information for the Current Sample

\begin{tabular}{|c|c|c|c|c|}
\hline & $n$ & $M(S D)$ & Skewness (SE) & Kurtosis (SE) \\
\hline Age & 24 & $34.88(15.61)$ & $1.41(.472)$ & $1.12(.918)$ \\
\hline Days in hospital & 20 & $5.7(6.96)$ & $3.45(.512)$ & $13.65(.992)$ \\
\hline Years of education & 24 & $12.13(1.26)$ & $-.254(.472)$ & $1.173(.918)$ \\
\hline $\begin{array}{l}\text { Age at first } \\
\text { psychotic episode }\end{array}$ & 17 & $18.12(7.53)$ & $.161(.550)$ & $.527(1.063)$ \\
\hline $\begin{array}{l}\text { Age at first } \\
\text { hospitalization }\end{array}$ & 22 & $19.75(8.57)$ & $2.14(.491)$ & $6.91(.953)$ \\
\hline $\begin{array}{l}\text { Number of } \\
\text { hospitalizations }\end{array}$ & 22 & $16.41(22.11)$ & $2.98(.491)$ & $9.97(.953)$ \\
\hline Duration of illness & 22 & $13.89(10.22)$ & $1.22(.491)$ & $1.799(.953)$ \\
\hline & Frequency & Percent & & \\
\hline $\begin{array}{l}\text { Primary Axis I } \\
\text { Schizophrenia } \\
\text { Schizoaffective }\end{array}$ & $\begin{array}{c}19 \\
5\end{array}$ & $\begin{array}{l}79.2 \\
20.8\end{array}$ & & \\
\hline $\begin{array}{l}\text { Primary Axis I } \\
\text { specifier } \\
\text { Paranoid } \\
\text { Undifferentiated } \\
\text { Bipolar (SAD) } \\
\text { Missing }\end{array}$ & $\begin{array}{l}14 \\
3 \\
1 \\
6\end{array}$ & $\begin{array}{c}58.3 \\
12.5 \\
4.2 \\
25.0\end{array}$ & & \\
\hline $\begin{array}{l}\text { Sex } \\
\text { Female } \\
\text { Male } \\
\text { Other }\end{array}$ & $\begin{array}{c}4 \\
20 \\
0\end{array}$ & $\begin{array}{c}16.7 \\
83.3 \\
0\end{array}$ & & \\
\hline Race & & & & \\
\hline
\end{tabular}




\begin{tabular}{|c|c|c|}
\hline $\begin{array}{l}\text { White } \\
\text { African-American } \\
\text { Asian } \\
\text { Biracial-Multiracial } \\
\text { Other }\end{array}$ & $\begin{array}{l}15 \\
8 \\
0 \\
0 \\
1\end{array}$ & $\begin{array}{c}62.5 \\
33.3 \\
0 \\
0 \\
4.2\end{array}$ \\
\hline \multicolumn{3}{|l|}{ Living Status } \\
\hline $\begin{array}{l}\text { Unsupervised in } \\
\text { house/apartment/etc. }\end{array}$ & 15 & 62.5 \\
\hline $\begin{array}{l}\text { Unsupervised in } \\
\text { rooming or boarding } \\
\text { house }\end{array}$ & 2 & 8.3 \\
\hline $\begin{array}{l}\text { Supervised in } \\
\text { Halfway house, } \\
\text { community house, } \\
\text { etc. }\end{array}$ & 1 & 4.2 \\
\hline Homeless/Shelter & 5 & 20.8 \\
\hline Other & 1 & 4.2 \\
\hline \multicolumn{3}{|l|}{$\begin{array}{l}\text { Medication } \\
\text { Compliance }\end{array}$} \\
\hline Never & 3 & 12.5 \\
\hline $\begin{array}{l}\text { Self-medicate by } \\
\text { own criteria }\end{array}$ & 2 & 8.3 \\
\hline $\begin{array}{r}\text { Sometimes as } \\
\text { Prescribed }\end{array}$ & 4 & 16.7 \\
\hline $\begin{array}{l}\text { Usually takes as } \\
\text { Prescribed }\end{array}$ & 4 & 16.7 \\
\hline $\begin{array}{l}\text { Always take as } \\
\text { Prescribed }\end{array}$ & 8 & 33.3 \\
\hline $\begin{array}{l}\text { First time on } \\
\text { Meds }\end{array}$ & 2 & 8.3 \\
\hline Missing & 2 & 4.2 \\
\hline
\end{tabular}


Table 6

$\underline{\text { Sample Characteristics for Predictor and Criterion Variables }}$

\begin{tabular}{|l|c|c|c|c|c|}
\hline & $M(S D)$ & Min & Max & Skewness (SE) & Kurtosis (SE) \\
\hline $\begin{array}{l}\text { PANAS } \\
\text { Total Score }\end{array}$ & $53.17(11.52)$ & 34.00 & 76.00 & $.225(.472)$ & $-.903(.918)$ \\
\hline PANAS NA & $38.50(17.89)$ & 20.00 & 74.00 & $.690(.472)$ & $-.973(.918)$ \\
\hline PANAS PA & $67.83(15.90)$ & 28.00 & 98.00 & $-.273(.472)$ & $.615(.918)$ \\
\hline TDI Total & $40.62(35.85)$ & 4.17 & 128.75 & $1.48(.472)$ & $1.10(.918)$ \\
\hline
\end{tabular}




\section{Table 7}

\section{Correlations for PANAS and TDI and Sociodemographic Variables}

\begin{tabular}{|c|c|c|c|c|c|c|c|}
\hline & Age & $\begin{array}{l}\text { Days in } \\
\text { hospital }\end{array}$ & $\begin{array}{c}\text { Education } \\
\text { in years }\end{array}$ & $\begin{array}{c}\text { Age at } \\
\text { first } \\
\text { psychiatric } \\
\text { episode }\end{array}$ & $\begin{array}{c}\text { Age at first } \\
\text { hospitalization }\end{array}$ & $\begin{array}{c}\text { Number of } \\
\text { hospitalizations }\end{array}$ & $\begin{array}{c}\text { Duration } \\
\text { of } \\
\text { illness }\end{array}$ \\
\hline $\begin{array}{l}\text { PANAS total } \\
\text { score }\end{array}$ & -.305 & -.103 & -.103 & -.125 & -.211 & -.209 & -.261 \\
\hline PANAS NA & -.263 & -.003 & -.130 & -.247 & -.156 & -.253 & -.285 \\
\hline PANAS PA & -.147 & -.174 & -.003 & .093 & -.130 & -.022 & -.058 \\
\hline TDI total & -.061 & .079 & .057 & -.347 & .113 & -.189 & -.125 \\
\hline Age & - & & & & & & \\
\hline $\begin{array}{l}\text { Days in } \\
\text { hospital }\end{array}$ & .350 & - & & & & & \\
\hline $\begin{array}{l}\text { Education in } \\
\text { years }\end{array}$ & .113 & .559 & - & & & & \\
\hline $\begin{array}{l}\text { Age at first } \\
\text { psychiatric } \\
\text { episode }\end{array}$ & $.566^{*}$ & .408 & .356 & - & & & \\
\hline $\begin{array}{l}\text { Age at first } \\
\text { hospitalization }\end{array}$ & $.747 * *$ & -.233 & .202 & $.616^{*}$ & - & & \\
\hline $\begin{array}{l}\text { Total number } \\
\text { of } \\
\text { hospitalizations }\end{array}$ & .138 & .440 & -.129 & .317 & -.021 & - & \\
\hline $\begin{array}{l}\text { Duration of } \\
\text { illness }\end{array}$ & $.830 * *$ & .050 & -.327 & .199 & .250 & .150 & - \\
\hline
\end{tabular}

$* * p<.01$ (2-tailed),$* p<.05$ (2-tailed) 
Table 8

Correlation analyses for PANAS and TDI and Sociodemographic Variables

\begin{tabular}{|l|c|c|c|c|}
\hline & $\begin{array}{c}\text { PANAS total } \\
\text { score }\end{array}$ & PANAS NA & PANAS PA & $\begin{array}{c}\text { TDI total } \\
\text { score }\end{array}$ \\
\hline $\begin{array}{l}\text { PANAS total } \\
\text { score }\end{array}$ & - & & & \\
\hline PANAS NA & $.726^{* *}$ & - & - & \\
\hline PANAS PA & $.633^{* *}$ & -.074 & -215 & - \\
\hline $\begin{array}{l}\text { TDI total } \\
\text { score }\end{array}$ & $.408^{*}$ & .335 & & \\
\hline
\end{tabular}

$* * p<.01$ (2-tailed)

$* p<.05$ (2-tailed) 


\section{Table 9}

Correlations for PANAS PA and NA and Exemplars of Top-Down Processing

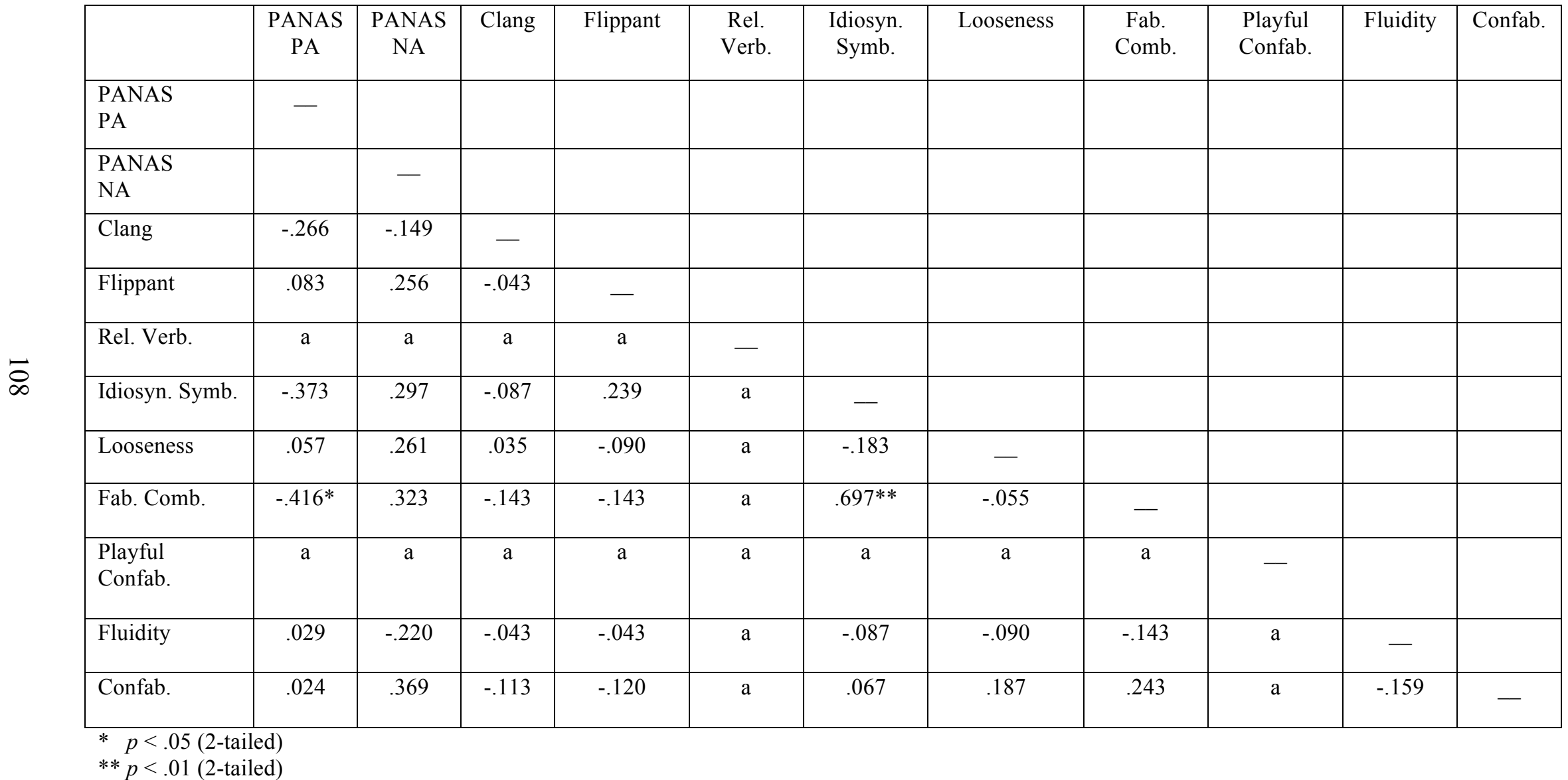

a. Frequency $=0$

Note. Confab. - confabulations; Fab. Comb. - fabulized combinations; Idio. Symb - idiosyncratic symbolism; NA - negative affect; Playful Confab. - playful confabulations; PA - positive affect; Rel. Verb. - relationship verbalization; 


\section{Table 10}

Correlations for PANAS PA and NA and Exemplars of Top-Down Processing

\begin{tabular}{|c|c|c|c|c|c|c|c|c|c|}
\hline & $\begin{array}{c}\text { PANAS } \\
\text { NA }\end{array}$ & $\begin{array}{c}\text { PANAS } \\
\text { PA }\end{array}$ & $\begin{array}{l}\text { Word } \\
\text { Find. } \\
\text { Diff. }\end{array}$ & Vague & $\begin{array}{l}\text { Inapp. } \\
\text { Dist. }\end{array}$ & Persev. & $\begin{array}{l}\text { Incong. } \\
\text { Comb. }\end{array}$ & Fragment. & $\begin{array}{l}\text { Autistic } \\
\text { Logic }\end{array}$ \\
\hline $\begin{array}{l}\text { PANAS } \\
\text { NA }\end{array}$ & - & & & & & & & & \\
\hline $\begin{array}{l}\text { PANAS } \\
\text { PA }\end{array}$ & & - & & & & & & & \\
\hline $\begin{array}{l}\text { Word } \\
\text { Find. } \\
\text { Diff. }\end{array}$ & -.125 & -.051 & - & & & & & & \\
\hline Vague & -.222 & .390 & .013 & - & & & & & \\
\hline $\begin{array}{l}\text { Inapp. } \\
\text { Dist. }\end{array}$ & .028 & -.126 & -.141 & -.173 & - & & & & \\
\hline Persev. & $\mathrm{a}$ & $\mathrm{a}$ & $\mathrm{a}$ & $\mathrm{a}$ & $\mathrm{a}$ & - & & & \\
\hline $\begin{array}{l}\text { Incong. } \\
\text { Comb. }\end{array}$ & ,093 & -.169 & .314 & -.211 & .111 & $\mathrm{a}$ & - & & \\
\hline Fragment. & -.232 & .177 & .150 & .113 & .330 & $\mathrm{a}$ & -.010 & - & \\
\hline $\begin{array}{l}\text { Autistic } \\
\text { Logic }\end{array}$ & $.423 *$ & .136 & -.043 & -.111 & -.141 & $\mathrm{a}$ & -.140 & -.083 & - \\
\hline
\end{tabular}

$* p<.05$ (2-tailed)

a. Frequency $=0$

Note. Fragment. - fragmentation; Inapp. Dist. - inappropriate distance; Incong. Comb. - incongruous combinations; NA - negative affect; PA - positive affect; Persev. - perseveration; Word. Find. Diff. - word finding difficulty. 
Table 11

Frequency of TDI Exemplars

\begin{tabular}{|l|c|}
\hline \multicolumn{1}{|c|}{ TDI Exemplars } & Frequency Count \\
\hline Inappropriate Distance & 22 \\
\hline Flippancy & 1 \\
\hline Vague & 15 \\
\hline Peculiar Verbalizations & 121 \\
\hline Word-finding Difficulty & 2 \\
\hline Clangs & 0 \\
\hline Perseveration & 13 \\
\hline $\begin{array}{l}\text { Incongruous } \\
\text { Combinations }\end{array}$ & 0 \\
\hline $\begin{array}{l}\text { Internal /External } \\
\text { Response }\end{array}$ & 0 \\
\hline $\begin{array}{l}\text { Relationship } \\
\text { Verbalization }\end{array}$ & 4 \\
\hline Idiosyncratic Symbolism & 27 \\
\hline Queer & 6 \\
\hline Confusion & 17 \\
\hline Looseness & 12 \\
\hline Fabulized Combinations & 0 \\
\hline Playful Confabulations & 6 \\
\hline Fragmentation & 1 \\
\hline Fluidity & 36 \\
\hline Absurd & 12 \\
\hline Confabulations & \\
\hline Autistic Logic & \\
\hline Contamination & \\
\hline Incoherence & \\
\hline Neologisms & \\
\hline & \\
\hline
\end{tabular}




\section{CURRICULUM VITAE}

\section{Rachel N. Waford}

\section{PERSONAL INFORMATION}

\section{Office Address:}

Harvard Medical School/

Beth Israel Deaconess Medical Center/

Massachusetts Mental Health Center/

75 Fenwood Rd. \#411

Boston, MA 02135

Phone: 617-626-9655

E-mail: rwaford@bidmc.harvard.edu rachel.waford@1ouisville.edu
Home Address:

81 Strathmore Rd. \#3

Boston, MA 02135

Phone: 270-303-6973

\section{EDUCATION}

Ph.D., Clinical Psychology, 2008-2013, University of Louisville, Louisville, KY Dissertation Title: The Role of Affective Intensity and Valence in Thought Disorder Severity in Schizophrenia.

Mentor: Richard R. J. Lewine, Ph.D.

M.A., Experimental Psychology, 2006, Western Kentucky University, Bowling Green, KY Thesis Title: Assessing Head Start Children's School Adjustment.

Advisor: Elizabeth A. Lemerise, Ph.D.

B.A., Psychology and Sociology, 2004, Western Kentucky University, Bowling Green, KY Majors: Psychology and Sociology, Minor: Criminology

\section{HONORS}

May 2006 Outstanding Graduate Student of the Year, College of Education and Behavioral Sciences, Western Kentucky University

May 2006 Experimental Psychology Graduate Student of the Year, Western Kentucky University

May 2004 Outstanding Alpha Kappa Delta Undergraduate Student, Department of Sociology, Western Kentucky University

\section{CLINICAL AND RESEARH INTERESTS}

Clinical interests include identifying and understanding prodromal features of psychotic disorders, efficacy of early interventions, and treatment factors related to recovery and community reintegration; and inpatient and emergency psychiatric populations, with a focus on understanding the phenomenology of illness and inter- and intra-individual differences related to engagement in outpatient treatment and recovery. 
Current research interests include the relationship between affect and cognition in severe psychopathology, and the development of and early intervention for psychotic disorders. Specific areas of research include thought disorder in schizophrenia and the moderating role of affect on the severity and course of this impairment. Recent training conducted by Dr. Deborah Levy from McLean Hospital and ongoing work focus on the use of the Rorschach Inkblot Test and the Thought Disorder Index to evaluate thought disorder in schizophrenia and other diagnostic groups. Other areas of specific research interest include the factors related to early treatmentseeking and engagement in prodromal and first-episode populations, early intervention and recovery, substance use, and familial support.

\section{RESEARCH EXPERIENCE}

July 2008-Present: Affect and Cognition Lab: Doctoral Student, Advisor: Richard R. J. Lewine, Ph.D.

- Hypothesis development, research, data analysis, and writing for the following new and ongoing projects:

- Affect and Cognition in Severe Psychopathology (funded by UofL IRIG)

- Moderating role of affect in thought disorder in schizophrenia

- Impact of personality traits on the relationship between affect and thought disorder

○ Cognitive impairment, negative symptoms, and schizophrenia

○ Implications of symptom severity versus diagnosis

$\circ$ Mood Induction and Critical Thinking in Undergraduates

- Dysphoria and Academic Success in Undergraduates

- Supervision of graduate and undergraduate students involved in research and training

June 2006-June 2008: Developmental Neuroscience Lab: Lab Coordinator/Project Coordinator, Supervisor: Dennis L. Molfese, Ph.D.

- Impact of sleep loss and simulated micro-gravity on neuropsychological functioning (funded by NASA)

$\circ$ Record, analyze, and interpret event-related potential brain imaging data

- Neuropsychological impact of sleep loss in children (funded by NIH)

○ Record, analyze, and interpret event-related potential brain imaging data

August 2003-May 2006: Social Development Lab: Undergraduate and Graduate Research Assistant, Advisor: Elizabeth A. Lemerise, Ph.D.

- Investigate influence of peer relationships, emotion, and aggression in cognitive, emotional, and social development in children 


\section{PEER-REVIEWED PUBLICATIONS}

Lewine, R., Sommers, A., Waford, R. N., Bustanoby, H., Robertson, C., Hall, R., \& Eisenmenger, K. Sex, affect, and academic performance: It's not what you think. International Journal of the Scholarship of Teaching and Learning. In Press.

Waford, R. N. \& Lewine, R. (2010). Is perseveration uniquely characteristic of schizophrenia? Schizophrenia Research, 118, 128-133.

Lemerise, E. A, Fredstrom, B. K., McCormick, B. G., Bowersox, A. L., \& Waford, R. N. (2006). Do Provocateurs' Emotion Displays Influence Children's Social Goals and Problem Solving? Journal of Abnormal Child Psychology, 34(4), 555-567.

\section{PUBLICATIONS UNDER REVIEW}

Waford, R. N. \& Lewine, R. R. J. Integrating the study of affect and thought disorder in schizophrenia. British Journal of Psychiatry (Manuscript under modification for re-submission).

Lewine, R., Sommers, A., Waford, R. N. Robertson, C., \& Hall, R. Setting the mood for critical thinking in the classroom. Teaching of Psychology (Manuscript under review).

\section{PROFESSIONAL PRESENTATIONS}

Waford, R. N., Robertson, C. R., Hart, M. A., \& Lewine, R. (September, 2012). Do affective intensity and valence moderate thought disorder severity in schizophrenia and schizoaffective disorder? Poster presented at the annual meeting of Society for Research in Psychopathology, Ann Arbor, MI.

Waford, R. N. \& Lewine, R. (September, 2011). The significance of affect in our understanding of thought disorder in schizophrenia. Poster presented at the annual meeting of Society for Research in Psychopathology, Boston, MA.

Robertson, C., Waford, R. N., \& Lewine, R. (September, 2011). Cognitive perseveration across diagnoses: A dimensional approach. Poster presented at the annual meeting of Society for Research in Psychopathology, Boston MA.

Lewine, R. Sommers, A., Waford, R. N., \& Robertson, C. (May, 2011). Mood and Critical Thinking. Poster presented at i2a Conference, Louisville, KY.

Waford, R. N. \& Lewine, R. (October, 2010). Negative symptoms and neuropsychological functioning in schizophrenia: Implications for functional outcome. Poster presented at Annual Meeting of Society for Research in Psychopathology, Seattle, WA.

Waford, R. N., Robertson, C., \& Lewine, R. (March, 2010). An Examination of Cognitive Perseveration at the Symptoms Level. Poster presented at annual meeting of Kentucky Psychological Association, Louisville, KY.

Waford, R. N. and Lewine, R. (September, 2009). Patients with OCD exhibit lower cognitive perseveration than healthy individuals: Implications and Questions. Poster presented at Annual Meeting of Society for Research in Psychopathology, Minneapolis, MN.

Waford, R. N. and Lewine, R. (September, 2008). Perseveration in Individuals with Schizophrenia, Bipolar Disorder, and Major Depression. Poster presented at annual meeting of Society for Research in Psychopathology, Pittsburgh, PA.

Molfese, D. L., Molfese, V. J., Barnes, M., Starkey, G., Tucker, L., Millis, B., Pratt, N., 
Waford, R. N., \& Gozal, D. (March, 2009). ERP Measures of Brain Activity Predict the Effects of Sleep Restriction on Attention. Symposium on Brain Measures of Cognitive Functioning: Understanding the Roles of Environment and Phenotype. Paper presented at the 42nd Annual Gatlinburg Conference, New Orleans.

Waford, R. N., Pratt, N., Warren, C., Brian, E., Kheirandish-Gozal, L., Molfese, D. (February, 2008). Variations in event-related potentials across time and sleep duration. Poster presented at Annual Meeting of International Neuropsychological Society, Waikoloa, HI.

Pope, J., Waford, R. N., \& McDade, A. (February, 2008). It's your turn to serve: An examination of attitudes toward the jury system. Society of Personality and Social Psychology Annual Conference, Albuquerque, New Mexico.

Waford, R. N., Bayarsaihan, N., Gozal, D., Molfese, V., \& Molfese, D. L. (October, 2007). Sex Differences and Electrophysiological Correlates of Attention Deficits using the CPT II. Poster presented at Research!Louisville, Louisville, Kentucky.

Armstrong, N. E., Barnes, M. E., Waford, R. N., Bayarsaihan, N., Gozal, D., Molfese, V., $\&$ Molfese, D. L. (October, 2007). Event Related Potentials Mediate Performance on RBANS Based on Alteration of Sleep-Wake Cycles. Poster presented at Research!Louisville, Louisville, KY.

Molfese, D. L. \& Waford, R. N. (Invited Presentation, October, 2007). The Science of Living in Space. Louisville Science Center, Research!Louisville Conference. Louisville, KY.

Waford, R. N., Pratt, N. L., Warren, C. G., Millis, B. G., \& Molfese, D. L. (June, 2007). Effects of sleep restriction on speech discrimination in children. Poster presented at the 21st Annual Meeting of the APSS, Minneapolis, MN.

Millis, B. G., Molfese, D. L., Warren, C. G., Pratt, N. L., \& Waford, R. N. (June, 2007). Brain responses predict impact of sleep loss on attention. Poster presented at the 21st Annual Meeting of the APSS, Minneapolis, MN.

Pope-Terrence, J. \& Waford, R.N. (March, 2007). It's your time to serve: An examination of attitudes toward jury service. Poster presented at the annual meeting of Off the Witness Stand: Using Psychology in the Practice of Justice, New York, NY.

Molfese, D. L., Waford, R., Warren, C., Pratt, N., Brian, E., Barnes, M., Gozal, D., \& Molfese, P. (February, 2007). Brain organization during an attention task changes following minor sleep loss and head-down tilt. Paper presented at NASA Human Research Program Investigators' Workshop, League City, Texas.

Wu, J., Molnar, A., Wagner, M., Waford, R. N., Warren, C., \& Molfese, D. L. (February, 2007). Sex Differences In Attention Across ERP and Near-Infrared Procedures On The Same Participants. Poster presented at International Neuropsychological Society, Portland, Oregon.

Molnar, A., Wagner, M., Wu, J., Waford, R. N., Warren, C., \& Molfese, D. L. (February, 2007). ERP and Near-Infrared Procedures in the Same Subjects Indicate Similar Brain Regions Activated. Poster presented at International Neuropsychological Society, Portland, Oregon.

Molfese, D. L., Waford, R. N., Warren, C., Pratt, N. Barnes, M., Roman, A., Stone, M., Gozal, D., \& Molfese, V. (Invited Presentation, November, 2006). Cognitive Impact of Weightlessness in NASA Astronauts. Paper presented at Kentucky 
Psychological Association, Louisville, KY.

Molnar, A., Wagner, M., Wu, J., Waford, R. N., \& Molfese, D. L. (October, 2006). Spatio-temporal characteristics of auditory oddball processing using ERP and near-infrared procedures. Poster presented at Research!Louisville, Louisville, Kentucky.

Wu, J., Molnar, A., Wagner, M., Waford, R., Warren, C., \& Molfese, D. L. (October, 2006). Sex differences in oddball task across ERP and Near-infrared methodology. Poster presented at Research!Louisville, Louisville, Kentucky.

Molfese, D. L., Wu, J., Molnar, A., Wagner, M., \& Waford, R. N. (August, 2006). The use of high-density array event-related potentials and near-infrared technologies to provide spatio-temporal insights into language processing. Paper presented at International Society on Oxygen Transport to Tissue, Louisville, KY.

Pope-Terrence, J. \& Waford, R. N. (June, 2006). Why Me? Attitudes toward serving on the jury. Paper presented at the annual meeting of the American Democracy Project, Snowbird, UT.

Lemerise, E. A., Arsenio, W. F., \& Waford, R. N. (June, 2006). Contextual effects on "Happy Victimizer" expectancies in normally developing and behaviorally disruptive children. Poster presented at the annual meeting of Jean Piaget Society, Baltimore, MD.

Waford, R. N., Lemerise, E. A., \& Blanton, E. (May, 2006). The impact of friends and enemies on young children's adjustment at school. Poster presented at the annual meeting of the American Psychological Society, New York, NY.

Waford, R. N., Lemerise, E. A., McCormick, B. G., \& Bowersox, A. L. (April, 2006). Assessing Head Start children's school adjustment. Poster presented the biennial meeting of the Conference of Human Development, Louisville, KY.

Lovitt, B., Waford, R. N. \& Lemerise, E. A. (November, 2005). The impact of dyadic relationships on elementary school children. Paper presented at the annual meeting of the Kentucky Academy of Science, Richmond, KY.

Waford, R. N., Lemerise, E. A., McCormick, B. G., Bowersox, A. L, \& Livingstone, G. (November, 2005). Having friends matters: An investigation of the impact of friendship on the school adjustment of preschool-age children. Paper presented at the annual meeting of the Kentucky Academy of Science, Richmond, KY.

\section{GRANT APPLICATIONS AND EXTERNAL FUNDING}

Lewine, R. (PI), \& Waford, R. N. A study of thinking and feeling in schizophrenia and schizoaffective disorder. Intramural Research Incentive Grants: Research Initiation Grant, University of Louisville, January 1-Decemeber 31, 2012, \$4000.

Lewine, R. (PI), Sommers, A. \& Waford, R. N. Mood induction, critical thinking, and cognitive flexibility. SUN Grant, Delphi Center, University of Louisville, January 1- December 31, 2009, \$5,000.

\section{TEACHING EXPERIENCE}

\section{Undergraduate Courses:}

Spring 2012

Abnormal Psychology, Undergraduate: Guest Lecturer and Teaching Assistant

- Met with students as needed for further tutoring

- Assisted in the development of exams

- Developed and presented two lectures during the semester 
Fall 2011

Spring 2011

Fall 2010

Quantitative Statistics, Undergraduate: Lab Instructor

- Develop a curriculum to supplement instructor's weekly class content

- Grade all lab assignments

- Meet with students as needed for further tutoring

- Developed a curriculum to teach steps necessary to successfully write a research paper

- Graded all lab assignments

- Met with students as needed for further tutoring Abnormal Psychology, Undergraduate: Guest Lecturer

- Developed a lecture discussing thought disorder and severe psychopathology

- Presented lecture to two classes

July 2008-June 2009 Introduction to Psychology, Undergraduate: Lab Instructor

- Taught weekly lab sections, providing information supplementary to large course lecture

\section{CLINICAL EXPERIENCE}

July 2012-Present

July 2012-Present

July 2012-Present

August 2010-June 2012
Doctoral Intern, Prevention and Recovery in Early Psychosis (PREP): The PREP clinic is an outpatient clinic and day program dedicated to the understanding and treatment of first-episode psychosis. This population of 16-30 year old young adults has experienced their first psychotic episode in the last five years and is in varying stages of the illness and recovery. Treatment includes individual psychotherapy, group psychotherapy, neuropsychological testing (MATRICS), individual family therapy, and the Multi-Family Group model of family therapy. Other features of the program include Cognitive Enhancement Therapy (CET) and opportunities to participate in relevant research related to first episode psychosis. Supervisor: Michelle Friedman-Yakoobian, Ph.D.

Doctoral Intern, Massachusetts Mental Health Center Continuing Care clinic (MMHC-CC): The MMHC-CC is a Department of Mental Health outpatient clinic offering individual psychotherapy and psychological testing to adults with severe and persistent mental illness living in a variety of outpatient and supported settings. The majority of clients seen at MMHC-CC are living with schizophrenia-spectrum disorders, or other psychotic disorders and severe psychopathology. Supervisor: Nora Otero, M.Ed., LMHC.

Doctoral Intern, Massachusetts Mental Health Center- Southard Clinic (MMHC-Southard): The MMHC-Southard is an outpatient clinic offering individual psychotherapy and psychological testing to adults experiencing a variety of psychiatric difficulties. Clients have been seen for mood disorders, anxiety disorders, and personality disorders. Supervisor: June Wolf, Ph.D.

Graduate Student Therapist, University of Louisville Psychological Services Center (PSC): Psychotherapeutic 
August 2009-June 2012

February 2011-August 2011

February 2011-August 2011

July 2009-July 2010 services are provided at the PSC. The PSC is a community clinic that offers treatment for a variety of psychological problems and accepts payment on a sliding scale. Psychotherapy is provided from a Cognitive-Behavior Therapy orientation and includes exposure and response prevention interventions. Clients have been seen for obsessive-compulsive disorder, social anxiety, generalized anxiety disorder, depression, post-traumatic stress disorder, and personality disorders. Supervisor: Janet Woodruff-Borden, Ph.D.

Graduate Student Therapist, Assessment: Assessment services are provided at the University of Louisville Psychological Services Center (PSC). Testing experience includes work with both children and adults for a variety of referral questions. Child assessment experience involves evaluation for eligibility for the advance placement program at Jefferson County Public Schools. This battery includes intelligence testing and collateral reports. Adult assessment experience encompasses evaluation for learning disabilities, Asperger's disorder, ADHD, and personality disorders. These batteries include semi-structured interviews, intellectual and achievement testing, personality assessment, neuropsychological testing, and self and observer reports. Supervisors: Bernadette Walter, Ph.D. and David Winsch, Ph.D.

Practicum Student: University of Louisville Hospital, Emergency Psychiatric Services. This practicum consisted of participation in morning treatment team meetings, including observing and conducting new patient interviews. Research for various local patient resources was also completed. Patients were seen for personality disorders, psychosis, substance abuse, suicidal ideation, depression, anxiety, panic disorder, and violent behavior. Supervisors: Dr. Richard Lewine, Ph.D. and Dr. Rifaat El-Mallakh, M.D.

Practicum Student: University of Louisville Hospital, Inpatient psychiatric unit. Time on the inpatient psychiatric unit was spent participating in physician rounds and observing meetings between patients and the supervising psychiatrist. Daily case conference meetings were also attended to observe treatment team discussions about patients currently on the unit.

Supervisors: Dr. Richard Lewine, Ph.D. and Dr. Rifaat ElMallakh, M.D.

Practicum student, Central State Hospital: This 20-hour/week placement provided exposure to a diverse clinical population and an array of responsibilities. Patients included (1) a range of ages from young adult to geriatric, (2) a variety of cultural groups, (3) experience with a range of disabilities including physical disabilities, hearing impairment, and low intellectual functioning, (4) and exposure to a myriad of different diagnoses 
August 2008-August 2010

and levels of symptom severity. Responsibilities consisted of individual therapy with patients experiencing depression, bipolar disorder, psychoses, substance abuse, anxiety disorders, personality disorders, suicidal ideation, and autism-spectrum disorders. Weekly group therapy was also conducted, as were suicide risk evaluations, and testing including but not limited to personality assessment, intellectual assessment, mental status, malingering assessment, and assessment of independent living skills. In addition, as a member of the interdisciplinary team, responsibilities involved presenting relevant information from therapy sessions and testing results to the treatment team.

Supervisor: James Putnam, Psy.D.

Graduate Student Therapist, University of Louisville Psychological Services Center (PSC): Psychotherapeutic services were provided at the PSC, a community clinic that offers treatment for a variety of psychological problems and accepts payment on a sliding scale. Psychotherapy was provided from an Integrative Psychotherapy orientation. Techniques learned and implemented included Cognitive Behavior Therapy, Narrative Therapy, Family Systems Therapy, and Mindfulness and Acceptance and Commitment Therapy. Clients were seen for personality disorders, depression, adjustment disorders, and prodromal psychotic symptoms. Supervisor: Jay Irby, Ph.D.

\section{RELEVANT WORK EXPERIENCE}

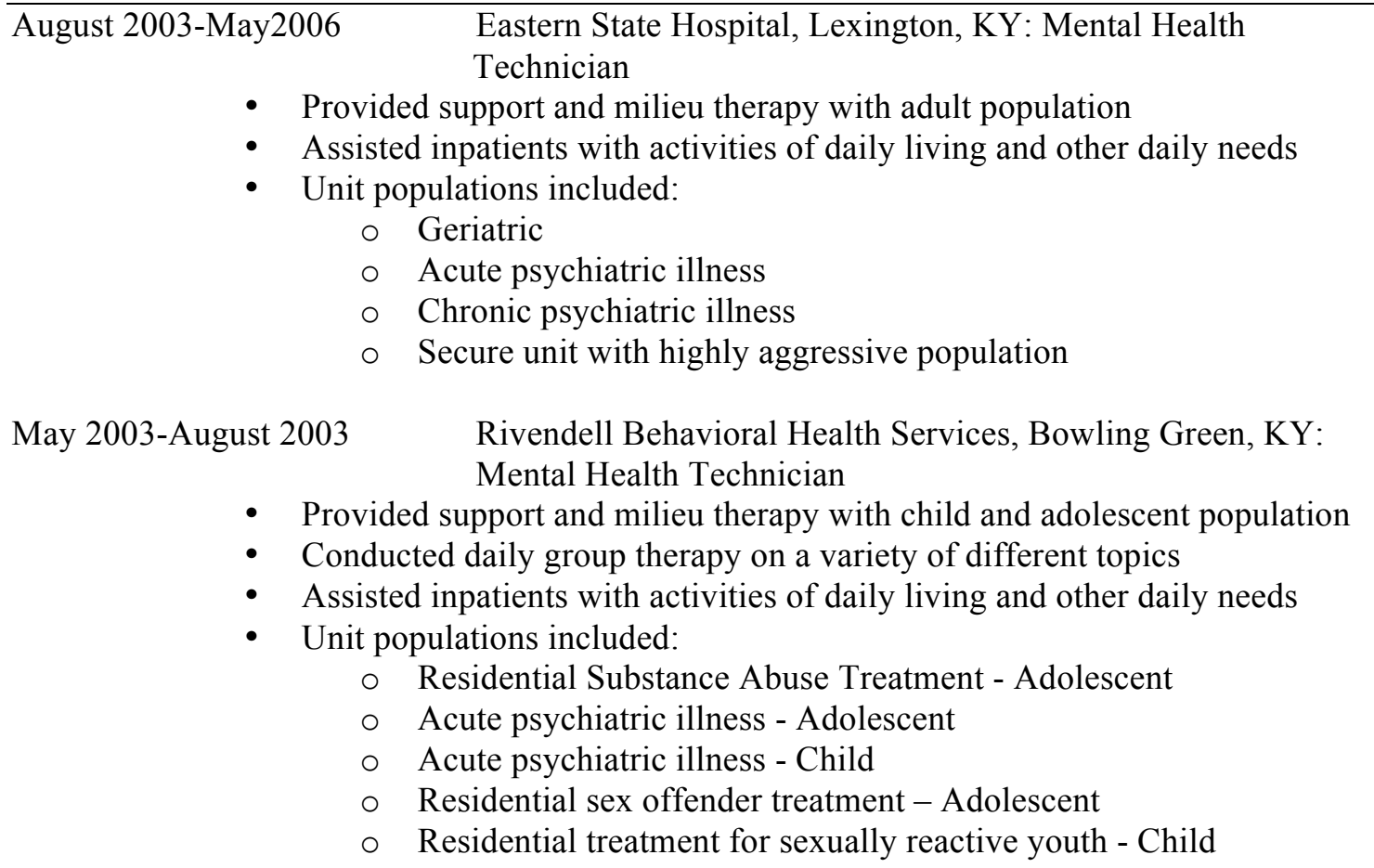


SERVICE EXPERIENCE

September 2011

July 2009-July 2012

Ciety for Research in Psychopathology: 2011 Student

Contributor, Publication Committee

July 2009-June 2011

Peer Mentor for incoming graduate students

Student Representative, Clinical Psychology Doctoral Program

\section{OTHER PROFESSIONAL ACTIVITIES AND AFFILIATIONS}

Massachusetts Mental Health Center, Psychosis Working Group: Identifying and developing measures of treatment efficacy and recovery

American Psychological Association - student member

Society for Research in Psychopathology - associate member

Kentucky Psychological Association - student member

\section{PROFESSIONAL REFERENCES}

Richard R. J. Lewine, Ph.D.

University of Louisville

Life Sciences Building, Rm. 343

Louisville, KY 40292

502-852-3243

rich.lewine@louisville.edu

Michelle Friedman-Yakoobian, Ph.D.

Commonwealth Research Center

Massachusetts Mental Health Center

Beth Israel Deaconess Medical Center

CEDAR Clinic 5th Floor

75 Fenwood Road

Boston, MA 02115

617-754-1210

mfriedm3@bidmc.harvard.edu

June Wolf, Ph.D.

Massachusetts Mental Health Center

75 Fenwood Road

Boston, MA 02115

617-626-9444

june_wolf@hms.harvard.edu

Chris Morse, Ph.D.

Massachusetts Mental Health Center

75 Fenwood Road

Boston, MA 02115

617-626-9443

cmorse1@bidmc.harvard.edu 